\title{
EXPANDING UNDERSTANDING OF MENTAL HEALTH RECOVERY: EFFECTS OF STIGMA AND WORKING ALLIANCE ON THE QUALITY OF LIFE OF PERSONS WITH SEVERE MENTAL DISABILITIES RECEIVING COMMUNITY-BASED CASE MANAGEMENT SERVICES
}

\author{
DISSERTATION \\ Presented in Partial Fulfillment of the Requirements for \\ the Degree Doctor of Philosophy in the \\ Graduate School of The Ohio State University \\ by \\ David Kondrat, M.S.W.
}

The Ohio State University 2008

Dissertation Committee:

Dr. Theresa Early, Adviser

Approved by

Dr. A. Celeste Burke

Adviser

Dr. Gilbert Greene

Social Work Graduate Program

Dr. Thomas Gregoire 


\section{Copyright by}

David C. Kondrat

2008 


\begin{abstract}
Mental illness self-stigma and the working alliance between case managers and clients of community mental health case management programs affect the mental health recovery chances of persons with SMD. Self-stigma decreases the life chances of persons with a mental illness and the presence of a strong working alliance increases life chances. The current study explored the effects of stigma and working alliance on subjective quality of life. Specifically, the current study explored whether mental illness self-stigma and working alliance independently affected subjective quality of life of persons who receive mental health case management, or whether working alliance mediated the effects of mental illness self- stigma on subjective quality of life. The researcher defined selfstigma from a modified labeling theory of mental illness perspective and defined selfstigma using two variables: devaluation and discrimination and stigma withdrawal as a coping mechanism. The researcher used Bordin's definition of working alliance. His definition articulated the working alliance as the agreement between helping professionals and clients on the goals and tasks of treatment and the presence of a strong bond between helping professionals and clients. Findings indicated that expectations of devaluation and discrimination and working alliance were independent related to subjective quality of life. Endorsement of expectations of devaluation and discrimination were associated with negative appraisals of subjective quality of life. Stronger working
\end{abstract}


alliance was associated with positive appraisals of subjective quality of life. Stigma withdrawal was not significantly related to subjective quality of life. The author articulates implications of the findings for social work practice, policy and research. 
Dedicated to my wife, Roxann, and my son, Evan 


\section{ACKNOWLEDGMENTS}

I would like to thank my chair, Dr. Theresa Early, for her encouragement and meticulous feedback on the many drafts of this dissertation. She has been a constant source of support for me throughout my academic career at OSU.

I appreciate the help, encouragement, and advice of Dr. Tom Gregoire. He was the first person to suggest I get a doctorate in social work and has been one of my biggest supporters.

I would like to thank Dr. Gil Greene, whose intellectual support, including encouraging me to learn about symbolic interaction, provided the foundation upon which this dissertation was based.

I am grateful for the help and encouragement of Dr. Celeste Burke. She challenged me to be a better researcher and scholar.

I would like to thank the Ohio Department of Mental Health and the people of the state of Ohio for funding this dissertation.

I am grateful to the mental health consumers who took time out of their day to participate in my study. They kept me focused on the reason for this dissertation

I am grateful to Anna Marie Robinson for her financial and inspirational support. She is truly an amazing social worker and mental health advocate.

I thank my mother, Mary Ellen Kondrat, for her support and advice. She was a role model to me as a social worker and remains one as an academic. 
I appreciate the love and support of my father. While he never knew me as a social worker, his commitment to social justice was incredibly important to my decision to become one.

Lastly, I am forever thankful to my wife, Roxann, for her love and understanding throughout my time in graduate school. Without you, I would never have been able to accomplish this. 
VITA

David C Kondrat

December, 1974

1998

1999

$2001-2007$
Born, Madison, Wisconsin

B.S.S.W. Saint Louis University

M.S.W: The Ohio State University

Graduate Administrative, Research \& Teaching Associate

\section{PUBLICATIONS}

1. Greene, G.J., Kondrat, D.C., Lee, M.Y., Clement, J., Siebert, H., Mentzer, R.A., \& Pinnell, S.R. (2006). A solution-focused approach to case management and recovery with consumers who have a severe mental disability. Families in Society, 87 (3), 339350 .

2. Teater B.A., \& Kondrat, D.C. (2006). Connecting Policy to Practice: Analyzing the variables of the Section 8 housing program policy process. The Social Policy Journal, 4 (3/4), 69 - 92.

\section{FIELDS OF STUDY}

Major Field: Social Work

Minor Field: Research Methods in Human Resource Management 


\section{TABLE OF CONTENTS}

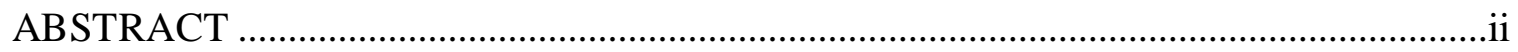

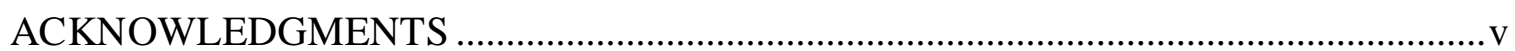

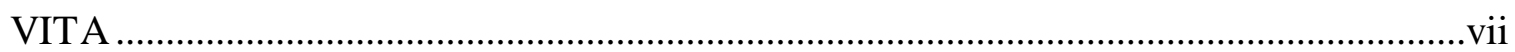

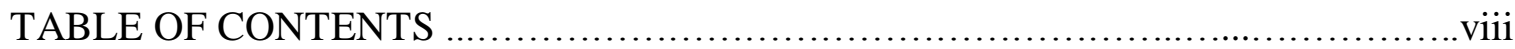

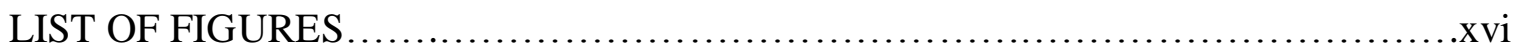

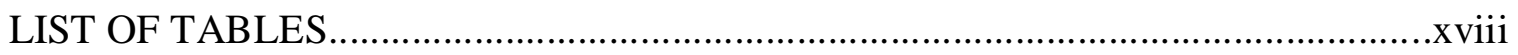

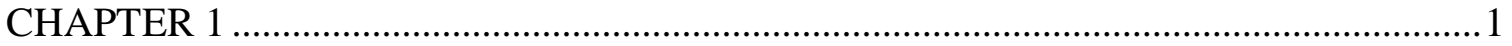

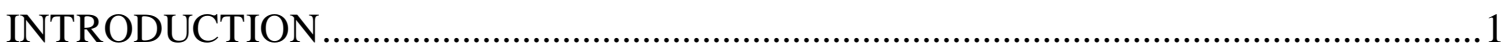

Stigma as a barrier to recovery ................................................................................

Labeling theory of mental illness .....................................................................................

Labeling theory of mental illness: A theoretical approach to understanding stigma and

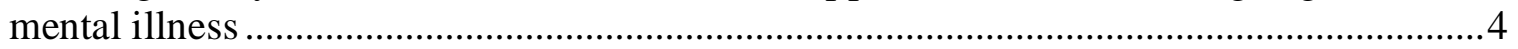

Community-based psychiatric treatment ………………….......................................

Defining the working alliance ...................................................................................

The effect of the working alliance on treatment outcomes...................................................

Stigma, the working alliance, and quality of life ……………....................................... 10

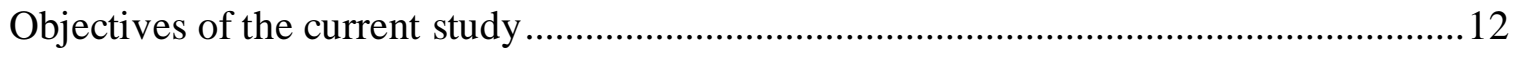

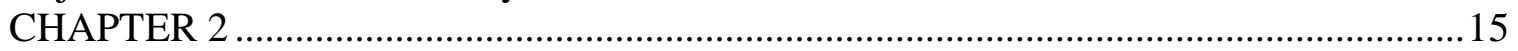

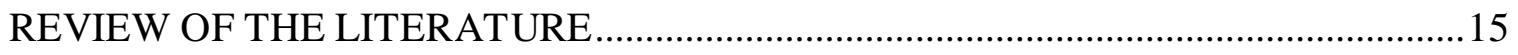

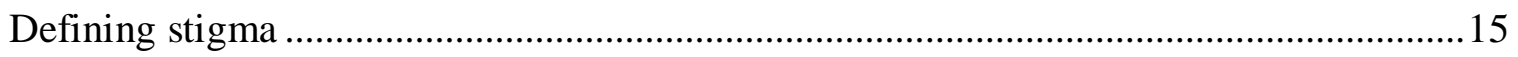

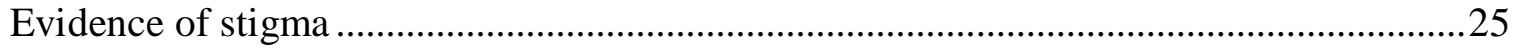

Early contributions to labeling theory of mental illness ...................................................26

Thomas Scheff's labeling theory of mental illness ..........................................................29

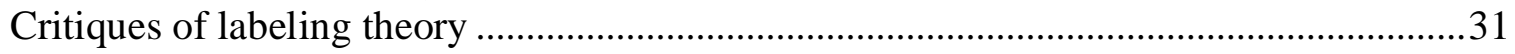

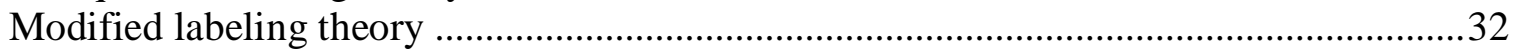

Testing Modified Labeling Theory ………………………..........................................

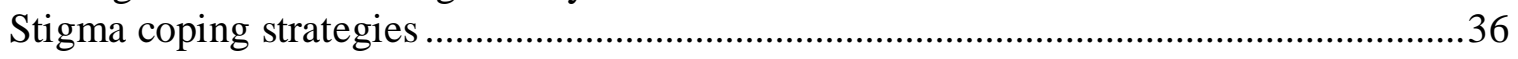

Studies of the effects of psychiatric labeling within treatment groups .................................38

Assessment of both treatment effects and stigma effects ....................................................43

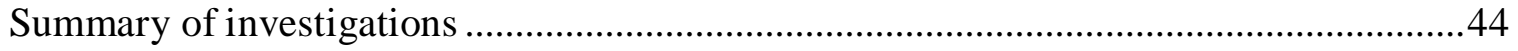

Assertive Community Treatment ......................................................................................4

Effectiveness of Assertive Community Treatment .............................................................4

Quality of life: A recovery based measure of ACT treatment success ...............................47

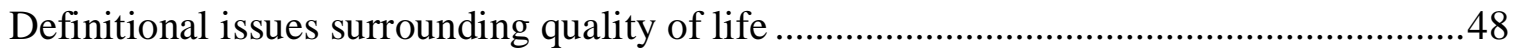

Assessing ACT effectiveness relative to Quality of life ....................................................52

$$
\text { viii }
$$


Mediating processes: understanding what works in ACT ….........................................54

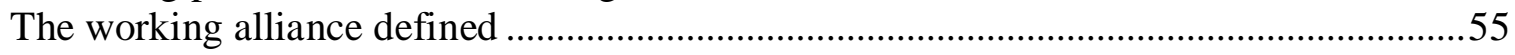

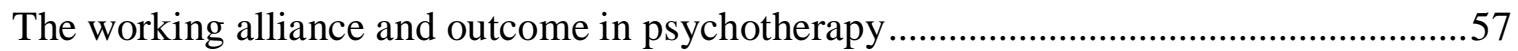

Relevance of the working alliance concept within ACT for persons with a SMD ...........59

The effects of working alliance on outcomes within case management and ACT programs

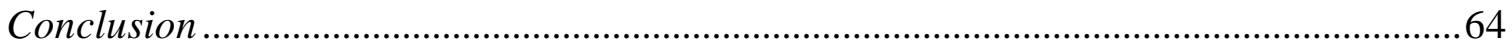

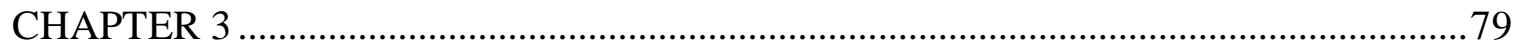

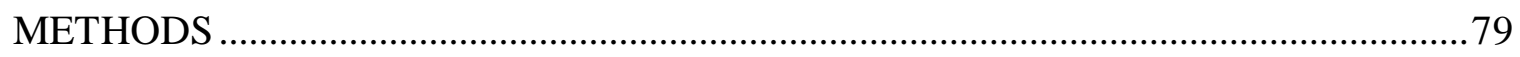

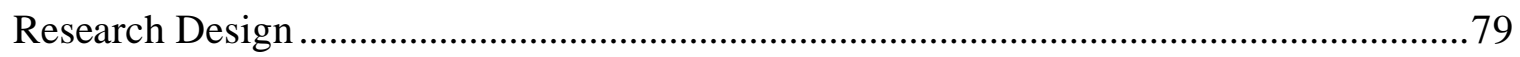

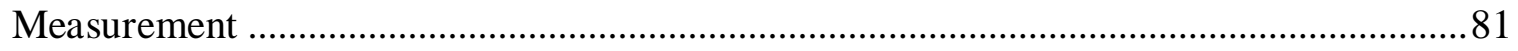

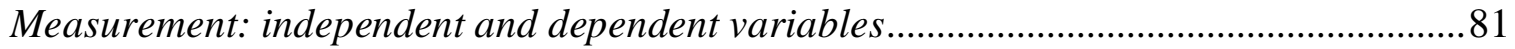

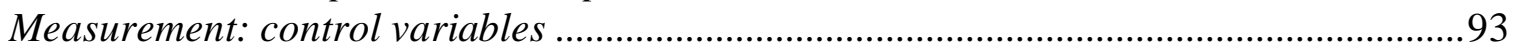

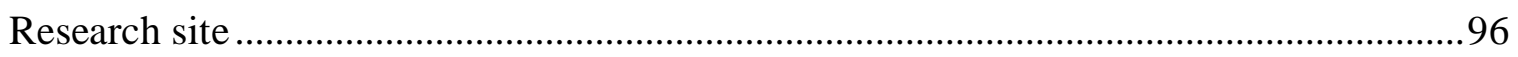

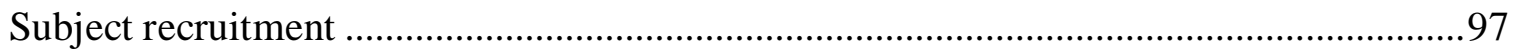

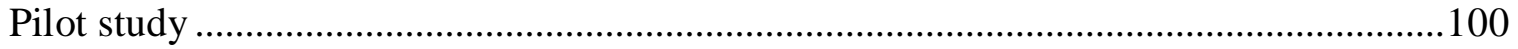

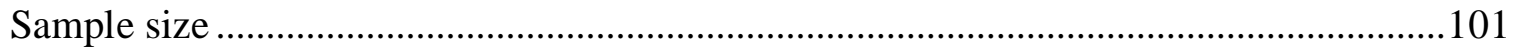

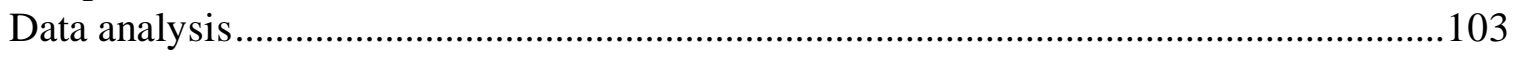

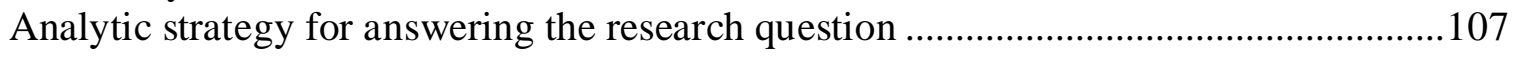

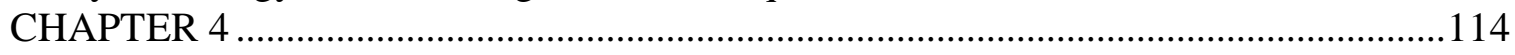

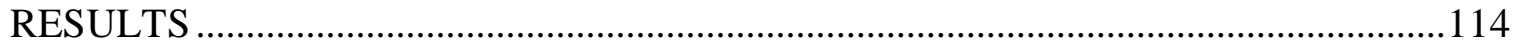

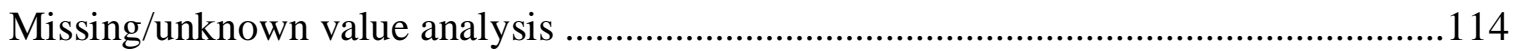

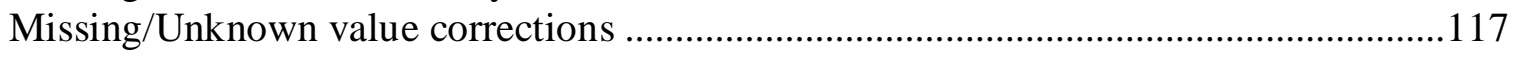

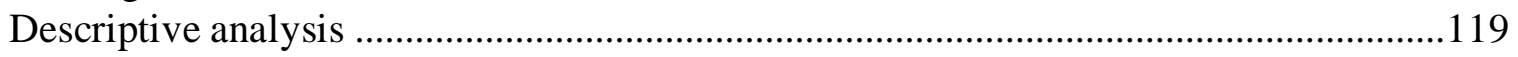

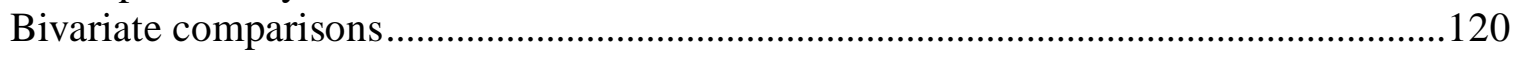

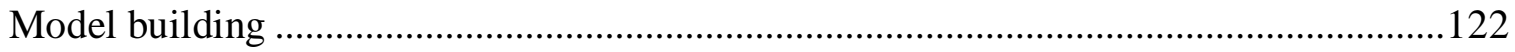

Statistical Analysis for research question one ................................................................ 126

Multilevel model of the effects of devaluation and discrimination, stigma withdrawal and

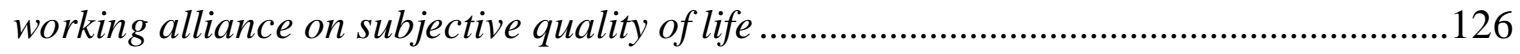

Statistical analysis for research question two ................................................................. 130

Multilevel model of the effect of devaluation and discrimination and stigma withdrawal on working alliance ............................................................................................................. 131

Multilevel statistical model of the effects of devaluation and discrimination, and stigma

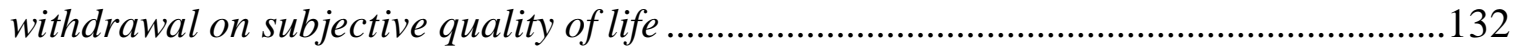

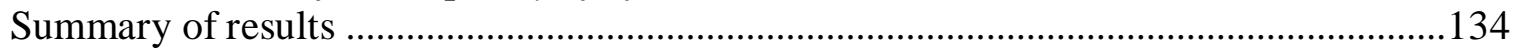

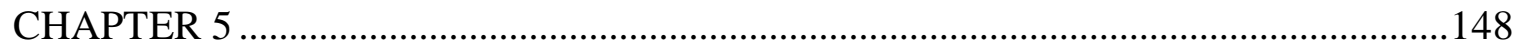

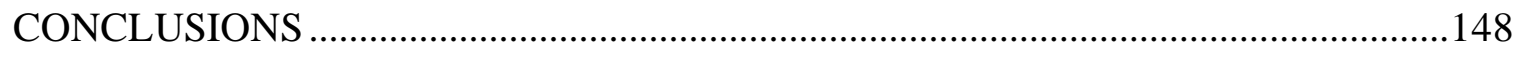

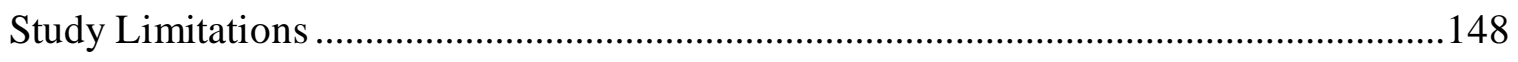

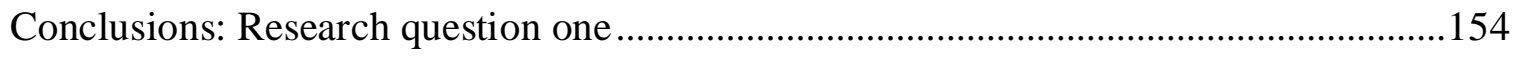

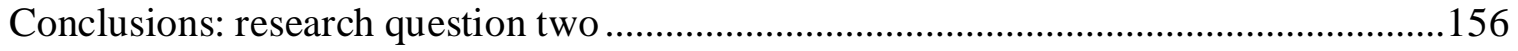

Conclusion: comparing results for question one with question two ..............................157

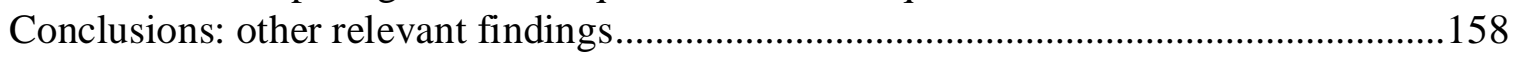

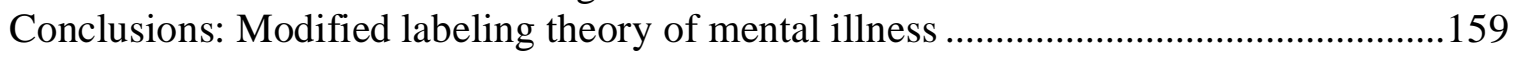

Conclusions: Bordin's working alliance theory ........................................................ 161

Conclusions: theories of the independent roles of stigma and treatment ........................ 161 


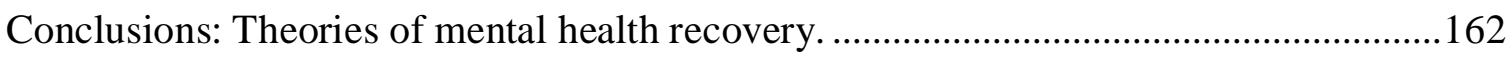

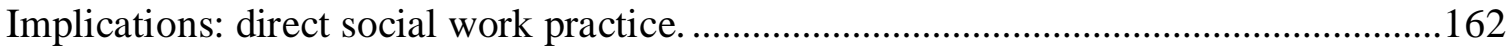

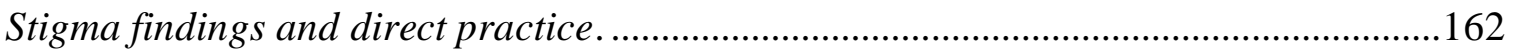

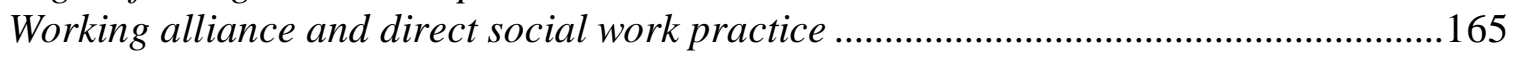

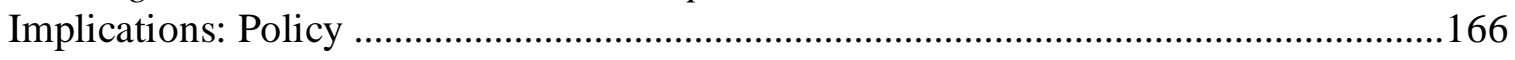

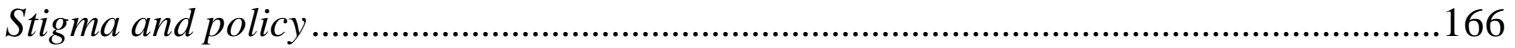

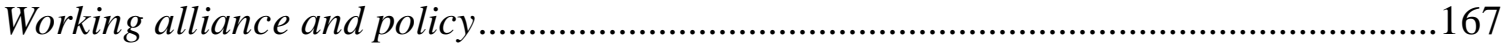

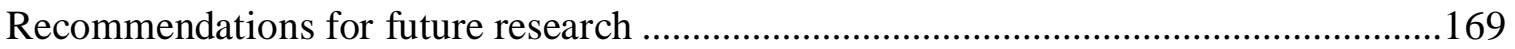

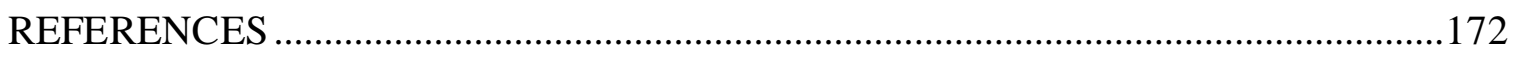

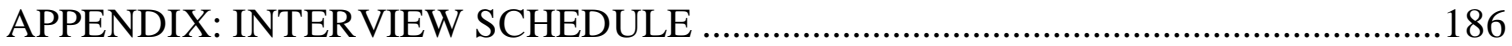

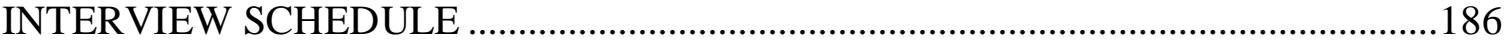




\section{LIST OF FIGURES}

Figure 1.1 Independent effects of stigma and working alliance on quality of life..... 14 Figure 1.2 The mediating effect of working alliance between stigma and quality of life 14

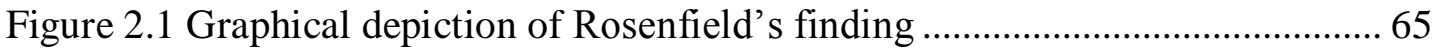

Figure 3.1 Graphical depiction of the nested data structure .................................... 109 Figure 3.2 Graphic depiction of mediation effects of working alliance between stigma related variables and subjective quality of life 


\section{LIST OF TABLES}

Table 2.1 Effects of devaluation and discrimination in Links community and treatment samples.... 66

Table 2.2 Social network and devaluation and discrimination findings from Link et. al (1989).....

Table 2.3 The effects of stigma coping mechanisms among individuals officially labeled

Table 2.4 Within treatment group studies of stigma

Table 2.5 ACT studies that have explored client-rated Subjective Quality of life .... 73

Table 2.6 Studies of the working alliance within case management

Table 3.1 Rational for inclusion of control variables

Table 3.2 Demographic comparison between sample of 175 and Southeast

Table 3.3 Demographic comparisons of the sample of 175 and the sample of 160.113

Table 4.1 Missing or unknown items

Table 4.2 Differences in missing values by gender, race, and primary diagnosis ... 137

Table 4.3 Multiple imputation regression values used to replace unknown values. 138

Table 4.4 Descriptive statistics for all variables included in the study

Table 4.5 Comparison of mean and standard deviation between current sample and past samples 142

Table 4.6 t-test and ANOVA comparisons 143

Table 4.7 Bi-variate Correlations $(\mathrm{n}=1600)$ 144

Table 4.8 Regression of subjective quality of life on control variables 144

Table 4.9 Regression of working alliance on control variables 144

Table 4.10 Final estimation for multilevel model of the effects of devaluation and discrimination, stigma withdrawal, working alliance on quality of life, controlling for demographic information and case managers

Table 4.11 Final estimation for multilevel model of the effects of devaluation and discrimination, and stigma withdrawal on working alliance controlling for demographic variables and case manager 146

Table 4.12 Final estimation for multilevel model of the effects of devaluation and discrimination, and stigma withdrawal on quality of life, controlling for demographic information and case managers 


\section{CHAPTER 1}

\section{INTRODUCTION}

Recovery from schizophrenia, bi-polar disorder, and major depression, which are known collectively as severe mental disabilities (SMD), is recognized as an achievable goal for persons in the public mental health system (Anthony, 2000; Ohio's Mental Health Commission; 2001). This focus on recovery represents a paradigmatic shift away from past beliefs about the long term, debilitating nature of SMD (Kruger, 2000). Mental health recovery is a belief that persons with SMD can, and often do, live self-defined, satisfying lives despite the apparent limitations of the disability and the societal stigma associated with SMD (Anthony, 1993).

This new focus on recovery has led to a new understanding for how community mental health interventions should measure success (Anthony et al., 2003) and how recovery itself should be measured (Noordsy et al., 2002). Anthony and colleagues (2003) have argued that recovery-based outcomes are outcomes considered important by persons who receive community treatment. Recovery is a multidimensional construct (Liberman \& Kopelowicz, 2004). Quality of life represents one outcome measure of recovery (Liberman \& Kopelowicz, 2004; Resnick, Fontana, Lehman \& Rosenheck, 2005). 
Researchers are working to develop a deeper understanding of the factors that facilitate mental health recovery and the recovery process, including environmental, psychological, and treatment-related factors (Loveland, Randall, \& Corrigan, 2005).

Two factors that potentially influence mental health recovery include the internalized stigma held by persons receiving psychiatric treatment, and the working alliance between clients of community mental health treatment and their treatment providers. This study will examine how the relationships between these two factors influence how persons receiving community-based psychiatric treatment perceive their subjective quality of life.

\section{Stigma as a barrier to recovery}

Recovery from SMD represents an achievable goal for persons with SMD. Yet the stigma associated with having SMD is a barrier to mental health recovery (Anthony, 1993; Perlick, 2001). While the symptoms and skill deficits associated with SMD can lead to negative outcomes for persons living with a SMD, so can the effects of stigma (Corrigan, 2000). Expectations held by individuals engaged in psychiatric treatment that they will be discriminated against and devalued by members of society simply because of their involvement in psychiatric treatment represents one aspect of the self-stigma process. These negative expectations about how society treats persons with SMD often lead to self-stigmatization, including withdrawing from normal social intercourse, and emotional responses such as shame.

These stigma concepts have been associated with reduced life chances or opportunities for persons receiving psychiatric treatment (Link \& Phelan, 2001). For 
example, individuals with a diagnosed SMD experience problems with unemployment and lower income compared to individuals who are not in treatment (Link, 1982). Negative stereotypes associated with SMD are deeply embedded in the collective psyche. For non-labeled persons, these views are not consequential; for persons with an official SMD label, these beliefs are activated and become self-defining (Link, 1987). Research on consumer-held negative stereotyped beliefs associated with persons with SMD held by the labeled persons themselves partly explain the association between persons with a diagnosed mental illness and unemployment and lower income (Link, 1987). According to Link (1987), these stereotyped beliefs of SMD did not explain low work participation or low income achievement among persons not officially labeled.

Stereotyped beliefs of persons with SMD held by labeled individuals were associated with lower rates of medication treatment compliance (e.g. Sirey, Bruce, Alexopoulos, Perlick, Friedman, \& Meyers, 2001), greater depressive symptoms (e.g. Link, Struening et al, 1997), negative appraisals of self-esteem, and negative perceptions of life satisfaction and quality of life (e.g. Markowitz, 1998, Rosenfield, 1997). These findings suggest that negative stereotypes of persons with SMD held by labeled persons negatively affect their own life chances.

Published accounts of mental health consumers' recovery stories detail actual experiences of self-stigma and self-stigmatization from consumers' perspectives (Angell, Cooke, \& Kovak, 2005, Gallo, 1994; Smith, 2000). These personal accounts amplify the negative impact of self-stigma upon the recovery chances of persons living with a SMD. For example, Gallo (1994) has written of her experience of anticipations of stigma: 
While we all know that stigmatization of the mentally ill exists and that it is always harmful, there is a kind of stigma that is actually more damaging than that inflicted by others. It is the all-too-real process and phenomenon of 'self-stigmatization' whereby mentally ill individuals torture themselves to an extent that exceeds what they suffer from the very worst that society-at-large can dish out to them....

....I perceived myself, quite accurately, unfortunately, as having a serious mental illness and therefore as having been relegated to what I called "the social garbage heap."

.... I tortured myself with the persistent and repetitive thought that people I would encounter, even total strangers, did not like me and wished that mentally ill people did not exist.

Thus, I would do things such as standing away from others at bus stops and hiding and cringing in the far corners of subway cars. Thinking of myself as garbage, I would even leave the sidewalk in what I thought of as exhibiting the proper deference to those above me in social class. The latter group, of course, included all other human beings. (p 407-408)

Gallo's description underscores how persons with a SMD experience themselves as a member of a stigmatized group and perceive themselves as open and vulnerable to devaluation and discrimination by members of society. Her account highlights how persons who carry a psychiatric label often act in accordance with their stigmatized, socially influenced, definition of what it means to be living with a mental illness.

Labeling theory of mental illness: A theoretical approach to understanding stigma and mental illness

Multiple approaches to understanding mental illness stigma exist (Link \& Phelan, 2001). Labeling theory of mental illness is one approach for understanding mental illness stigma. As the name suggests, labeling theory of mental illness focuses on the effects of psychiatric labels. Labeling occurs when an individual becomes defined as having a SMD. Labeling theory of mental illness posits that the societal response to a psychiatric label negatively affects the life chances or social psychological states of individuals who 
live with the label (Scheff, 1966, 1970, 1999). The original formulations of labeling theory of mental illness offered by Scheff, which is rooted in the symbolic interactionist tradition in sociology (Markowitz, 2005a), provides an alternative to the medical model for understanding the causes and course of SMD. Labeling theory articulates a socially driven, rather than a biologically or psychologically driven, understanding of the origination and maintenance of an individual's SMD identity development and behavioral manifestations. The labeling theory of mental illness articulated an understanding of both the causes and consequences of the application of a psychiatric label. In keeping with the purpose of this study, a focus on the effects or consequences of a psychiatric label on the lives of persons with a SMD will be highlighted, explored, and studied.

In Scheff's (1999) labeling theory of mental illness, the label, which carries with it negative cultural connotations in, is the primary cause of the negative consequences of living with a psychiatric label. Psychiatric labels engender strong, and mostly negative, emotional responses in members of the general public that become attached to the individual carrying the label. The application of a psychiatric label and the negative responses of others towards the labeled individual collude to formulate in the labeled individual an identity defined by the psychiatric label. Ultimately, this stigmatization process leads to the adoption of future symptomatic behavior, which Scheff (1999) and others (Lemert, 1967) term "secondary deviance." Labeling theory placed the reaction of others towards the psychiatric label as one culprit in the creation and maintenance of a new negative identity for persons with SMD.

Link and his colleagues (Link, 1987, Link et al., 1989; Link et al. 1991, Link et al., 2001) developed a modified labeling theory. Where Scheff (1999) argued for a view 
of the labeling process that emphasized the reactions of others towards the labeled person, modified labeling theory placed the emphasis on the reactions of labeled persons to their own labeled status. Modified labeling theorists argued for a self-stigma approach to understanding the negative effects of the label. Self-stigma is a process operating within labeled individuals, in which labeled individuals apply negative stereotypes of SMD to themselves and thus, self-discriminate, including withdrawing from normal social intercourse. Yet, modified labeling theory researchers have typically measured only a few aspects of this self-stigma process, including labeled individuals holding stereotypes of SMD; use of withdrawal as a stigma coping mechanism; and holding negative emotions, such as shame and embarrassment, associated with having a psychiatric label (Link et al. 2001). They argued that negative stereotypes associated with SMD become relevant for individuals who receive an official psychiatric label. Individuals with SMD who hold negative stereotypes of persons with SMD suffer negative consequences, such as negative economic achievement, smaller social networks, and poor self-esteem. Labeled individuals also develop stigma coping strategies to deal with their new and tainted status that are associated with negative life outcomes (Link et al., 1991). In addition, labeled individuals develop strong emotional responses towards their status that lead to negative life chances outcomes (Link et al., 2002). These negative consequences lead to greater vulnerability to future psychiatric distress.

Research on modified labeling theory of mental illness has generally been supportive of the claims made by the theory's proponents. Results from research on modified labeling suggest officially labeled persons who hold negative stereotypes of persons with SMD, use stigma coping strategies, and express negative emotional 
responses to their labeled status often experience reduced life chances (Link, 1987; Link et al., 1989, 1991, 2001, 2002). The negative effects of these stigma related variables are appreciable despite the negative effects of symptom distress.

While proponents of modified labeling theory argued that labels have negative consequences for labeled individuals, they acknowledged that psychiatric treatment, particularly evidence based forms of treatment, may also be beneficial (Link \& Cullen, 1990; Link et al, 1997; Rosenfield, 1997). Research on the impact of both held stereotypes of SMD and psychiatric treatment on psychiatrically labeled persons indicated that both treatment and held stereotypes operated independently to create both positive and negative outcomes for psychiatrically labeled persons. Model forms of treatment have been associated with positive outcomes and held stereotypes, with negative outcomes.

\section{Community-based psychiatric treatment}

While self-stigma is a potential barrier to recovery, community-based mental health treatment is a potential catalyst of mental health recovery. Researchers have investigated how receiving community mental health services can positively affect the lives of individuals with SMD. Assertive community treatment (ACT) is one communitybased approach to working with individuals with a SMD (Test, 1992). By providing comprehensive, team-based treatment in the community, ACT was initially developed to work with consumers with SMD who demonstrated significant impairments in community functioning (Marx, Test, \& Stein, 1973). 
Initial findings from the first ACT program, then known as "Training in Community Living," were generally favorable, including findings that ACT was superior to treatment as usual in terms of fewer hospitalizations, less symptom distress, and more positive perceptions of satisfaction with life (Stien \& Test, 1980). However, ACT has more recently been found to be superior only in terms of fewer hospitalizations and shorter hospital stays (Burns \& Santos, 1995; Olfson, 1990). The diffusion of structural and treatment components of ACT, which have narrowed the differences between ACT and other forms of community care, may explain ACT's comparability with other forms of community treatment on non-hospitalization based outcomes (Olfson, 1990). Studies of fidelity of ACT programs to the ideal ACT model have not found a significant association between fidelity and outcome (Bond \& Slayers, 2004). Antony (2003a, 2003b) and Solomon and Stanhope (2004) argued that process related similarities, such as the development of a working alliance between community mental health workers and their clients, might account for the comparability of ACT and other forms of community based treatment on treatment related outcomes. Within research on recovery, some have called for a greater focus on the contribution of process related variables to consumers' movement towards recovery (e.g. Anthony et al., 2003; Solomon, \& Stanhope, 2004).

Consumers of mental health services have discussed the powerful role of a strong working relationship with community workers on consumers' road to recovery. Consumers of mental health services stated developing a relationship with community mental health workers promotes active engagement in treatment through the development of trust (Chinman, Allende, Bailey, Maust, \& Davidson, 1999). Consumers' trust in case managers requires, in part, the development of a strong working alliance. Deegen (1996), 
a mental health consumer, has argued that the therapeutic relationship is "the most powerful tool" that treatment providers have for facilitating recovery oriented change.

Defining the working alliance

The working alliance, which has also been called the therapeutic alliance, therapeutic bond, and helping alliance, has been variously defined and measured (Martin, Garske, and Davis, 2000). These different definitions of the working alliance typically share two common dimensions: a) the bond that exists between the client and the therapist, and b) the collaboration between the client and the therapist (Bordin, 1979; Martin, Garske, \& Davis, 2000; McCabe \& Priebe, 2004). Research on working alliance in community mental health case management have generally used Bordin's (1979) definition of the working alliance (Howgego, Yellowlees, Owen, Meldrum, and Dark, 2003). Bordin (1979) defined the working alliance using three elements: a) the bond that exists between the therapist and the client, b) the agreement between the therapist and the client about the goals of therapy, and c) the agreement between the therapist and the client about the tasks of therapy. Bodin's (1979) definition was intended to be pantheoretical. He posited that his definition of the working alliance could be applied to any change-oriented relationship, including case management.

The effect of the working alliance on treatment outcomes

Studies of the working alliance between case managers and their clients have supported the positive role that the development of a strong working alliance can have on consumer treatment related outcomes. In case management studies, a strong working alliance has been associated with fewer psychiatric symptoms (e.g. Kinkenberg et al., 
1998; Neale \& Rosenheck, 1995), fewer hospitalizations, and greater work participation (Priebe \& Gruyters, 1993). Further, a strong working alliance has been associated with positive attitudes towards medication compliance, greater satisfaction with treatment, and positive perceptions of life satisfaction/quality of life (e.g. Solomon et al., 1995). Calsyn (2002) and colleagues found the working alliance was in part a therapeutic process associated with treatment successes. Clearly, a strong working alliance has a positive effect on consumers' treatment success.

Stigma, the working alliance, and quality of life Researchers have simultaneously studied the impact of aspects of the self-stigma process and treatment received by individuals receiving community-based treatment (Rosenfield, 1997, Link, Struening et al., 1997). Both Rosenfield (1997) and Link and colleagues (1997) measured negative stereotypes of SMD held by labeled individuals as a measure of this self-stigma process. Their research findings indicate both the types of psychiatric treatment undertaken and the negative stereotypes of SMD held by psychiatrically labeled persons were significantly and independently associated to quality of life. Held negative stereotypes were associated with negative perceptions of quality of life, while positive perceptions of subjective quality of life were associated with greater frequency of psychiatric treatment (Rosenfield, 1997). Researchers have studied the impact of both received psychiatric treatment and negative stereotypes on subjective quality of life, but have not studied independent effects of both self-stigma related variables and working alliance variables on subjective quality of life. However, Rosenfield's (1997) research findings, coupled with findings from working alliance 
studies (e.g. Solomon \& Drain, 1995), suggest that self-stigma related variables and working alliance variables may both affect subjective quality of life. Endorsement of self-stigma related variables, including held negative stereotypes of SMD and use of withdrawal as a stigma coping mechanism, might be associated with negative appraisals of subjective quality of life. Simultaneously, strong working alliances might be associated with positive perceptions of subjective quality of life. Indeed, self-stigma and working alliance might both independently and differently impact perceptions of subjective quality of life (see figure 1.1).

Rosenfield's (1997) research suggested that different types of treatment received and negative stereotypes of SMD held by psychiatrically labeled persons independently affect quality of life. However, working alliance is a treatment-related process that is expected to mediate the effects of treatment on outcome (Calsyn et al., 2002). Strong working alliances were presumed to explain the effects of treatment on outcome. Unlike the effects of types of treatment received and self-stigma variables on subjective quality of life, the working alliance might mediate, or offset, the effects of self-stigma related variables on subjective quality of life.

In the context of the current study, working alliance might serve as a partial mediator between self-stigma related variables and quality of life. Strong working alliances might mitigate the negative effects of self-stigma related variables on subjective quality of life. While self-stigma related variables negatively affect perceptions of subjective quality of life, strong working alliances, when present, might partly buffer the effects of self-stigma related variables resulting in positive appraisals of subjective 
quality of life. Figure 1.2 provides a graphic depiction of the mediating role of working alliance between self-stigma related variables and subjective quality of life.

\section{Objectives of the current study}

The purpose of this study was to determine if self-stigma related variables and the working alliance independently affect quality of life or if the working alliance mediates the relationship between self-stigma related variables and quality of life among consumers of ACT-like programs. This study represents the first time these two concepts were assessed together. The independent variable, self-stigma, was generally defined based on self-stigma related variables from modified labeling theory (Link, Yang, Phelan, \& Collins, 2004) including consumers' stigma related stereotypes as measured by the "devaluation and discrimination scale", stigma coping strategies as measured by the "stigma withdrawal scale", and stigma related emotions as measured by the "feeling different and ashamed scale." These self-stigma related variables were studied from the consumer's perspective. Each of these three stigma related variables was treated as a separate variable and each was interpreted as a unique aspect of the stigma process. The independent variable, “working alliance”, was defined using Bordin’s (1979) definition of the working alliance, which consisted of three components. The first component was the bond between the caseworker and the client. The next component was the agreement between the caseworker and client on the goals, or desired result, of treatment. The final component was the agreement between the caseworker and client on the tasks of treatment, which are the therapeutic activities used to achieve the goals of treatment. These three separate components were evaluated as one larger variable, the working 
alliance. The dependent variable "subjective quality of life" was defined as clients" subjective appraisals of their general life satisfaction, living situation, daily activities, family relations, social relations, finances, work, safety, and health. In the analysis, all of the separate dimensions of quality of life variables were treated as one overall quality of life variable. The variables, "ethnicity," "gender," "symptom distress," "current psychiatric diagnosis," "secondary alcohol or drug diagnosis," and "current case manager," were statistically controlled in the study.

Two research questions were explored:

1) To what extent do client perceptions of self-stigma and the working alliance between clients and their primary ACT worker independently affect client perceptions of subjective quality of life among consumers of ACT and ACT-like services?

2) To what extent do client perceptions of the working alliance between clients and their primary ACT worker mediate the relationship between perceptions of selfstigma and client perceptions of subjective quality of life among consumers of ACT and ACT-like services 


\section{Figures}

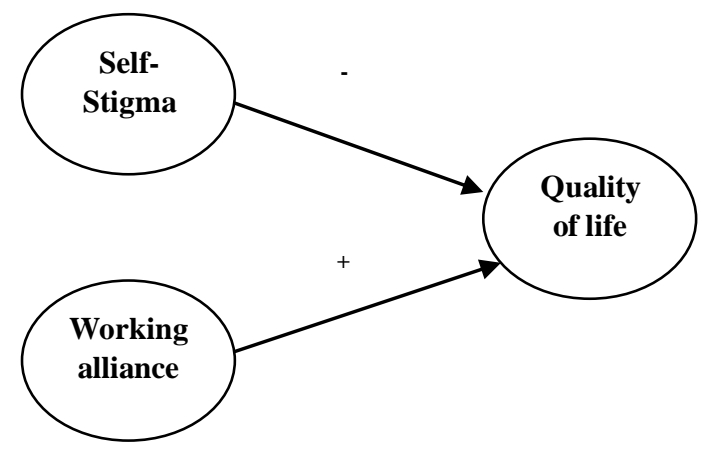

Figure.1.1: Independent effects of stigma and working alliance on quality of life

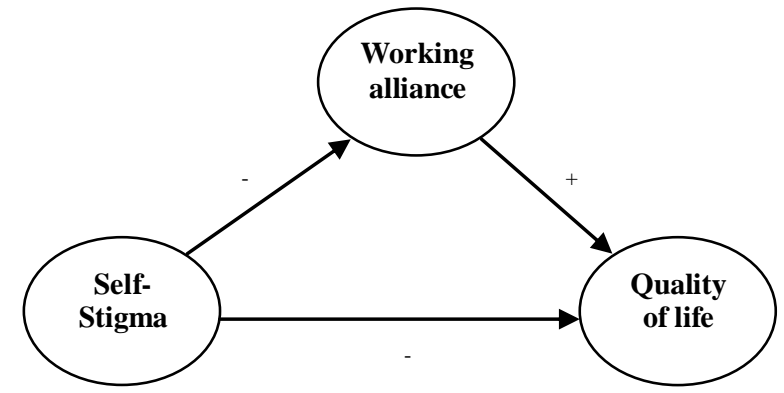

Figure 1.2. The mediating effect of working alliance between stigma and quality of life 


\section{CHAPTER 2}

\section{REVIEW OF THE LITERATURE}

Both self-stigma and the working alliance between community mental health case managers and their clients represent significant factors that impact perceptions of subjective quality of life of persons who receive community-based mental health services. This literature review will begin with a discussion of self-stigma and labeling theory of mental illness and explore how self-stigma serves as a barrier to mental health recovery. Next, this literature review will describe assertive community treatment (ACT) for persons with a serious mental disability (SMD). The literature review will explore how ACT affects perceptions of subjective quality of life for persons with SMD. Finally, the review will explore the concept of working alliance and how it is purported to help improve the psychological and social well-being of persons with SMD.

\section{Defining stigma}

Stigma is an elusive concept. Authors from different disciplines, including psychology, political science, anthropology, and sociology, have defined and used the term stigma in different ways and for different purposes (Link \& Phelan, 2001). Goffman (1963) offered one of the first modern definitions of stigma. For Goffman, a stigmatized 
person possesses " .... an attribute that makes him (sic) different from others.... He is reduced in our minds from a whole and usual person to a tainted, discounted one." (p.3). Thus, stigma is the process whereby society negatively defines a particular "mark" such as symptom or symptoms of mental illness as “... an attribute that is deeply discrediting...." (p.3) To Goffman (1963), stigma encompassed deeply held negative conceptions of labeled persons based on the social meaning of the mark. The mark and the associated stereotype lead members of society to treat persons like those with SMD as less than human. Moreover, the mark and associated stereotype also lead persons like those with SMD to view and act towards themselves in a similarly negative way (Goffman, 1963).

More recently, Corrigan and colleagues (Corrigan, 2000; Corrigan \& Watson, 2002; Corrigan \& Kleinlein, 2005) defined stigma as a social cognitive process that is situational. This process consists of four components: the signal, stereotypes, prejudice, and discrimination. The signal is the first step in the stigma process (Corrigan, 2000). Signals, which are akin to what Goffman referred to as the mark, identify a person as a member of a stigmatized group of persons. Signals associated with SMD include psychiatric labels, symptoms, skill deficits, and outward appearance (Corrigan, 2000).

Signals lead to stereotypes (Corrigan, 2000; Corrigan \& Watson, 2002). Stereotypes are social beliefs or knowledge collectively held by members of general society and " ....are especially efficient means of categorizing information about social groups.” (Corrigan \& Watson, 2002). For example, a general stereotype implies that persons with schizophrenia are dangerous (Pescosolido, \& Tuch, 2000). Stereotypes are like social schemata; people have learned over time society's views about groups who 
hold a particular stigmatizing signal. This information becomes relevant to an individual when they meet a person who appears to fit the stereotype or when they become identified as a person within the stigmatized group.

Members of society may or may not believe in the validity of the stereotype. Not everyone who has knowledge of a stereotype will agree it applies to all stigmatized persons or situations. Prejudice is the agreement with the stereotype within a given situational context (Corrigan, 2000; Corrigan \& Watson, 2002). As already stated, dangerousness is a stereotype of persons with schizophrenia. Yet, not every person who has contact with someone they believe to have schizophrenia applies the stereotype to that individual. While some individuals may be fearful of persons with schizophrenia, others my have relatively benign personal beliefs about persons with schizophrenia. Further, someone might fear a person with schizophrenia whom he or she does not know, but might be friendly with a person with schizophrenia whom he or she does know.

Discrimination is the behavioral manifestation of prejudice (Corrigan \& Watson, 2002). An individual who is fearful of persons with schizophrenia may avoid contact with persons they believe to have a SMD. If the fearful person is an employer, that person may not employ a person with schizophrenia, and if the fearful person is a landlord, they may not rent to a person with schizophrenia. The manifestation of discrimination is linked to the stereotype that supports the prejudice (Corrigan, 2000). For example, individuals who believe that persons with schizophrenia are dangerous place distance between themselves and the person they think has schizophrenia by crossing the street out of concern for their personal safety (Pescosolido, \& Tuch, 2000). 
Corrigan and Watson (2002) differentiate between public-stigma and self-stigma. Both processes can lead to reduced life chances and distortions in the self-concept of individuals living with a stigmatized status. The distinction between public- and selfstigma lies with who carries out the social cognitive, stigma process. Public stigma is the social cognitive process where members of the public move from stereotypes towards actual discriminatory behavior (Corrigan \& Kleinlein, 2005). An example of public stigma is the property owner who refuses to rent to a person with bipolar illness. In contrast, individuals engage in self-stigma when they apply held negative stereotypes of SMD to themselves (Watson \& River, 2005). An example of the manifestation of selfstigma is when persons with bipolar illness will not try to rent an apartment because they believe that their tainted status negates their right to have the apartment.

Both public- and self-stigma share the distinction of being situational. As an example of the situational nature of public stigma, landlords may not rent a newly renovated apartment to a person with a mental illness because they are worried about the potential destruction of the apartment, while being willing to hire the same person for a janitorial job without much hesitation. As an example of the situational nature of selfstigma, a psychiatrically labeled person who is also an electrical engineer might not apply for an engineering job because of an anticipatory fear of not being hired. However, the same person might be willing to apply for a janitorial job because she or he feels that this type of job is appropriate, given the labeled status. The situation determines the response.

Link and colleagues (Link and Phelan, 2001; Link et al., 2004) provided a modern sociological definition of stigma that draws on the work of Goffman (1963) and others (e.g. Scheff, 1999). Their definition of stigma consists of six interrelated components. 
The initial component of stigma is the labeling of differences. Through social processes, human differences are separated out and named. While many human differences, such as eye color, are socially irrelevant, some human differences, including SMD, are accorded higher degrees of consequence and are thus considered defining social characteristics. Another component of stigma is the association of the label with negative stereotypes (Link \& Phelan, 2001). The public links the label to socially prescribed and negative characteristics of persons who comprise the labeled group. Societal knowledge about persons with SMD is associated with relatively negative stereotypes (Link, 1987). This component of Link and Phelan's (2001) stigma definition is analogous to Goffman's (1963) idea that stigma is the association between an attribute and the mark. Link and Phelan (2001) identify the label as a deeply discrediting attribute. It is important to reiterate that these stereotypes of SMD are not only held by members of the public with regard to labeled persons, but are also held by labeled persons themselves.

A further component of stigma involves the separation of the labeled individual from the rest of society (Link \& Phelan, 2001). The stereotypes that exist about individuals with a label become a rationale for viewing labeled persons as different and not fully human, and consequently move the labeled individual to the margins of society. Link and Phalen (2001) wrote: “... when labeled persons are believed to be distinctly different, stereotypes can be smoothly accomplished because there is little harm in attributing all manner of bad characteristics to "them"” (p. 370). This separation of "us" from "them" is not only carried out by unlabeled members of society towards labeled persons, but is also a social process that is sometimes purposefully and sometimes 
unconsciously carried out by the labeled persons themselves. Individuals who selfstigmatize move themselves to the margins of society.

The emotional reactions to the label by both the stigmatized persons and persons who stigmatize is another component of stigma (Link et al., 2004). For those who stigmatize, the label is often met " ... with emotions of anger, irritation, anxiety, pity, and fear" (Link et al., 2004, p 513). For those who are stigmatized, owning the label is often accompanied with "...emotions of embarrassment, shame, fear, alienation, or anger...." (Link et al., 2004, p. 513). These emotions can produce a powerful and negative effect on those who carry a stigmatized label. While Link and colleagues (2004) added the emotional reaction component to an earlier definition of stigma offered by Link and Phelan (2001), the role of emotions and stigma is not new. Goffman (1963) wrote, “(s)hame becomes a central possibility, arising from the individual's perception of one of his (sic) own attributes as being a defiling thing to posses, and one he can readily see himself possessing" (p.7). For Scheff (1999), the application of a psychiatric label often produces a “... deep and intense emotional response involving fear, anger, and/or embarrassment" among members of the public towards the labeled individual (p.46). These negative emotions became a further rationale for discrimination against labeled persons. Scheff (1999) saw the emotion of shame as a powerful and negative response to the label.

An additional component of stigma is the experience of discrimination and status loss by stigmatized persons (Link \& Phelan, 2001). The experience of status loss may result from discrimination like that described by Corrigan and Watson (2002). Members of society discriminate against persons with SMD. For example, others might not hire a 
labeled person for a job or rent a labeled person an apartment. Likewise, persons with SMD self-discriminate. Labeled persons may not seek out the life chances they deserve, such as housing, income, and friendship. The net result for labeled persons of both discrimination and self-discrimination is status loss.

The final component of stigma is power (Link \& Phelan, 2001). "Stigma is entirely dependent on social, economic and political power - it takes power to stigmatize" (p. 375). Without the application of power, there is no stigma. In order to understand the role of power in the stigma process, Link and Phelan (2001) describe a situation that is stigma-like except for the absence of power. These authors describe how many persons living with SMD often hold negative views of psychiatric professionals, such as being "pill pushers." As a result, individuals living with a SMD may attempt to separate themselves from psychiatric professionals and act towards the professionals in a discriminatory way. However, Link and Phelan (2001) argue that because individuals labeled as having SMD lack official and actual power, they are not capable of stigmatizing professionals, even though their beliefs and actions appear to represent the stigma process.

All three definitions of stigma offer practical and theoretical utility. Goffman's (1963) definition provided the basis for future sociological investigations suggesting that stigma occurs when negative stereotypes are applied to individual characteristics or attributes. He posited that the association of stereotypes to individual characteristics negatively affected the selfhood and life chances of persons with SMD. His definition separated individuals from their discrediting and stigmatizing marks, yet members of the public reacted to the stigmatizing marks, labeling individuals based on their deeply held 
stereotypes of persons with SMD. Of course, labeled individuals were also affected by how others reacted to them. This distinction between the person and their stigmatizing mark leaves open one pathway for changing the stigma of mental illness, eliminate the association between negative stereotypes and stigmatizing characteristics. Eliminate the association and the life chances of individuals affected by stigma may change for the better.

Corrigan and colleagues' (Corrigan, 2000; Corrigan \& Watson, 2002) social cognitive definition of stigma is relevant for two reasons. First, their definition suggests that stigma can be found in the cognitions and reactions of others towards psychiatrically labeled persons, and in the cognitions and reactions of stigmatized individuals towards themselves, which is called self-stigma. Moreover, because psychiatrically labeled individuals can carry out the self-stigma process towards themselves, self-stigma may negatively affect individuals with SMD in the absence of overt stigmatization and discrimination of others in society.

Second, the social cognitive definition of the stigma process is situation specific (Corrigan, 2000; Corrigan \& Watson, 2002). From a self-stigma standpoint, stigmatized individuals my not suffer the effects of stigma in every situation. One stigmatized individual may feel stigmatized in applying for a job and another individual in the same situation may not feel any sense of discrimination. The crux of this distinction lies in whether the stigmatized individual applies a known negative stereotype to him- or herself in a specific situation. A practical consequence of the situational nature of stigma relates to stigma research. Researchers must be aware of how they operationally define stigma 
and know what types of stigmatizing situations they are sampling before advancing their definition of stigma.

Link and Phelan's (2001) definition of stigma is relevant for understanding and researching stigma for at least three reasons. First, their definition provides a broader context in which to view stigma. The authors link stigma to power. The presence of stigma rests, in part, on groups of individuals who have power to define some attribute or group of persons as worthy of discrimination. Those in positions of power have the ability to discriminate against persons with SMD and to consequently block labeled persons' life chances. Corrigan (2004) argues that the media, policy makers, health care professionals, landlords, employers, and criminal justice professionals represent some of the power groups who can affect the lives of persons with SMD. Persons in positions of power do not necessary intend to block the life chances of persons with SMD. Rather, their discriminatory actions towards labeled individuals are based on their received stereotyped understandings of persons with SMD, their fear of the "bizarre" symptomatic behavior of persons with SMD, and their insensitivity to the needs of persons with SMD.

Because symptom distress and status loss associated with SMD often leave labeled persons partially dependent on others for help, a power differential often emerges between persons saddled with a psychiatric label and those who help the labeled person, such as psychiatric social workers. Hence, those in positions of power need to examine their beliefs and actions associated with those beliefs about persons assigned various labels. Anti-stigma interventions should target persons in positions of power to challenge their beliefs about persons with mental illness and the associated behavioral manifestations. 
Second, Link and Phelan's (2001) definition of stigma provides several useful concepts that can be applied in research studies to understanding mental illness stigma and the effects of this stigma on labeled groups (Link \& Phelan, 2001). For example, Link (1987) developed the stigma devaluation and discrimination scale that assesses the degree to which an individual believes members of society hold negative views of persons with SMD and discriminate against persons with SMD. The devaluation and discrimination scale measures a person's understanding of the SMD stereotypes commonly held by members of society. This author will use the phrase "devaluation and discrimination" to mean: “...expectations as to whether most people will reject an individual with a mental illness as a friend, employee, neighbor, or intimate partner, and whether most people will devalue a person with a mental illness as less trustworthy, intelligent, and competent” (Link and Phelan, 2001). Link and colleagues (1991) developed the stigma withdrawal scale, which examines the degree to which persons with an SMD separate themselves from general society. Link and colleagues (2001) developed the stigma feelings of different and ashamed scale, which measures negative emotional reactions of labeled persons towards their status.

As with Corrigan and colleagues (Corrigan, 2000; Corrigan \& Kleinlein, 2005; Corrigan \& Watson, 2002; Watson \& River, 2005 ), Link and Phelan's (2001) definition of stigma recognizes the stigmatizing process is not only carried out by members of the general public towards persons with a SMD. Persons with SMD can also self-stigmatize and self-discriminate simply by having internalized negative stereotypes themselves. Therefore, stigma is not only something external that happens to the labeled individual, but also triggers an internal psychological process that frequently leads individuals with 
the label to self-stigmatize. This internal process has been the focus of much of the research on modified labeling theory of mental illness (Link et al., 1989).

\section{Evidence of stigma}

Before beginning a thorough discussion of the effects of mental health stigma, the problem of stigma needs to be situated in terms of the extent to which the public holds negative stereotypes about persons with SMD and as a result discriminates against them. Research on public perceptions of persons with a SMD indicates that the public does hold negative views of persons with a mental illness. Martin, Pescosolido, and Tush (2000), using information for the 1996 General Social Survey, studied responses of participants who were randomly assigned one of five vignettes. Four of the five vignettes presented persons labeled as having a SMD (schizophrenia, depression, alcohol addition, and drug addition) and the fifth did not. The researchers explored respondents' reactions to the vignette related to causal attribution of the problem, dangerousness, and avoidance. The researchers found that about 48 percent of the sample stated that they would avoid contact with a person with schizophrenia and that 37 percent would avoid contact with a person with major depression. The perception of dangerousness was a significant reason for avoiding contact with persons with SMD. Controlling for demographic variations among respondents and respondents' causal attributions of the problem (including genetic transmission or chemical imbalance), the researchers found that dangerousness accounted for an additional $8.6 \%$ of the variance in avoidance of persons with SMD.

Persons living with a severe mental disability (SMD) also hold negative stereotypes about persons with a SMD. Link (1987) studied endorsement of negative 
stereotypes of SMD between persons with an official psychiatric label and persons without an official psychiatric label. He used his devaluation and discrimination scale to determine the degree to which persons endorse knowledge of negative stereotypes of SMD. He found that persons both with and without a psychiatric label endorsed knowing negative stereotypes of SMD. Further, he found that both groups did not significantly differ in their endorsement of knowledge of stereotypes of SMD.

Early contributions to labeling theory of mental illness

Labeling theory of mental illness has been intimately tied to the symbolic interaction study of deviance (Herman-Kinney, 2003). The study of deviance from a symbolic interaction perspective holds that definitions of deviance are socially defined. Those outside the SI tradition have been concerned with individual causes of deviance (Herman-Kinney, 2003). While those within the symbolic interaction tradition focused on the social processes that lead an individual to become defined as deviant by society, and the subsequent societal reactions of labeled individual to the deviant label. Rather than blaming the individual for deviance, deviance is seen as part of the larger social system comprised of shared expectations and norms for behavior, and rewards and punishments for conformity or nonconformity to these shared expectations (Scheff, 1999).

Individuals who recognizably do not conform to these shared expectations have often been labeled by society as deviant. Members of society apply the deviant label, whether criminal, drug abuser, prostitute, or mental patient, onto those they believe deserve the label (Lemert, 1967). The social reaction towards the deviant role has 
tangible consequences for labeled individuals. These consequences include internalization of the deviant role and identity, restricted social relationships and employment opportunities. (Lemert, 1967). The deviant label became a "master status" for the labeled individual towards which members of society negatively react (Becker, 1964). While most individuals identify with and are identified by multiple roles, persons with SMD identities are restricted to the patient role. The label becomes the primary lens through which individuals with SMD view themselves. Further, the label becomes the lens thought which others view persons with SMD.

The symbolic interaction perspective amplifies the importance of the deviant label. The concepts of primary and secondary deviance underscore the essential nature of the connection between deviance and the label. "Primary deviance is assumed to arise in a wide variety of social, cultural, and psychological contexts and at best has only marginal implications for the psychic structure of the individual" (Lemert, 1967, p. 17). Primary deviance, involving the initial and maybe periodic breaking of social norms, has been known to derive from different sources, and has not necessarily resulted in the definition of an individual as deviant. The potential negative effects of primary deviance were viewed as temporary, except to the extent that it may become a future rationale for defining an individual as a deviant.

Secondary deviance was seen as deviant behavior that resulted from an individual officially becoming labeled as a deviant. "Secondary deviation is deviant behavior, or social roles based upon it, which becomes a means of social defense, attack or adjustment to the overt and covert problems created by the social reaction to primary deviance" (Lemert, 1967, p. 17). Secondary deviance, involving continued norm violations, occurs 
with an individual's response to the application of a deviant label and the social reaction to that label. Secondary deviance is a means of protecting oneself from the effects of others' reactions. For example, self-isolation from others is a sign of mental illness, and self-isolation is a way to avoid discrimination. Unlike primary deviance, which is temporary in effect, secondary deviance is prolonged and chronic. The distinction between primary and secondary deviance had a strong influence on Scheff's (1999) conceptualization of the labeling theory of mental illness.

Another fundamental aspect of the symbolic interaction study of deviance was in defining how individuals with a deviant label attempt to deal with their "spoiled" identity. Goffman (1963) argued that individuals attempt to cope with their devalued status through managing who comprises their social networks. Individuals who carry a stigmatizing mark feel outside of the social world, that they are unacceptable to others in society. Two groups of individuals, the "own" and the "wise", “... are sympathetic others who are ready to adopt his (sic) standpoint in the world and to share with him the feeling that he is human and 'essentially' normal in spite of appearances and in spite of his own self-doubt" (pp 20-21). The "own" are individuals who share the stigmatized status with the labeled individual and the "wise" are individuals "related through social structure to a stigmatized individuals," such as other family members or close friends who are willing to share with the individual their stigmatizing status. In essence, the social world of the stigmatized person becomes restricted to these two groups, whether because of the stigmatized individual's own volition or because of outside social pressures. Goffman's work on the ways in which individuals with a stigmatizing mark attempt to manage their 
identity, including his conception of the own and the wise, influenced the work of Link and his colleagues (1991) on their conceptualization of stigma coping orientations.

Thomas Scheff's labeling theory of mental illness

Thomas Scheff $(1966,1970,1999)$, was among the first to fully articulate a social reaction or labeling theory of mental illness. Scheff (1999) argued SMD was a special kind of deviance, what he termed residual deviance. Deviant behavior is the breaking of societal-based rules or norms of conduct. Most types of deviant behavior are easily classified into specific deviant categories such as murder, drug abuse, and prostitution. Each of these categories of deviance is based on a set of behavioral expectations and each of these categories carries with it societal prescriptions and sanctions for dealing with the violation of the associated norms or rules of conduct. For example, society labels someone who has sex with others for money as a prostitute; if the police, or other legal authority, become aware of this person's deviant behavior, he or she may spend time in jail and/or pay a fine.

By contrast, Scheff (1999) termed the deviance associated with SMD as residual deviance. The classification of SMD as a form of deviance was the breaking of not easily classified rules or norms. Rules that govern residual deviance are taken for granted and the rules are implicitly understood. Scheff (1999) used an example of rules that govern eye contact in social interaction to illustrate this point. In most human interaction in western society, there is an implicit expectation of at least periodic direct eye contact between communicators. When this expectation is not fulfilled by one of the individuals involved in interaction, the other views the individual as if something were wrong. 
Because the rules that govern eye contact are so taken for granted, and thus not easily classified, the other individual may think that the lack of eye contact indicates SMD. Scheff (1999) articulated a series of nine propositions to describe this labeling theory. Highlighting the central role of society in the labeling process, Scheff (1999) argued that members of the public are socialized early in life to understand what constitutes SMD. Individuals are socialized about SMD through interactions with family, friends, and the popular media. This early socialization is continually affirmed throughout regular social interactions over a lifetime, leading individuals to develop a stereotyped representation of what it means to have SMD and how society responds to those individuals who have a SMD

Scheff (1999) argued that behaviors classified as residual deviance arise from multiple sources, including biological, psychological, and social. Similar to Lemert's (1967) conception of primary deviance, not every individual who commits acts of residual deviance becomes labeled as having a SMD. In fact, more often than not, the breaking of rules that govern a definition of residual deviance go unnoticed or are ignored by others. Further, in most cases, the actual occurrence of deviant behavior is temporary. When an individual becomes labeled as having SMD, and thus as a deviant, a different social process ensues (Scheff, 1999). Once officially labeled, the individual is rewarded by some, including treatment professionals, for acting in accordance with the deviant role. The labeled individual is also punished by others, including treatment professionals, for attempting to act "normal." Because of these social pressures, labeled individuals may accept the label as self-defining, and the individual begins to engage in behaviors that are associated with this deviant role, similar to Lemert's (1967) conception 
of secondary deviance. Speaking to the power of the social reaction to individuals with SMD, Scheff(1999) wrote: “Among residual rule-breakers, labeling is among the most important causes of careers of residual deviance” ( $p$ 92). In essence, the psychiatric label leads individuals with the label to develop an identity consumed by the label, what Becker (1964) called a "master status.”

\section{Critiques of labeling theory}

Opponents of labeling theory of mental illness have debated and criticized the merits of the theory. Walter Gove and his associates have been critical of the labeling approach (Gove, 1970, 1982; Gove and Fain, 1973). One of the points of contention between labeling theorists and their critics was the role of the societal reaction in the creation of continued deviant or symptomatic behavior. Critics of labeling theory argued that the stigma associated with a mental illness was related to actual behaviors of individuals with SMD and not to the social process outlined above. While stigma may be experienced and perceived by an individual living with a SMD, “...in the vast majority of cases the stigma appears to be transitory and does not appear to pose a severe problem” (Gove, 1982, p. 280). Gove (1970) argued that symptomatic behavior of individuals with a SMD and not the societal reaction to the psychiatric label result in negative consequences, such as re-hospitalization and the permanency of the deviant status.

A second point of contention between labeling theorists and their critics dealt with the impact of psychiatric treatment. While labeling theorists see the stigma associated with receiving treatment for SMD as contributing to secondary deviance, critics (Gove, 1970, 1982; Gove \& Fain, 1973) argued that treatment can and usually does have a 
positive impact on persons who receive psychiatric help. Treatment represents a restitutive process that helps to mitigate the negative and harsh effects of psychiatric symptoms on consumers and their families (Gove, 1970). As evidence of this restitutive process, Gove and Fain (1973) found that, based on a single group retrospective study, receiving hospital based treatment did not lead to a decrease in patients' assessment of their own instrumental performance, economic position, relationships with family and with others, ability to handle problems, and overall life satisfaction. Their findings stand in opposition to the expectations of labeling theorists (Scheff, 1999), treatment appearing to be beneficial for individuals with SMD.

\section{Modified labeling theory}

Partly in response to the critics of labeling theory, Link (1982) sought to explore the effects of labeling persons with SMD. Rather than assessing the impact of the label in terms of the development of deviant behavior or the development of an identity as the label, Link explored the effects of labeling in other life areas, specifically income and employment. In addition, Link (1982) placed less emphasis on the role of others towards the labeled individual and instead focused on the reactions of labeled individuals to societal conceptions of mental illness. Link's (1982) understanding of the stigma process focused on self-stigma: how individuals with a psychiatric label know negative social stereotypes of SMD, apply these stereotypes to themselves, and consequently engage in self-discriminatory behaviors.

Using a sample of community residents, including those who met criteria for having a SMD but were untreated $(n=429)$, and a sample of individuals currently 
receiving treatment $(n=164)$, Link $(1982)$ assessed the impact of an official psychiatric label, as defined by occupancy in treatment, upon income and work. Controlling for psychiatric symptoms, including a measure of psychiatric symptoms given to community residents, and other variables associated with income and work status, Link found that being in treatment, compared to not being in treatment, was associated with less income and greater unemployment. Persons who were not labeled but were experiencing symptoms of mental illness exhibited similar results to those who were not labeled and not experiencing symptoms. In interpreting the results of his study, Link argued that the effects of stigma on individuals living with an official definition of SMD may be attributed to a process operating through individuals in treatment so that they attribute to themselves negative stereotypes about SMD generally believed by society, and thus selfdiscriminate.

Drawing on his 1982 study, Link and his colleagues (Link, 1987; Link et al., 1989; Link et al., 1991) articulated what has come to be known as modified labeling theory of mental illness, posited a series of five steps to the modified labeling process. First, individuals learn about negative societal conceptions, or stereotypes, associated with SMD, and use these conceptions as a guide for understanding SMD and its consequences. The authors liken this process of learning societal conceptions of SMD to Mead's (1934) taking the role of the generalized other, or society as it is understood by the individual, in which individuals partially see themselves and other social objects as they think a "general person" in society views them.

Second, an individual is officially labeled. Once officially labeled, an individual's earlier learning about SMD become relevant, including the negative stereotypes 
associated with mental illness. Third, individuals develop coping strategies to respond to their stigmatized status. Drawing on the work of Goffman (1963), Link and colleagues argued that individuals attempt to hide their status from others through secrecy or withdrawal from social interaction. Link et al. (1989) stated that the use of these coping mechanisms often backfire on persons with SMD. For example, withdrawal from social interaction may help the person avoid negative interactions, but also limit potentially positive experiences as well. Next, individuals suffer negative consequences - such as deterioration in their self-esteem, earning power, and social networks - as a result of incorporating negative stereotypes of SMD into one's self-structure and engaging in selfdiscrimination.

Finally, the impact of these negative consequences may leave indi viduals vulnerable to new psychiatric disorders or to repeat episodes of their psychiatric condition. Link and his colleagues (1989) have suggested that the stress caused by the impact of self-stigmatization leads to new episodes of mental illness. The stress of having the label, and not reality of the label itself, was implicated in future episodes of psychiatric distress.

\section{Testing Modified Labeling Theory}

Using a strategy similar to Link's (1982) first study of labeling theory, Link and his colleagues (Link, 1987; Link et al., 1989; Link et al., 1991) attempted to tease out this self-stigma process. In order to determine the effects of public conceptions of SMD on labeled individuals, Link (1987) developed the devaluation and discrimination scale that measures the extent to which individuals know of the negative stereotypes of SMD. 
Larger scores on the devaluation and discrimination scale meant greater endorsement of knowledge of stereotypes of SMD. Link (1987) studied the effects of endorsing items on the devaluation and discrimination scale on outcomes using a combined treatment and community sample. Analysis was conduced within each group. See table 2.1 for findings from these studies.

Within the same study, Link (1989) and colleagues explored the effects of perceptions of negative stereotypes, as measured by the devaluation and discrimination scale, on social network variables. They studied these relationships only among individuals who held a psychiatric label. The authors were interested in discovering how greater endorsement of devaluation and discrimination affected the number of instrumental supports a person had (instrumental supports being persons who can be counted on for help). In addition, the authors explored how greater endorsement of the devaluation and discrimination scale affected extensiveness of task coverage by others. They paid particular attention to household family, non-household family, and friendship sources of supports. Table 2.2 reports findings from this study

As findings from this study indicate, self-stigma is a reality for individuals with a SMD (Link, 1987; Link et al. 1989). SMD and the social knowledge available to those with SMD were sources of demoralization for individuals who receive treatment and were associated with less time employed and less income (Link, 1987). The effects of stigma on work and income were time delayed. The effects of greater endorsement of the devaluation and discrimination scale on income did not manifest itself among individuals who had been labeled for less than a year. However, Link stated that information about income and work participation was based on information that was available from the year 
before the individual received an official label. Thus, the immediate economic situation of individuals with the label for less than a year may be worse than the findings suggest. Findings from Link (1989) and colleagues' study suggest that the self-stigma process on social networks is complex. It was found that household family members increased support to their labeled family member in correlation to the more the labeled person endorsed knowing negative stereotypes of SMD. Labeled individuals relied most frequently on immediate family for help; non-household relatives were not as helpful. In fact, as perceptions of devaluation and deviation increased, the individual was less likely to receive help from these relatives. Lastly, perceptions of devaluation and discrimination did not affect support received from friends and non-relatives. Link et al. (1989) suggested that this finding could be related to an increase in support from other persons living with a SMD. However, the authors did not control for the labeled status of nonrelatives.

\section{Stigma coping strategies}

Link and his colleagues (Link et al., 1989; Link et al., 1991) also explored how stigma coping orientations - secrecy, withdrawal, and education - affected individuals living with a psychiatric label. Labeled individuals use these coping orientations as a way to mitigate the effects of stigma, including public stigma. However, Link $(1989,1991)$ and colleagues posited that these coping strategies would have a negative effect on individuals with a mental illness who endorsed use of these coping strategies. Greater endorsement of the stigma secrecy scale, stigma withdrawal scale, and stigma education 
scale meant that individuals endorsed used these coping orientations. Results from these studies of stigma coping mechanisms are summarized in table 2.3

A couple of points are worth noting about the use of stigma coping mechanisms. Stigma withdrawal was the most damaging of these coping mechanisms. Endorsement of stigma withdrawal negatively affected feelings of demoralization, work participation, and non-family social supports. Neither stigma secrecy nor stigma education were statistically associated with social supports, feelings of demoralization, or work participation, yet endorsement of education as a coping strategy was associated with greater endorsement of devaluation and discrimination (Link et al. 1991). Based on the evidence concerning coping orientations, Link and his colleagues (1991) conclude:

Far from offering patients a way to manage their stigmatized status, the coping orientations we studied hurt more than helped. It seems that patients individually strive to overcome their stigmatizing status, but as they seek to manipulate strategically the conditions that lie before them, they inadvertently limit their opportunities and induce psychological malaise. (p.316)

Both perceptions of devaluation and discrimination and endorsement of coping strategies, particularly stigma withdrawal, have a negative impact on the social and psychological wellbeing of individuals with a psychiatric label. Contrary to criticism of labeling theory, psychiatric labels do appear to matter. 
Studies of the effects of psychiatric labeling within treatment groups

Link and his colleagues (Link 1987; Link, et al. 1989; Link et al., 1991) initially used both community samples and treatment samples to test modified labeling theory. Recent studies of modified labeling theory have used samples from only treatment populations -- holding label status constant -- to expand an understanding of the effects of the psychiatric label and the self-stigma process. Table 4.4 provides a summary of these studies.

The studies of modified labeling theory broaden an understanding of the effects of self-stigma on multiple outcomes. Measures of self-stigma were associated with psychiatric symptoms. Markowitz (1998) and Link and colleagues $(2001,2002)$ found that greater endorsement of devaluation and discrimination was associated with greater depressive symptoms. However, Markowitz (1998) found greater endorsement of devaluation and discrimination was not related to other psychiatric symptoms. Rather, endorsement of devaluation and discrimination was negatively associated with self-hood variables, including self-esteem (Markowitz, 1998, Rosenfield, 1998). Markowitz (1998), Link et al. (2001, 2002), and Kahng and Mowbray (2005a) found that greater endorsement of devaluation and discrimination was associated with lower levels of selfesteem. In addition, these studies found that devaluation and discrimination was negatively associated with life-satisfaction (Markowitz, 1998), economic wellbeing (Markowitz, 1998), participation in social leisure activities (Perlik et al., 2001), medication compliance (Siriey et al., 2001) and psychological integration (Prince \& Prince, 2002). 
Some of these studies found that endorsement of devaluation and discrimination was not associated with outcomes. Markowitz (1998) found that the devaluation and discrimination scale was not associated with self-efficacy or psychotic symptoms. Perlik and colleagues (2001) found that a combined measure of devaluation and discrimination and stigma withdrawal was not associated with overall social adjustment, extended family relations, or rejection sensitivity. Prince and Prince (2002) found that endorsement of devaluation and discrimination was not associated with social integration or physical integration. As measured by the devaluation and discrimination scale, the findings suggest that self-stigma does not universally affect outcomes.

Individuals with and without an official label generally believe that persons with a SMD are negatively stereotyped by members of society, as measured by endorsement of devaluation and discrimination (Link, 1987). Two of these studies point to the stability of negative stereotypes over time. Markowitz (1998) found that scores on the devaluation and discrimination scale did not significantly change over an 18-month time period. Link et al. (2002) developed an intervention to challenge self-stigma attitudes among persons with SMD. The authors found that their intervention did not change participants' scores on the devaluation and discrimination scales. This finding suggests that individuals' understanding of the negative stereotypes of SMD does not change over time. Further, the authors found that their intervention did not change participants' endorsement of stigma withdrawal or stigma secrecy as stigma coping methods, and did not change participants' endorsement of feeling different and ashamed and feeling misunderstood by others. 
A rival explanation for the effects of self-stigma on the psychological and social wellbeing of persons with SMD are the symptoms and skill deficits associated with the disability (Gove, 1970). The reviewed studies showed the complex nature of the effects of self-stigma related variables and symptoms on the life chances and psychological and social wellbeing of persons with a SMD. Rather than being either self-stigma related variables or psychiatric symptoms, these studies point to the effects of self-stigma related variables and psychiatric symptoms on the lives of persons with a SMD. Kahng and Mowbray (2005a) found that self-esteem was negatively affected by endorsement of devaluation and discrimination, manifesting in both depressive and psychiatric symptoms. Prince and Prince (2002) found that psychosocial functioning, a measure of skill deficits associated with SMD, was positively related to psychological integration, and that devaluation and discrimination was negatively related to psychological integration.

Adding to the complexity of the effects of self-stigma related variables and psychiatric symptoms on the lives of persons with SMD were the effects of symptoms on self-stigma related variables (Kahng \& Mowbray, 2005b; Lysaker et al, 2007). Using their particular measure of perceived self-stigma, Lysaker (2007) and colleagues found a positive relationship between self-stigma and psychiatric symptoms. Consumers who reported greater self-stigma reported more psychiatric symptoms. Kahng and Mowbray, (2005b) explored antecedents of withdrawal and secrecy coping orientations. The authors found that greater endorsement of devaluation and discrimination and positive and negative symptoms were associated with lower self-esteem and greater self-deprecation. Further, they found self-esteem and self-deprecation mediated the effects of positive and 
negative symptoms and devaluation and discrimination on endorsement of both stigma withdrawal and stigma secrecy.

Some of these studies assessed the role of stigma-coping orientations and stigma feelings on the lives of persons with SMD. The stigma-coping mechanisms included stigma withdrawal (Link et al, 1989), stigma secrecy, stigma education (Link et al., 1991), challenging others, and distancing oneself from others (Link et al., 2002). Link and colleagues (2001) added two emotional states, feeling different and ashamed and feeling misunderstood by others. Greater endorsement of these self-stigma emotional state variables is associated with feeling different and ashamed and feeling misunderstood. Except for distancing oneself from others and secrecy, the average item scores on the other coping mechanisms and self-stigma emotional state variables were higher than the mid-point value of the scale. Values above the mid-point of the scale indicate endorsement of the coping mechanism and emotional states. These findings demonstrate that persons with SMD do endorse using these coping mechanisms and do endorse having negative self-stigma related emotions.

The effects of the stigma coping mechanisms and emotions on the lives of persons with SMD were not uniform. Link et al. (2002) explored the effects of all of the selfstigma related coping mechanisms and emotions on self-esteem and depressive symptoms. Using bivariate correlations, the authors found that stigma secrecy, stigma withdrawal and distancing oneself from others, and feeling different and ashamed were negatively associated with self-esteem. Endorsement of each of these self-stigma related variables was associated with more negative appraisals of ones self-esteem. With the exception of distancing oneself from others, these self-stigma coping strategies and 
emotional states were associated with greater depressive symptoms. When outcomes were assessed using multiple regression, only stigma withdrawal, stigma secrecy, and feeling different and ashamed were associated with depressive symptoms and selfesteem. While not always directly associated with negative outcomes, these self-stigma coping mechanisms and emotional states do explain different ways individuals attempt to deal with their tainted status.

Two of these studies explored the relative effects of self-stigma related variables and public stigma related variables. Markowitz (1998) explored the effects of endorsement of devaluation and discrimination and a one-item measure of rejection experiences, a measure of public stigma. Markowitz (1998) included both the rejection experiences variable and the devaluation and discrimination variable in his statistical model. He found that the inclusion of rejection experiences reduced the power of the effects of endorsement of devaluation and discrimination on self-esteem, depressive symptoms, life satisfaction, and economic satisfaction by up to $30 \%$. However, Markowitz operationally defined rejection experiences with a one-item measure. Single item measures of a construct are not as valid and reliable as multi-item measures of a construct (Kazdin, 2003). Link (2001, 2002) and colleagues, using a multi-item rejection experiences scale, found that rejection experiences, and devaluation and discrimination were related to self-esteem and depressive symptoms. These two studies point to the separate, significant, and negative effects of both self-stigma related variables and actual experiences of rejection on persons with SMD.

Finally, devaluation and discrimination affected how persons interpreted their sense of self. Kahng and Mowbray (2005a), Link and colleagues (2002), and Markowitz 
(1998) found that self-stigma related variables negatively affected self-esteem. In addition, Markowitz found that self-esteem mediated the effect of devaluation and discrimination on depression; the more one endorsed devaluation and discrimination, the lower one's self-esteem and the greater one's level of depression. Davidson (2003) posited that the development of a positive sense of self is an essential process of mental health recovery. Endorsement of devaluation and discrimination was found to be a barrier to the development of a positive sense of self and, consequently, mental health recovery.

Assessment of both treatment effects and stigma effects

All of the studies discussed so far have treated psychiatric treatment as a constant or have compared the effects of treatment, through the application of a label, to the broader unlabeled or untreated population. Two studies explored the effects of selfstigma related variables and the effects of treatment received on the lives of persons with SMD (Link et al., 1997; Rosenfield, 1997). Rosenfield (1997) explored the effects of both received services and devaluation and discrimination on subjective quality of life of individuals in a clubhouse program. Further, she assessed the potential mediating effect on subjective quality of life of self-esteem and self-mastery, both measures of selfconcept, between both devaluation and discrimination and service use. She found the amount of specific types of received services (e.g. vocational services, financial support services, mental health and AOD groups, leisure group activities) and endorsement of devaluation and discrimination operated through self-esteem and self-mastery, to affect subjective quality of life. Rosenfield (1997) found that the more services one received, the greater one's self-esteem and self-mastery and the more positive one's appraisals of 
quality of life. In contrast, she found that greater endorsement of devaluation and discrimination led to lower self-esteem; self-esteem remained positively associated with subjective quality of life. Rosenfield (1997) also found that services received and devaluation and discrimination operated independently to affect subjective quality of life. Figure 2.1 provides a diagramed view of her findings.

Link and colleagues (1997) investigated the effects of devaluation and discrimination and type of treatment received on depressive symptoms in a sample of persons with both a psychiatric and alcohol or other drug diagnosis. Subjects received treatment from either a therapeutic community or a residential treatment program. As with Rosenfield's (1997) study, Link et al. (1997) found that both types of treatment received and endorsement of devaluation and discrimination independently affected depressive symptoms. The authors noted that receiving services from a therapeutic community was associated with lower levels of depression. In addition, greater endorsement of devaluation and discrimination was associated with greater levels of depression.

Summary of investigations of modified labeling theory of mental illness

The reviewed studies of modified labeling theory suggested that endorsement of devaluation and discrimination and self-stigma coping strategies have a negative impact on the social and psychological states of psychiatrically labeled individuals. Initial comparisons between patient and non-patient samples supported the contention that endorsement of devaluation and discrimination was associated with less economic achievement and a greater sense of demoralization among persons with a SMD who are 
in treatment (Link, 1987). Endorsement of devaluation and discrimination did not affect the lives of persons who were not receiving psychiatric treatment (Link, 1987). However, studies of devaluation and discrimination limited to only persons receiving treatment suggested that the effects of devaluation and discrimination go beyond economic achievement and feelings of demoralization, and include quality of life (Rosenfield, 1997) and symptom distress, to name a few.

Both Rosenfield's (1997) and Link and colleagues' (1997) work on the effects of treatment related variables and self-stigma related variables suggested that receiving psychiatric treatment offers both positive and negative effects on individuals engaged in treatment. Link and colleagues (1997) argued: “...that the effects of treatment and stigma coexist and yield a kind of 'package deal' of good and bad effects that result from official labeling” (p. 187). Rosenfield (1997) suggested that the labeling process, which she found had a negative effect on the quality of life of labeled individuals, and the treatment variables, which had a positive effect on the quality of life of labeled individuals, represent two separate yet related constructs. As she wrote, “...treatment stands as an oasis. Within this oasis everything is provided.... But an oasis implies that a larger, harsher environment surrounds it; and treatment programs exist within communities that for the most part are hostile to people with mental illness...." (p. 670).

\section{Assertive Community Treatment}

Evidence-based psychiatric treatment for persons with SMD represents one potential catalyst of mental health recovery. One of the earliest community-based psychiatric programs was Assertive Community Treatment (Deci, Santos, Hiott, 
Schoenwald, \& Dias, 1995). Assertive Community Treatment (ACT) is among the most researched forms of community care for persons with SMD (Stein \& Santos, 1998). ACT has shown consistent findings related to reductions in hospitalizations and time spent in hospital compared to other forms of treatment (Dixon, 2000). ACT is one of the most widely used models of community care for persons with a SMD, though not every program identifying with the ACT model necessarily comports to the ideal ACT model (Deci, et al. 1995).

Assertive Community Treatment (ACT) originated in Madison, Wisconsin in the late 1960s and early 1970s at Mendota Mental Health Institute (Marx et al., 1973; Stein \& Test, 1980). The innovators of the first ACT program, then known as Training in Community Living, recognized that the current forms of treatment for persons living with a SMD were inadequate as evidenced by high hospital recidivism rates (Stein \& Santos, 1998). The dominant form of treatment was short-term hospitalizations (which often included innovative forms of psychosocial treatments) with follow-up referrals to the local community mental health agency. Stein and Santos (1998) stated that the originators of ACT recognized that treatment provided in the hospital, which focused on helping persons with SMD to live successfully in the community, did not actually transfer to clients living successfully in the community. Clients were not connecting with aftercare opportunities available in the community once they left the hospital (Test, 1992). ACT was developed to deal with these problems and was designed using the best available research (Dixon, 2000). ACT is a multidisciplinary team approach to case management. The ACT team serves as a fixed point of responsibility, and provides and coordinates all of the service needs of consumers (Test, 1992). Members of the ACT include social workers, nurses, and psychiatrists, to name a few. The team assertively provides services to clients in the community: “... staff do not wait for 
patients to come to a central setting for services, but rather reach out and take both biological and psychosocial services to the patient” (Test, 1992, p. 156).

\section{Effectiveness of Assertive Community Treatment}

Original outcome studies of Assertive Community treatment indicated that ACT was better than treatment as usual in terms of positive quality of life, fewer days hospitalized, more days in the community, and shorter length of hospital stays (Stein et al., 1980; Test et al 1980, Weisbrod et al. 1980). Yet, over time, the effectiveness of ACT compared to other forms of treatment on many treatment related outcomes has waned. This trend holds true of most treatment related outcomes except for measurements associated with community tenure and hospitalization (Burns \& Santos, 1995; Olfson, 1990).

Quality of life: A recovery based measure of ACT treatment success.

In an era of recovery, mental health treatment needs to show effectiveness relative to outcomes that consumers consider important, such as quality of life. The assent of the concept of recovery has introduced a new emphasis on how community mental health interventions should be evaluated (Anthony et al., 2003). Past research focused on hospitalizations and symptoms as measures of consumer treatment success. These pathology based measures of consumer success are necessary, but inadequate, to understanding consumers' journeys towards recovery (Anthony et al., 2003; Solomon \& Stanhope, 2004). Proponents of the recovery perspective have highlighted the need to use treatment-based success measures that support consumer perspective on recovery 
(Anthony et al., 20003; Solomon \& Stanhope, 2004; Noordsy, et al., 2002). One recovery-oriented outcome is quality of life (Lieberman \& Kopelwoicz, 2004; Resnick et al., 2005).

Quality of life (QOL) has received increasing attention in the professional literature (Fakhoury \& Priebe, 2002; Holloway \& Carson, 2002). The increased attention on QOL among persons with a SMD is related to the desire among social scientists and mental health practitioners to "...apply a more holistic perspective to treatment, rehabilitation, and evaluation of treatment outcomes" (Eklund, Bäckströme and Hansson, 2003, p.134). This focus on a more holistic perspective can be traced back to an expanded view of health first offered in the medical health care literature, a view which sees health as not only encompassing reductions in negative outcomes such as symptom distress, but also increases in other positive outcomes, such as quality of life (Gladis, Gosh, Dishuk, \& Crits-Christopher, 1999). The increased attention to quality of life marked an attempt to include consumers' perspective in assessment of treatment effectiveness (Lehman, 1996).

\section{Definitional issues surrounding quality of life}

Before proceeding with a discussion of the effectiveness of assertive community treatment (ACT) at improving perceptions of quality of life of consumers, definitional issues surrounding quality of life (QOL) need to be illuminated. Quality of life is conceptually hard to define (Holloway \& Carson, 2002) because of a lack of consensus regarding different types of life domains (e.g. housing, employment, sexuality, family) included in different definitions of quality of life. Karr and Ford (2003) found 63 life 
domains covered in 14 instruments purporting to measure QOL, with no two QOL instruments measuring quality of life with the same bundle of life domains.

Another conceptual issue related to QOL is whether the instruments measure subjective indices of quality of life, objective indices of quality of life, or both (Gladis, et al., 1999). According to Gladis et al. (1999), there are two general models for assessing quality of life. The first model, the satisfaction model, assesses only subjective ratings of quality of life across a set of life domains. Opponents of the satisfaction model question its for measuring quality of life. The primary criticism of the use of the satisfaction model with persons with SMD is that satisfaction measures of QOL are confounded by psychopathology (Gladis et al., 1999; Korr \& Ford, 2003). However, using difference score reliability and factor analysis, Lehman (1983) showed that subjective appraisals of both global and domain specific quality of life are distinct concepts from measures of psychopathology. Lehman (1996) argued that subjective appraisals of quality of life are affected by the adaptation of persons with SMD to impoverished and adverse life conditions. Although measures of subjective quality of life are not confounded by psychiatric symptoms, QOL scores may reflect an individual's adaptation to impoverished life conditions.

The second model, the three components model, does not rely solely on subjective appraisals of quality of life. In addition to subjective appraisals, the three components model assesses at least one of two measures of objective quality of life: the measures of functioning (e.g. role performance) and measures of social-material conditions (e.g. employment, income, housing.). Gladis et al. (1999) stated that the three components model represented a better measure of quality of life for persons living with SMD 
because objective measures, which are less susceptible to the impact of impaired judgment, broaden the assessment of quality of life. Gladis and colleagues (1999) further argued that respondents' subjective appraisals, which can provide valuable information related to the respondents' perception of their life, are not discounted with the application of the three components model.

Although the three components model represents a more comprehensive model of quality of life than does the satisfaction model, the three components model is not without its critics. A primary criticism of the three components models argues that the model puts too much weight on the objective measures of quality of life. To those who support the subjective models of quality of life, appraisals of quality of life reflect individual value judgments about what is important (Frisch, Cornell, Villanueva, \& Retzelaff, 1992), whereas objective indices represent societal value judgments about what constitutes a good quality of life (Gladis et al., 1999). Therefore, subjective quality of life is how one reacts to one's own life conditions. For example, one objective indicator is income. Yet, such measures negate personal perceptions about what qualifies as a "good level of income." For a person with a mental illness who has never had much of an income, making $\$ 12,000$ may represent a good level of income, whereas for a person with or without a mental illness who has always held a job and earned $\$ 15,000$ or more, $\$ 12,000$ may represent a level of impoverishment. Opponents of the three components model see satisfaction models as negating the societal value judgments inherent in the objective components (Gladis et al, 1999).

The current study used a subjective model of quality of life for two reasons. First, subjective quality of life allows for an assessment of consumers' views of their life 
circumstances and reflects a recovery-oriented view of the individuality of the recovery process. The points made in support of subjective models of quality of life are congruent with definitions of the mental health recovery process. Definitions of mental health recovery have described the deeply personal aspects of the recovery process (Anthony, 1992). Recovery is different for different individuals. Some argue that subjective models of quality of life assess the connection or disconnection between what an individual has and what she or he would like to have relative to different life domains (Frisch et al., 1992). Subjective quality of life models, which allow for individual value judgments and definitions of recovery, and which consequently view recovery as an individual process, are congruent.

Second, subjective quality of life serves as a useful treatment-planning tool that provides information not available in deficit-based outcome indicators (Frisch et al., 1992). Lehman (1996) wrote of the utility of subjective indicators of quality of life for treatment planning:

Patients are unlikely to be motivated to change circumstances with which they are content even if the clinician feels otherwise. Conversely, failure to address an area of life with which the patient is dissatisfied, even though the clinician and family view the patient's circumstances as satisfactory, can adversely affect the treatment alliance with the patient. (p.89)

The quote by Lehman (1996) underscores the important clinical utility of subjective indicators of quality of life for the purposes of treatment planning. Further, the quote suggests that failure to take the information provided by such indicators into account can have an iatrogenic effect on consumers. 


\section{Assessing ACT effectiveness relative to Quality of life}

As already stated, time seems to have weakened the effectiveness of ACT relative to other forms of treatment on many treatment-based outcome variables (Burns \& Santos, 1995; Olfson, 1990). Does this trend hold true for those studies that have explored the effectiveness of ACT relative to subjective quality of life? Table 4.5 provides a review of ACT studies that have included subjective quality of life as an indicator of program effectiveness. The studies represented in table 4.5 include all studies of ACT since 1980 in North America that included a subjective measure of QOL as one dependent variable. The researcher organized table 4.5 so that studies with more than one comparison between two groups were listed multiple times.

Two interesting trends appear from this review of ACT and QOL. First, the effectiveness of ACT compared to other forms of psychiatric treatment in improving subjective QOL appears to have diminished over time. The first major study of ACT (Stein et al., 1980) found a significant difference in effect between ACT and treatment as usual on quality of life. ACT was associated with more positive appraisals of QOL than was treatment as usual. Most of the other ACT and QOL studies found no significant difference in effect between ACT and other forms of treatment on subjective quality of life (Bond et al., 1988, 1990, 1991, Chandler, 1996, Fekete, 1998, \& Stein et al, 1999).

While the trend of these ACT studies points to ACT not being significantly better that other forms of treatment at improving perceptions of QOL, some of the reviewed studies did find that ACT leads to significantly better QOL outcomes compared to other forms of treatment. Bond (1991) and colleagues found a favorable different in effect for ACT over treatment as usual on QOL, but did not find the same difference on QOL when 
ACT was compared with other forms of in-vivo, or assertive, treatment. Lehman (1997) and colleagues found a difference in effect for ACT over treatment as usual at a sixmonth measurement, with consumers of ACT reporting more positive appraisals of quality of life than with treatment as usual. However, in the same study, no differences in effect between ACT and treatment as usual on QOL appeared for the two- and 12month measures. These findings suggest that treatment as usual may have a lag effect on improving quality of life. Over time, ACT was no better than treatment as usual at improving perceptions of QOL. Finally, Drake (1998) and colleagues found favorable differences in effect for ACT compared to treatment as usual for overall quality of life and financial quality of life, but not for the living situation, daily activities, social contacts, and family contacts subscales of QOL.

Information from all of these studies of ACT and QOL suggest that ACT is, in fact, no better than other forms of community treatment at positively changing perceptions of quality of life. Two explanations account for this finding. First, subjective quality of life may be a stable construct. Individuals may assess their subjective quality of life in the same way over time. For example, Lehman (1988) found measures of QOL, taken a week apart, were relatively stable. Another possible explanation is that mental health technologies used in ACT have permeated the rest of the mental health system. The differences in effect between ACT and other community treatments are no longer true differences, but rather shared components (Burns \& Santos, 1995; Olfson, 1990). In fact, Bond and colleagues (1991) found that ACT was better than treatment as usual on QOL, but not better than other forms of assertive or in-vivo treatment, which hints at the diffusion of ACT-based technology. In vivo treatment is a 
hallmark of ACT service provision. For Bond and colleagues (1994), a possible explanation for the absence of differences in effect between ACT and the in-vivo form of treatment on subjective quality was the diffusion of the in-vivo treatment technology.

The second trend relates to the evolution of ACT. Since the 2000s, research on ACT has moved away from looking at differences between ACT and other forms of treatment and has moved toward an exploration of the critical component of ACT, which has lead to different treatment-based consumer outcomes. For example, Bond et al. (2001) explored how different types of vocational program affect clients' work life and quality of life, which included overall quality of life and satisfaction with finances and employment. The authors found that ACT teams that placed individuals into competitive employment resulted in consumers with significantly higher perceptions of employment quality of life than consumers had in community programs that did not offer this additional work intervention component. Thus, adding specific and targeted treatment components, such as employment programs, to the typical ACT model may have an impact on specific domains of quality of life associated with those add-on programs.

Mediating processes: understanding what works in ACT Burns and Santos (1995) and Olfson (1990) suggested that the diffusion of ACT treatment components, such as the in vivo approach, to other forms of community treatment represented a possible explanation for the similar effect of ACT compared to other forms of community treatment on non-hospital based outcomes. The diffusion of ACT treatment components has minimized the differences between ACT and other forms of treatment. Anthony (2003a) argued to advance understanding of how psychiatric 
treatment works to move individuals towards recovery, attention must be paid to shared treatment components and process that potentate recovery.

Rosenfield's (1997) research on amounts and types of treatment and self-stigma related variables highlights the importance of these process-related variables. In her study of the dual impact of self-stigma and treatment, she found that one of the strongest predictors of positive appraisals of quality of life was clients' perception that the treatment environment was an empowering environment. While she did not treat this concept as a mediating process between other forms of treatment and outcome, clients' perceptions that the treatment environment was empowering might be one therapeutic process through which the effects of psychiatric treatment work. Both Anthony (2003a) and Solomon and Stanhope (2004) argued that the working alliance between mental health workers and clients represented another potentially profitable therapeutic process worthy of further study. Calsyn (2002) and colleagues analyzed the working alliance as a treatment process. They found that the working alliance was positively related to satisfaction with treatment and that the working alliance mediated the effects of different types of treatment on treatment satisfaction.

The working alliance defined

The working alliance, which has been called the therapeutic alliance, therapeutic bond, and helping alliance, has been variously defined (Martin, Garske, and Davis, 2000). Rogers $(1957,1959)$ provided one of the first systematic attempts to articulate the curative factors of the therapeutic relationship. Rogers viewed the development of the therapeutic relationship as essential to client treatment progress. He argued that, for a 
therapeutic relationship to develop, the therapist must be congruent in the relationship, express and experience unconditional positive regard toward the client, and express and experience empathetic understanding of the client, including the client's perception of the client's own lived experiences. For Rogers, the therapist was primarily responsible for the development of a strong therapeutic relationship.

Strong (1968) provided another view of the therapeutic relationship, one based on interpersonal influence theory. Strong (1968) argued that the ideal therapeutic relationship consisted of the client viewing the therapist as an expert, as trustworthy, and as attractive. To the extent that the client viewed the therapist positively on these three dimensions, positive therapeutic outcomes would result.

Luborsky (1984) provided a psychodynamic view of the working alliance. Luborsky's definition focused on two components of the working alliance: a) the patient's view that the therapist is providing needed help, and b) the patient's view that the therapist is collaboratively working with the client. Unlike the previous two definitions, Loborsky's definition underscores the mutuality of the therapeutic process.

Bordin (1979) provided a pan-theoretical definition of the working alliance. He argued that his conception of the working alliance was not just applicable to therapy but to any change-oriented activity, like case management. Bordin (1979) conceptualized the working alliance as consisting of three components, a) the therapist's and client's agreement on the goals of therapy, b) the therapist's and client's agreement on the tasks of therapy, and c) the positive bond that exists between the therapist and the client. Goals of therapy are the expected end result of therapy and tasks are therapeutic activities used 
to meet these goals. Bordin's definition placed heavy emphasis on the mutuality of the therapeutic relationship.

Bordin (1979) viewed his definition of the working alliance as being applicable to any change oriented interaction. He argued that the working alliance was the vehicle through which different types of change oriented activities were, in part, successful. "A positive alliance provides the essential common context within which different therapeutic traditions build unique bridges to help clients negotiate the journey between emotional pain and mental health" (Horvath, 2001, p. 370). While multiple definitions of the working alliance exist, Bordin's (1979) pan-theoretical approach to the working alliance, as operationalized through the Working Alliance Inventory (WAI) (Horvath and Greenberg, 1989), has been the most widely used operational definition of the working alliance within case management studies (Howgego et al., 2003).

The working alliance and outcome in psychotherapy Psychotherapy theoreticians initially developed the concept of the working alliance for study in psychotherapy settings. In his most recent search of the literature, Horvath (2001) found that 89 studies of the working alliance that had a quantifiable measure of alliance and outcome, including at least five clients, used individual therapy, and were published or presented between 1977 and 2000. Their study built on the metaanalysis of Horvath and Symonds (1991) and Martin (2000) and colleagues. These metaanalyses of the working alliance research have shown the working alliance as a robust predictor of therapeutic success. Results from meta-analyses indicated that the average effect size between measures of the working alliance and therapeutic outcome was in the 
low- to mid-.20s. Horvath and Symonds (1991) found an average weighted effect size of .26 in meta-analysis of 24 studies of the working alliance published between 1977 and 1990. Martin and colleagues (2000) found an average weighted effect size of .22 among 79 studies, including studies used in Horvath and Symonds's (1991) meta-analysis. More recently, Horvath (2001) reported an average weighted effect size between working alliance and therapy outcome of .21 for studies including data from the previous two meta-analyses plus ten addition studies that were conducted between 1997 and 2000. The results from these meta-analyses indicated that working alliance was significantly related to therapy outcome, with stronger perceptions of the working alliance being associated with positive therapeutic outcomes.

An additional finding from these meta-analyses is relevant for the current study. This additional finding deals with the timing of the assessment of the working alliance. Horvath (2001) found an average effect size of .22 when measurement of the alliance was taken early in treatment, .19 when measurement of the alliance was taken at a middle point in treatment, and .25 when taken late in treatment. Horvath (2001) stated that methodological issues precluded the use of statistical tests of the difference between these measures. Horvath (2001) cautioned that the larger correlation between working alliance and outcome in later phases of treatment might actually reflect the benefits of therapy and not the working alliance relationship. He stated that measures of the working alliance taken early in treatment had the most accurate predictive potential. 
Relevance of the working alliance concept within ACT for persons with a SMD

Researchers have applied the working alliance concept to case management and ACT programs (Calsyn, et al., 2002; Chinman, et al., 2000; Klinkenberg, et al., 1998; Neale \& Rosenheck, 1995; Priebe \& Gruyters, 1993; Solomon, et al., 1995; Tyrell, et al., 1999). Mental health recovery scholars argue that the working alliance is one treatment related process that when present may help consumers move towards recovery (Anthony et al., 2003, Anthony 2003a, 2003b, Solomon, \& Stanhope, 2004). Hohmann (1999) argued that the error variance in mental health research studies might be explained by process-related variables such as the working alliance. Knowledge of these process related variables might provide information about how and why interventions are successful at helping move clients toward mental health recovery.

Consumers of mental health services have indicated that the working alliance with their mental health workers is an important and necessary recovery-based therapeutic process. Chinman and colleagues (1999) found consumers' development of a positive treatment relationship facilitated consumer trust of their treatment providers. Moreover, the trust engendered through the development of a strong treatment relationship helped consumers to be more willing to engage in treatment related activities suggested by their caseworkers.

On the other hand, failure to develop a working alliance between consumers and their community workers can have an iatrogenic effect, including a stigmatizing effect, on consumers (Angell et al., 2004). Degeen (1995), a consumer of mental health services, wrote of some consumer relationships with psychiatric professionals: “... many of us who have been psychiatrically labeled have received powerful messages from 
professionals who in effect tell us that by virtue of our diagnosis the question of our being has already been answered and our futures are already sealed" (p.92). Leete (1989), also a consumer of mental health services, wrote about consumer interactions with mental health professionals: "Unfortunately our progress continues to be measured by professionals with concepts like 'consent' and 'cooperate' and 'comply,' instead of 'choice' insinuating that we are incapable of taking an active role as partners in our own recovery” (p.200). Both quotes suggest that for a strong working alliance to develop, psychiatric professionals need to actively engage consumers in the treatment planning process, including encouraging consumers to articulate the goals and tasks of treatment. Mead and Copeland (2000) highlighted this point by arguing that consumers must play an active role in treatment planning, and that professionals must encourage consumers to take risks in meeting their life goals. The working alliance, as articulated by Bordin (1979), necessitates that consumers and clinicians work cooperatively to plan and work on treatment goals and treatment activities/tasks.

A potential barrier to the study of the working alliance within ACT programs must be noted. As originally conceived, ACT services were provided by a group of treatment professionals. The group was responsible for the treatment planning and treatment needs of consumers (Stein \& Test, 1978). Recent conceptualizations of ACT have moved towards structures in which one community worker is assigned to serve as the primary link between the ACT team and the consumer (Stein \& Santos, 1998; Test, 1992). While the team remains responsible for providing community-based treatment to consumers, the consumers' primary worker coordinates services and represents the primary connection between the treatment team and consumers. The use of a primary 
clinician makes possible the assessment of the working alliance between ACT case managers and their consumers.

The effects of working alliance on outcomes within case management and ACT programs.

A number of case management studies have explored the effect of the working alliance on treatment outcomes. Table 2.6 provides a summery of research conducted on the working alliance within case management studies. Strong working alliances were associated with fewer hospitalizations and days hospitalized (Prievie \& Gruters, 1993), and less symptom distress (Neile \& Rosenheck, 1995) and depression (Tyrell et al., 1999). Strong working alliances were associated with positive global functioning (Neile \& Rosenheck, 1995; Tyrrell et al., 1999), greater number of community living skills (Neile \& Rosenheck, 1995), positive attitude toward medication adherence (Solomon et al., 1995), and fewer days homeless (Chinman et al., 2000).

Studies of the working alliance within case management programs found that strong working alliances were associated with positive perceptions of quality of life. Solomon et al. (1995) found that consumer ratings of the working alliance were positively associated with an overall measure of the working alliance, and stronger working alliances were associated with positive appraisals of quality of life. Likewise, Chinman et al. (2000) found that a three-month measure of working alliance was associated with positive appraisals of general life satisfaction. Tyrrell et al. (1999) noted that strong working alliances were associated with positive appraisals of general life satisfaction, family, and social relations satisfaction. 
These studies of working alliance in case management raised three important methodological issues. Timing of measurement of the working alliance variable is one issue. As stressed by the psychotherapy literature on the working alliance (Horvath, 2001), the issue of timing of measurement has also been raised within studies of the working alliance in case management and ACT (Chinman et al., 2000). Klinkenberg and colleagues (1998) found that the working alliance measured early in treatment, at month two, was related to more positive treatment related outcomes than a measure of the working alliance taken at month 14 . Solomon and colleagues (1995) found a measure of the working alliance at two years to be associated with a number of subjectively based treatment outcomes. And Chinman and colleagues (2000) found later measurement of the working alliance to be associated with the same variables as at three and twelve months. For one of the variables, days homeless, a stark difference between high and low alliance scores did not materialize until the 12 month measurement. Horvath (2001) has warned that the association of the working alliance and outcome later in treatment may be confounded by treatment improvement. However, individuals in ACT often need ongoing assistance to maintain the gains they make in treatment (Stein \& Test, 1980). So, the working alliance within ACT may take time to develop (Chinman et al, 2000), more than the two or three sessions suggested in psychotherapy literature (Horvath, 2001).

Another important methodological issue within studies of the working alliance in case management is who provides the measure of the working alliance -- client versus therapist/case manager. Neile and Rosneheck (1995) found that case manager ratings of the working alliance were associated with higher measure of treatment outcomes than were client ratings. Solomon and colleagues (1995) found that client ratings of the 
working alliance were related to more treatment outcomes than were case manager ratings. Consumer ratings were associated with two outcomes and case manager ratings of the working alliance, alone, were not related to any outcome. Solomon and colleagues (1995) found client ratings were associated only with dependent variables that assessed the clients' subjective perceptions of outcome. Findings that consumer-rated alliance is significantly associated with consumer-rated outcome may be subject to potential method bias. For example, consumers who are happy with the working alliance might rate outcomes more positively than consumers who are not happy with the alliance. Although meta-analyses from the psychotherapy literature do not support this potential bias (Horvath, 2001; Horvath \& Symonds, 1991), findings from case management/ACT studies have not assessed the source of measurement as a potential source of measurement bias.

Without exception, these studies of working alliance suffer from one major methodological flaw. None of the studies accounted for case manager effects on therapeutic outcomes. Failure to account for case manager effects represents an ecological fallacy by statistically assuming that variances in consumer outcomes not dependent on the grouping variable, case manager (Luke, 2004). Ryan, Sherman, and Judd (1994) argued that failure to account for case manager effects is a problem that plagues most case management studies. Indeed, all of the case management studies reviewed here failed to account for case manager effects. Yet Ryan (1994) and colleagues found that case managers play an important role in determining consumer therapeutic outcomes. The authors explained that different case mangers make, "a difference to the extent that providers are nonequivalent in their implementation of each service, or they 
differentially influence the outcomes of their clients in ways that are not tied to the particular type of service under study" (p. 965). Although Neile and Rosneheck (1995) and Solomon (1995) and colleagues accounted for case manager views of the working alliance, they did not account for other potential effects of the case managers. It seems plausible that case managers develop different working alliances with clients and have other unmeasured characteristics or aptitudes that affect consumer outcomes. Future studies of working alliance need to account for the potential effects of case managers on client outcome.

\section{Conclusion}

This review showed both self-stigma related variables and working alliance contribute to chances for mental health recovery for persons with SMD. Self-stigma related variables reduced consumers' chances for recovery. Conversely, the working alliance increased consumers' chances for recovery. This review showed that ACT, one of the most widely adapted models of community care for persons with SMD, has not been found to differ from other types of treatment at positively affecting perceptions of quality of life. In addition, this review argued that the working alliance represented one treatment related process within ACT that may account for changes in recovery-oriented outcomes such as quality of life. None of the reviewed studies explored the effects of both the working alliance and self-stigma related variables on recovery-based outcomes. Thus, the purpose of the present study has been to explore the relationship between the working alliance and self-stigma related variables as they affect perceptions of quality of life among persons with a SMD 
Tables and Figures

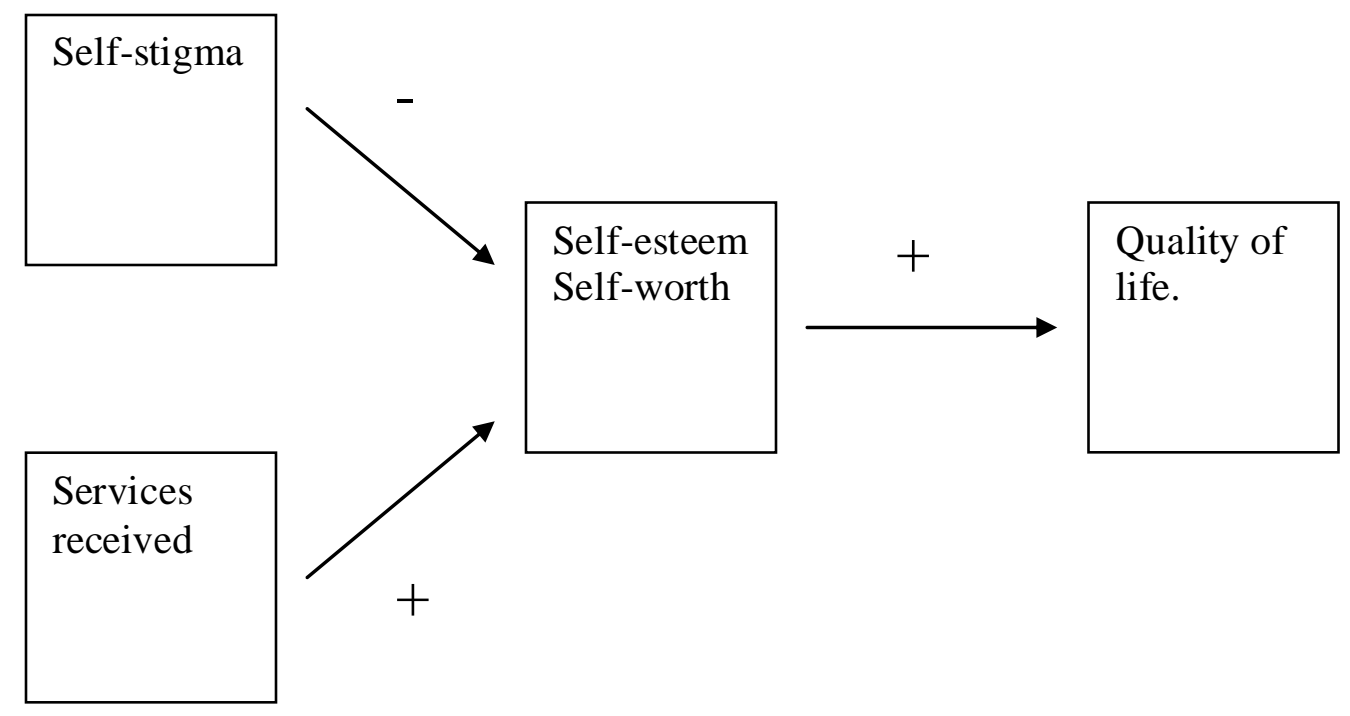

Figure 2.1. Graphical depiction of Rosenfield's finding 


\begin{tabular}{|c|c|c|c|}
\hline Author & Outcome Measures & Group & Findings \\
\hline \multirow[t]{4}{*}{ Link (1987) } & $\begin{array}{l}\text { Income, } \\
\text { Work participation, } \\
\text { Demoralization }\end{array}$ & $\begin{array}{l}\text { Unlabeled }(\mathrm{n}=171) \\
\text { and untreated SMD }(\mathrm{n}= \\
142)\end{array}$ & $\begin{array}{l}\text { No relationship between } \\
\text { devaluation and } \\
\text { discrimination and work } \\
\text { or income }\end{array}$ \\
\hline & & $\begin{array}{l}\text { Labeled less then a year } \\
(n=67)\end{array}$ & $\begin{array}{l}\text { Devaluation and } \\
\text { discrimination positively } \\
\text { associated with } \\
\text { demoralization. } \\
\text { No effects on income or } \\
\text { work participation }\end{array}$ \\
\hline & & $\begin{array}{l}\text { Labeled longer then a } \\
\text { year }(n=117)\end{array}$ & $\begin{array}{l}\text { Devaluation and } \\
\text { discrimination was } \\
\text { positively associated } \\
\text { with demoralization and } \\
\text { negatively associated } \\
\text { with work participation } \\
\text { and income }\end{array}$ \\
\hline & & $\begin{array}{l}\text { Previously receiving } \\
\text { treatment }(\mathrm{n}=96)\end{array}$ & $\begin{array}{l}\text { Devaluation and } \\
\text { discrimination not } \\
\text { associated with income } \\
\text { work participation or } \\
\text { demoralization }\end{array}$ \\
\hline
\end{tabular}

Table2.1. Effects of devaluation and discrimination in Links community and treatment samples 
Type of support

\begin{tabular}{lll}
\multicolumn{1}{c}{ Relationship } & \multicolumn{1}{c}{ Instrumental } & \multicolumn{1}{c}{ Extensiveness } \\
\hline Family, non-household & $\begin{array}{l}\text { Significant finding: } \\
\text { Higher perceptions of devaluation } \\
\text { and discrimination wer } \\
\text { associated with fewer } \\
\text { instrumental supports. }\end{array}$ & $\begin{array}{l}\text { Significant finding: } \\
\text { Higher perceptions of devaluation } \\
\text { and discrimination were } \\
\text { associated with less extensive } \\
\text { coverage }\end{array}$ \\
Family, household & No significant findings & $\begin{array}{l}\text { Significant finding: } \\
\text { Higher perceptions of devaluation } \\
\text { and discrimination lead to greater } \\
\text { coverage of tasks by family } \\
\text { members }\end{array}$ \\
Non-relatives & No significant findings & No significant findings \\
\hline
\end{tabular}

Table2.2. Social network and devaluation and discrimination findings from Link et. al. (1989) 


\begin{tabular}{|c|c|c|c|}
\hline Author & $\begin{array}{l}\text { Coping } \\
\text { mechanisms } \\
\text { studied }\end{array}$ & Outcomes measured & Result \\
\hline \multirow{7}{*}{$\begin{array}{l}\text { Link et al. } \\
1989\end{array}$} & Withdrawal & Instrumental household family & No significant relationship \\
\hline & & Instrumental non-household family & No significant relationship \\
\hline & & Instrumental non-relatives & Significant relationship: \\
\hline & & & $\begin{array}{l}\text { Greater endorsement of withdrawal } \\
\text { is associated with fewer } \\
\text { instrumental support from non- } \\
\text { relatives }\end{array}$ \\
\hline & & Extensiveness household family & No significant relationship \\
\hline & & $\begin{array}{l}\text { Extensiveness non-household } \\
\text { family }\end{array}$ & No-significant relationship \\
\hline & & Extensiveness non-relatives & $\begin{array}{l}\text { Significant relationship: } \\
\text { Greater endorsement of withdrawal } \\
\text { is associated with less extensiveness } \\
\text { of task coverage support from non- } \\
\text { relatives }\end{array}$ \\
\hline \multirow[t]{2}{*}{$\begin{array}{l}\text { Link et al. } \\
1991\end{array}$} & $\begin{array}{l}\text { Withdrawal } \\
\text { Secrecy } \\
\text { Education }\end{array}$ & $\begin{array}{l}\text { Employment } \\
\text { Demoralization }\end{array}$ & $\begin{array}{l}\text { No significant relationships between } \\
\text { secrecy and education and either } \\
\text { outcome variables }\end{array}$ \\
\hline & & & $\begin{array}{l}\text { Significant relationship between } \\
\text { withdrawal and both feelings of } \\
\text { demoralization and lower } \\
\text { employment }\end{array}$ \\
\hline
\end{tabular}

Table 2.3. The effects of stigma coping mechanisms among individuals officially labeled 


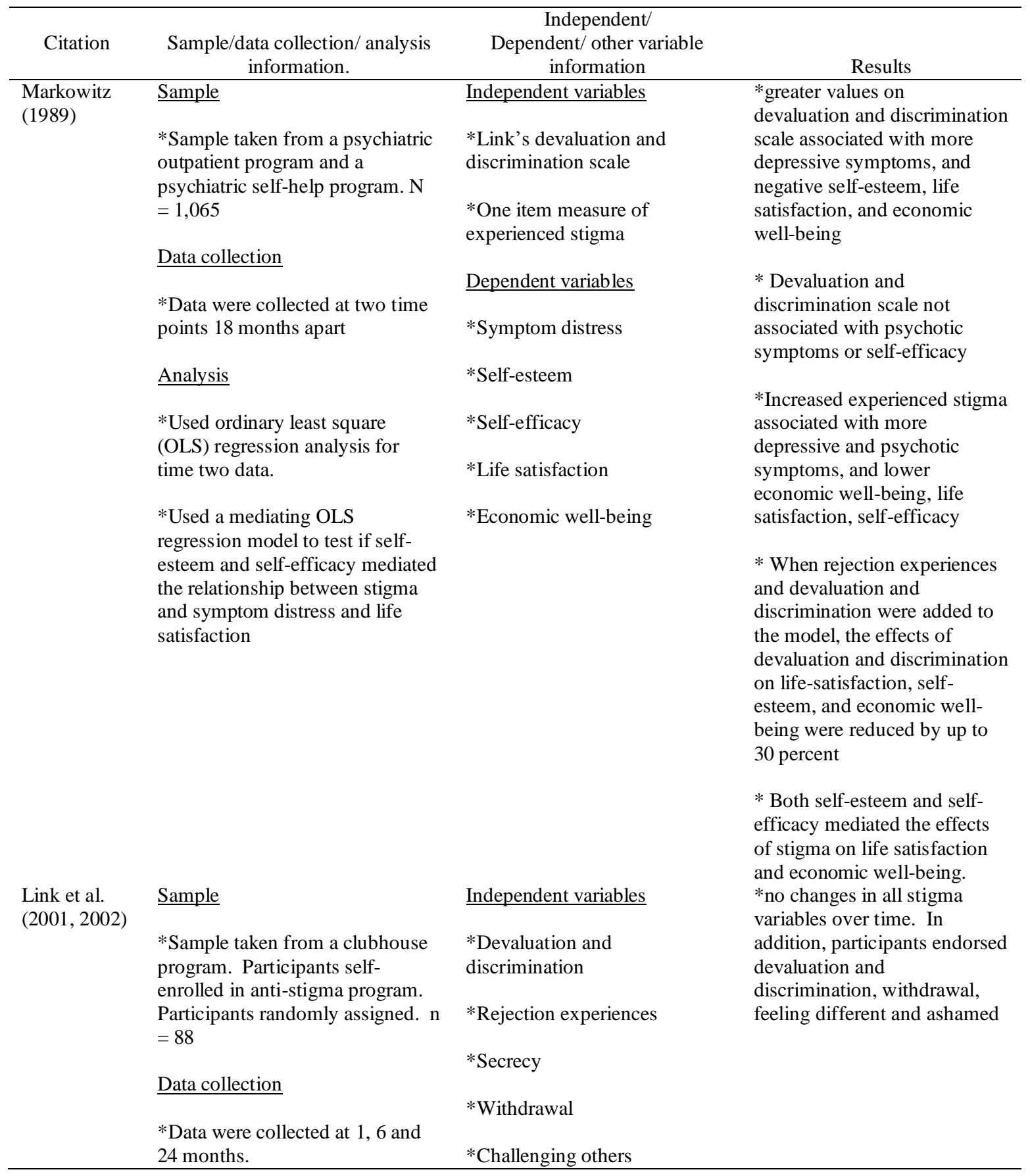

Table 2.4. Within treatment group studies of stigma

Continued 
Table 2.4 Continued

\begin{tabular}{|c|c|c|c|}
\hline Citation & $\begin{array}{l}\text { Sample/data collection/ } \\
\text { analysis information. }\end{array}$ & $\begin{array}{c}\text { Independent/ } \\
\text { Dependent/ other variable } \\
\text { information }\end{array}$ & Results \\
\hline \multirow{8}{*}{$\begin{array}{l}\text { Link et al, } \\
(2001, \\
\text { 2002) } \\
\text { continued }\end{array}$} & Analysis & Independent variables & *Self-esteem was \\
\hline & \multirow{7}{*}{$\begin{array}{l}\text { *Used bi-variate and ordinary } \\
\text { least square (OLS) regression } \\
\text { analysis to test relationships } \\
\text { between independent and } \\
\text { dependent variables }\end{array}$} & *Feeling misunderstood & $\begin{array}{l}\text { negatively correlated with } \\
\text { devaluation and }\end{array}$ \\
\hline & & $\begin{array}{l}\text { *Feeling different and } \\
\text { ashamed }\end{array}$ & $\begin{array}{l}\text { discrimination, secrecy, } \\
\text { withdrawal, feeling } \\
\text { different and ashamed }\end{array}$ \\
\hline & & $\begin{array}{l}\text { *Anti-stigma program or no } \\
\text { program }\end{array}$ & $\begin{array}{l}\text { * There were no } \\
\text { differences on devaluation } \\
\text { and discrimination, }\end{array}$ \\
\hline & & Dependent variables & $\begin{array}{l}\text { secrecy, withdrawal, } \\
\text { challenging others, feeling }\end{array}$ \\
\hline & & *Self-esteem & \\
\hline & & *Depressive symptoms & $\begin{array}{l}\text { depressive symptoms and } \\
\text { self-esteem between } \\
\text { persons who participated in } \\
\text { the anti- stigma program } \\
\text { compared to control group }\end{array}$ \\
\hline & & & $\begin{array}{l}\text { *Devaluation and } \\
\text { discrimination, rejection } \\
\text { experiences, withdrawal, } \\
\text { and feeling different and } \\
\text { ashamed accounted for } \\
26 \% \text { of variance in self- } \\
\text { esteem and } 41 \% \text { in } \\
\text { depressive symptoms }\end{array}$ \\
\hline \multirow{6}{*}{$\begin{array}{l}\text { Perlik et al. } \\
\text { (2001) }\end{array}$} & $\underline{\text { Sample }}$ & Independent variables & \\
\hline & \multirow{2}{*}{$\begin{array}{l}* \text { Sample of persons with bi- } \\
\text { polar disorder or } \\
\text { schizoaffective disorder who } \\
\text { were admitted to a hospital or } \\
\text { outpatient program } n=254\end{array}$} & $\begin{array}{l}\text { *Combined devaluation and } \\
\text { discrimination and working } \\
\text { alliance scale }\end{array}$ & $\begin{array}{l}\text { *The baseline combined } \\
\text { stigma scale was associated } \\
\text { with less in participation in } \\
\text { social leisure activities, and } \\
\text { more psychological }\end{array}$ \\
\hline & & Dependent variables & $\begin{array}{l}\text { isolation and behavioral } \\
\text { avoidance. }\end{array}$ \\
\hline & Data collection & *Overall social adjustment & \\
\hline & \multirow{2}{*}{$\begin{array}{l}\text { * Measurements taken at } \\
\text { baseline and seven months }\end{array}$} & *Extended family relations & \\
\hline & & * Social leisure activities & \\
\hline
\end{tabular}

Table 2.4 Continued 
Table 2.4 Continued

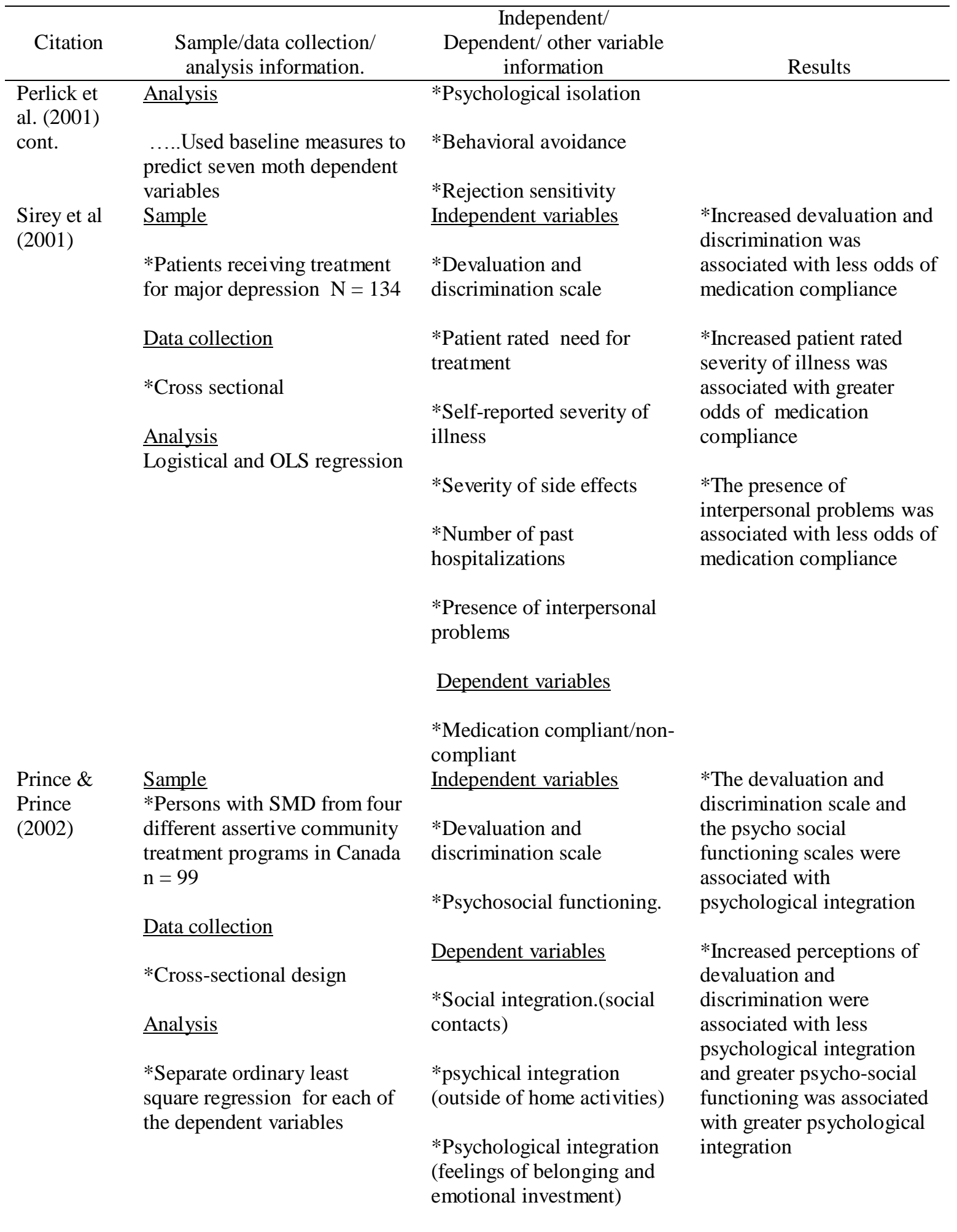

Table 2.4 Continued 
Table 2.4 Continued

\begin{tabular}{|c|c|c|c|}
\hline Citation & $\begin{array}{l}\text { Sample/data collection/ } \\
\text { analysis information. }\end{array}$ & $\begin{array}{l}\text { Independent/ } \\
\text { Dependent/ other variable } \\
\text { information }\end{array}$ & Results \\
\hline \multirow{14}{*}{$\begin{array}{l}\text { Kahng \& } \\
\text { Mowbray } \\
\text { (2005a, } \\
2005 b)\end{array}$} & Sample & Independent variables & *Self-esteem was \\
\hline & $\begin{array}{l}\text { *The sample is from a larger } \\
\text { NIMH study. Sample } \\
\text { consisted of consumers with }\end{array}$ & $\begin{array}{l}\text { *devaluation and } \\
\text { discrimination scale }\end{array}$ & $\begin{array}{l}\text { positively related to service } \\
\text { satisfaction and important } \\
\text { social roles }\end{array}$ \\
\hline & SMD from 47 different & *depressive symptoms & *Self-esteem was \\
\hline & psycnosocial renabilitation, & *.psychiatric symptoms & devaluation and \\
\hline & programs $n-=461$ & $\begin{array}{l}\text { *perceived important social } \\
\text { roles }\end{array}$ & $\begin{array}{l}\text { symptoms, psychiatric } \\
\text { symptoms, and }\end{array}$ \\
\hline & Data collection & & supernatural causal \\
\hline & & *.service satisfaction & attribution \\
\hline & ${ }^{*}$ Cross-sectional design & & \\
\hline & Analysis & $\begin{array}{l}\text { *causal attribution: stressful } \\
\text { life and supernatural. }\end{array}$ & $\begin{array}{l}\text { * Devaluation and } \\
\text { discrimination and positive } \\
\text { and negative affect were }\end{array}$ \\
\hline & $\begin{array}{l}\text { *Ordinary least square } \\
\text { regression to determine what }\end{array}$ & *Positive affect & $\begin{array}{l}\text { related to withdrawal and } \\
\text { secrecy as coping }\end{array}$ \\
\hline & affected self-esteem & *negative affect & $\begin{array}{l}\text { mechanisms. Devaluation } \\
\text { and discrimination and }\end{array}$ \\
\hline & $\begin{array}{l}\text { *Structural equation modeling } \\
\text { used to determine what }\end{array}$ & *self-deprecation & $\begin{array}{l}\text { positive and negative affect } \\
\text { on withdrawal and secrecy }\end{array}$ \\
\hline & $\begin{array}{l}\text { affected withdrawal and } \\
\text { secrecy }\end{array}$ & Dependent Variables & $\begin{array}{l}\text { were mediated by self- } \\
\text { esteem and self- }\end{array}$ \\
\hline & & Self-esteem & deprecation \\
\hline \multirow[t]{10}{*}{$\begin{array}{l}\text { Lysaker et } \\
\text { al. (2007) }\end{array}$} & Sample & Independent variables & $\begin{array}{l}\text { *Baseline internalized } \\
\text { stigma was related to }\end{array}$ \\
\hline & *part of a Veterans & *Positive symptoms & baseline positive symptoms \\
\hline & $\begin{array}{l}\text { Administration study. Study } \\
\text { participants were persons with } \\
\text { schizophrenia or }\end{array}$ & *Negative symptoms & \multirow{8}{*}{$\begin{array}{l}\text { *Internalized stigma at six } \\
\text { months was positively } \\
\text { related to baseline } \\
\text { internalized stigma scores } \\
\text { and to emotional } \\
\text { discomfort. Internalized } \\
\text { stigma at six months was } \\
\text { negatively related to } \\
\text { interpersonal relationships }\end{array}$} \\
\hline & $\begin{array}{l}\text { schizoaffective disorder. } \mathrm{N}= \\
36 .\end{array}$ & *Emotional discomfort & \\
\hline & & *Intrapersonal relationships & \\
\hline & Data collection & *Intrapsychic foundations & \\
\hline & $\begin{array}{l}\text { *measurements taken at } \\
\text { baseline and six months. }\end{array}$ & $\begin{array}{l}\text { *Baseline measure of } \\
\text { stigma used to predict six }\end{array}$ & \\
\hline & Analysis & month measure of stigma. & \\
\hline & $\begin{array}{l}\text {..... Ordinary east square } \\
\text { regression used for data at }\end{array}$ & Dependent variable & \\
\hline & each time point & $\begin{array}{l}\text { *Internalized stigma of } \\
\text { mental illness scale. }\end{array}$ & \\
\hline
\end{tabular}




\begin{tabular}{|c|c|c|c|c|c|}
\hline Citation & $\begin{array}{c}\text { Experimental (E) } \\
\text { vs. Quasi- } \\
\text { experimental (Q) }\end{array}$ & $\begin{array}{l}\text { Comparison } \\
\text { group }\end{array}$ & $\begin{array}{l}\text { Sample } \\
\text { size }\end{array}$ & $\begin{array}{c}\text { Measure of } \\
\text { subjective QOL }\end{array}$ & Outcomes \\
\hline $\begin{array}{l}\text { Stein et al. } \\
(1980)\end{array}$ & $\mathrm{E}$ & $\begin{array}{l}\text { Treatment as } \\
\text { usual }\end{array}$ & $\begin{array}{l}\mathrm{E}=65 \\
\mathrm{C}=65\end{array}$ & $\begin{array}{l}\text { General } \\
\text { satisfaction } \\
\text { with life. From } \\
\text { community } \\
\text { adjustment } \\
\text { scale. }\end{array}$ & $\begin{array}{l}\text { Positive differences } \\
\text { between groups; ACT } \\
\text { consumers report } \\
\text { greater satisfaction }\end{array}$ \\
\hline $\begin{array}{l}\text { Bond et al. } \\
\text { (1988) }\end{array}$ & $\mathrm{E}$ & $\begin{array}{l}\text { Treatment as } \\
\text { usual } 1\end{array}$ & $\begin{array}{l}\mathrm{E}=29 \\
\mathrm{C}=32\end{array}$ & $\begin{array}{l}\text { Life- } \\
\text { satisfaction } \\
\text { checklist }\end{array}$ & $\begin{array}{l}\text { No between group } \\
\text { differences found }\end{array}$ \\
\hline $\begin{array}{l}\text { Bond et al. } \\
\text { (1988) }\end{array}$ & $\mathrm{E}$ & $\begin{array}{l}\text { Treatment as } \\
\text { usual } 2\end{array}$ & $\begin{array}{l}\mathrm{E}=34 \\
\mathrm{C}=30\end{array}$ & $\begin{array}{l}\text { Life- } \\
\text { satisfaction } \\
\text { checklist }\end{array}$ & $\begin{array}{l}\text { No between group } \\
\text { differences found }\end{array}$ \\
\hline $\begin{array}{l}\text { Bond et al. } \\
\text { (1988) }\end{array}$ & E & $\begin{array}{l}\text { Treatment as } \\
\text { usual } 3\end{array}$ & $\begin{array}{l}E=21 \\
C=21\end{array}$ & $\begin{array}{l}\text { Life- } \\
\text { satisfaction } \\
\text { checklist }\end{array}$ & $\begin{array}{l}\text { No between group } \\
\text { differences found }\end{array}$ \\
\hline $\begin{array}{l}\text { Bond et al. } \\
\text { (1990) }\end{array}$ & $\mathrm{Q}$ & Drop-in center & $\begin{array}{l}E=14 \\
C=14\end{array}$ & $\begin{array}{l}\text { Life } \\
\text { satisfaction } \\
\text { checklist }\end{array}$ & $\begin{array}{l}\text { No between group } \\
\text { differences found. } \\
\text { Though authors report } \\
\text { that differences } \\
\text { approach significant }\end{array}$ \\
\hline $\begin{array}{l}\text { Bond et al. } \\
\text { (1991) }\end{array}$ & $\mathrm{Q}$ & $\begin{array}{l}\text { Group } \\
\text { treatment with } \\
\text { in vivo } \\
\text { supports }\end{array}$ & $\begin{array}{l}E=31 \\
C=23\end{array}$ & $\begin{array}{l}\text { Life- } \\
\text { satisfaction } \\
\text { checklist }\end{array}$ & $\begin{array}{l}\text { No between group } \\
\text { differences found }\end{array}$ \\
\hline $\begin{array}{l}\text { Bond et al. } \\
\text { (1991) }\end{array}$ & $\mathrm{Q}$ & $\begin{array}{l}\text { Treatment as } \\
\text { usual }\end{array}$ & $\begin{array}{l}E=31 \\
C=43\end{array}$ & $\begin{array}{l}\text { Life- } \\
\text { satisfaction } \\
\text { checklist }\end{array}$ & $\begin{array}{l}\text { Positive finding for } \\
\text { ACT. Treatment as } \\
\text { usual reported lower } \\
\text { life satisfaction }\end{array}$ \\
\hline $\begin{array}{l}\text { Chandler } \\
\text { et al. } \\
\text { (1996) }\end{array}$ & $\mathrm{E}$ & $\begin{array}{l}\text { Treatment as } \\
\text { usual }\end{array}$ & $\begin{array}{l}E=30 \\
C=29\end{array}$ & $\begin{array}{l}\text { Lehman's } \\
\text { Quality of life } \\
\text { interview }\end{array}$ & $\begin{array}{l}\text { No difference between } \\
\text { groups found }\end{array}$ \\
\hline $\begin{array}{l}\text { Lafave et } \\
\text { al. }\end{array}$ & E & $\begin{array}{l}\text { Hospital based } \\
\text { community } \\
\text { care }\end{array}$ & $\begin{array}{l}E=33 \\
C=32\end{array}$ & $\begin{array}{l}\text { Lehman's } \\
\text { Quality of life } \\
\text { interview }\end{array}$ & $\begin{array}{l}\text { Positive difference for } \\
\text { ACT on living } \\
\text { situation. No other } \\
\text { domains showed a } \\
\text { difference }\end{array}$ \\
\hline
\end{tabular}

Table 2.5. ACT studies that have explored client-rated Subjective Quality of life

Continued 
Table 2.5 Continued

\begin{tabular}{|c|c|c|c|c|c|}
\hline Citation & $\begin{array}{l}\text { Experimental (E) } \\
\text { vs. Quasi- } \\
\text { experimental (Q) }\end{array}$ & $\begin{array}{l}\text { Comparison } \\
\text { group }\end{array}$ & $\begin{array}{l}\text { Sample } \\
\text { size }\end{array}$ & $\begin{array}{l}\text { Measure of } \\
\text { subjective } \\
\text { QOL }\end{array}$ & Outcomes \\
\hline $\begin{array}{l}\text { Lehman et } \\
\text { al. (1997) }\end{array}$ & $\mathrm{E}$ & $\begin{array}{l}\text { Treatment as } \\
\text { usual }\end{array}$ & $\begin{array}{l}E=77 \\
C=75\end{array}$ & $\begin{array}{l}\text { Lehman's } \\
\text { Quality of life } \\
\text { interview }\end{array}$ & $\begin{array}{l}\text { No between group } \\
\text { differences at } 2 \text { or } 12 \\
\text { months; ACT had } \\
\text { significantly greater } \\
\text { reports of life } \\
\text { satisfaction at } 6 \text { months }\end{array}$ \\
\hline $\begin{array}{l}\text { Drake et al } \\
(1998)\end{array}$ & $\mathrm{E}$ & $\begin{array}{l}\text { Treatment as } \\
\text { usual }\end{array}$ & $\begin{array}{l}E=105 \\
C=98\end{array}$ & $\begin{array}{l}\text { Lehman's } \\
\text { Quality of life } \\
\text { interview }\end{array}$ & $\begin{array}{l}\text { Significant between } \\
\text { group differences for } \\
\text { overall and financial } \\
\text { quality of life in favor } \\
\text { of ACT; no differences } \\
\text { for living situation, } \\
\text { daily activities, social } \\
\text { contacts and family } \\
\text { contacts. }\end{array}$ \\
\hline $\begin{array}{l}\text { Fekete } \\
(1998)\end{array}$ & $\mathrm{E}$ & $\begin{array}{l}\text { Treatment as } \\
\text { usual }\end{array}$ & $\begin{array}{l}E=80 \\
C=80\end{array}$ & $\begin{array}{l}\text { Life- } \\
\text { satisfaction } \\
\text { checklist }\end{array}$ & $\begin{array}{l}\text { No between group } \\
\text { differences found }\end{array}$ \\
\hline $\begin{array}{l}\text { Stein et al. } \\
\text { (1999) }\end{array}$ & Q & $\begin{array}{l}\text { Club-house } \\
\text { model }\end{array}$ & $\begin{array}{l}\mathrm{E}=21 \\
\mathrm{C}=38\end{array}$ & $\begin{array}{l}\text { Wisconsin } \\
\text { Quality of life } \\
\text { measure (social } \\
\text { and vocational } \\
\text { measures) }\end{array}$ & $\begin{array}{l}\text { No between group } \\
\text { differences found }\end{array}$ \\
\hline
\end{tabular}




\begin{tabular}{|c|c|c|c|}
\hline Citation & $\begin{array}{l}\text { Sample/data collection/ } \\
\text { analysis information. }\end{array}$ & $\begin{array}{c}\text { Independent/ } \\
\text { Dependent/ other variable } \\
\text { information }\end{array}$ & Results \\
\hline \multirow[t]{2}{*}{$\begin{array}{l}\text { Prievie \& } \\
\text { Gruyters } \\
\text { (1993) }\end{array}$} & $\begin{array}{l}\text { Sample } \\
\text { *Persons receiving mental } \\
\text { health case management in } \\
\text { Germany } \mathrm{n}=73\end{array}$ & $\begin{array}{l}\text { Independent variables } \\
\text { *Author developed five- } \\
\text { item measure of the working } \\
\text { alliance }\end{array}$ & $\begin{array}{l}\text { * working alliance score } \\
\text { not associated with changes } \\
\text { in living situation }\end{array}$ \\
\hline & $\begin{array}{l}\text { Data collection } \\
\text { *Working alliance measure } \\
\text { taken at baseline. Measures of } \\
\text { the dependent variables taken } \\
\text { at } 20 \text { months } \\
\underline{\text { Analysis }} \\
\text { *Bi-variate analysis }\end{array}$ & $\begin{array}{l}\text { Dependent variables } \\
\text { *number of hospitalizations } \\
\text { and partial hospitalizations } \\
\text { over twenty month period } \\
\text { *Changes in living situation } \\
\text { over twenty-month period } \\
\text { *Changes in work situation } \\
\text { over twenty-month period }\end{array}$ & $\begin{array}{l}* \text { Strong working alliance } \\
\text { score associated with } \\
\text { reductions in } \\
\text { hospitalization over twenty } \\
\text { month period and } \\
\text { associated with movement } \\
\text { towards full-time work }\end{array}$ \\
\hline $\begin{array}{l}\text { Neile \& } \\
\text { Rosenheck } \\
\text { (1995) }\end{array}$ & $\begin{array}{l}\text { * Cross-sectional design. } \\
\text { Measurements of independent } \\
\text { and dependent variables taken } \\
\text { after participants had been in } \\
\text { the program two years } \\
\text { Analysis } \\
\text { * Ordinary least square } \\
\text { regression }\end{array}$ & $\begin{array}{l}\text { *Case manager and } \\
\text { consumer composite } \\
\text { measure of perceived } \\
\text { improvements, benefits and } \\
\text { satisfaction related to } \\
\text { treatment } \\
\text { *Consumer rated } \\
\text { community living skills } \\
\text { *Staff rated symptom } \\
\text { severity } \\
\text { *Global assessment of } \\
\text { functioning (GAF) } \\
\text { *Number of inpatient days } \\
\text { over past two years. }\end{array}$ & $\begin{array}{l}\text { * Case manager rated WAI } \\
\text { associated with positive } \\
\text { increases in case manager } \\
\text { rated composite measure of } \\
\text { improvements, benefits and } \\
\text { satisfaction, negatively } \\
\text { associated with symptoms, } \\
\text { and positively associated } \\
\text { with GAF. Case manager } \\
\text { rated WAI associated with } \\
\text { positive client ratings of } \\
\text { community living skills } \\
\text { * Consumer rated WAI } \\
\text { positively associated with } \\
\text { consumer rated composite } \\
\text { measure } \\
\text { * When considered } \\
\text { together, both consumer } \\
\text { and case manager WAI } \\
\text { were associated with fewer } \\
\text { hospitalizations }\end{array}$ \\
\hline
\end{tabular}

Table 2.6: Studies of the working alliance within case management

Continued 
Table 2.6 Continued

\begin{tabular}{|c|c|c|c|}
\hline Citation & $\begin{array}{l}\text { Sample/data collection/ analysis } \\
\text { information. }\end{array}$ & $\begin{array}{c}\text { Independent/ } \\
\text { Dependent/ other variable } \\
\text { information }\end{array}$ & Results \\
\hline $\begin{array}{l}\text { Solomon et } \\
\text { al. (1995) }\end{array}$ & $\begin{array}{l}\frac{\text { Sample }}{* \text { Consumers of ACT program } n=} \\
90 \\
\frac{\text { Data collection }}{* \text { Part of larger study of consumer }} \\
\text { and non-consumer case managers. } \\
\text { Measurements taken after } \\
\text { consumers in program for two } \\
\text { years } \\
\frac{\text { Analysis }}{* \text { Ordinary least square regression }}\end{array}$ & $\begin{array}{l}\text { Independent variables } \\
* \text { Consumer and case manager } \\
\text { versions of the working } \\
\text { alliance inventory (WAI), } \\
\text { modified for case management } \\
\text { *consumer or non-consumer } \\
\text { case manager } \\
\text { Dependent variables } \\
\text { *total score from Lehman's } \\
\text { subjective quality of life } \\
\text { inventory } \\
* \text { symptom severity } \\
\text { *family contact } \\
\text { *social activities } \\
\text { *attitude towards medication } \\
\text { compliance } \\
\text { *satisfaction with treatment } \\
\text { * number of days hospitalized } \\
\text { since program entry. }\end{array}$ & $\begin{array}{l}\text { *Consumer ratings of the WAI } \\
\text { explained } 21 \text { percent of the } \\
\text { variance in quality of life. } \\
\text { Stronger ratings on the WAI } \\
\text { were associated with more } \\
\text { positive perceptions of } \\
\text { subjective quality of life } \\
\text { * Consumer ratings of WAI } \\
\text { explained } 25 \text { percent of } \\
\text { attitudes towards medication } \\
\text { compliance. Stronger ratings } \\
\text { of the WAI associated with } \\
\text { positive attitudes towards } \\
\text { medication compliance } \\
\text { * Both consumer and case } \\
\text { manager ratings of the WAI, } \\
\text { when assessed together, } \\
\text { accounted for } 54 \text { percent of } \\
\text { the variation in satisfaction } \\
\text { with treatment. Stronger } \\
\text { scores on both versions of the } \\
\text { WAI were associated with } \\
\text { greater treatment satisfaction }\end{array}$ \\
\hline $\begin{array}{l}\text { Draine \& } \\
\text { Solomon, } \\
(1996)\end{array}$ & $\begin{array}{l}\frac{\text { Sample }}{\text { *Consumers of ACT. } n=90} \\
\frac{\text { Data collection }}{\text { *Part of larger study of consumer }} \\
\text { and non-consumer case managers. } \\
\text { Measurements taken after } \\
\text { consumers in program for two } \\
\text { years } \\
\frac{\text { Analysis }}{* \text { Ordinary least square regression }}\end{array}$ & $\begin{array}{l}\text { *Age } \\
* \text { Ethnicity } \\
\frac{\text { Dependent variables }}{* \text { Consumer WAI modified for }} \\
\text { case management and } \\
\text { subscales: bond, goal, task. }\end{array}$ & $\begin{array}{l}\text { *A history of criminal arrests } \\
\text { was associated with stronger } \\
\text { ratings of the bond and task } \\
\text { WAI subscales, but not the } \\
\text { overall WAI scale }\end{array}$ \\
\hline
\end{tabular}

Table 2.6 Continued 
Table 2.6 Continued

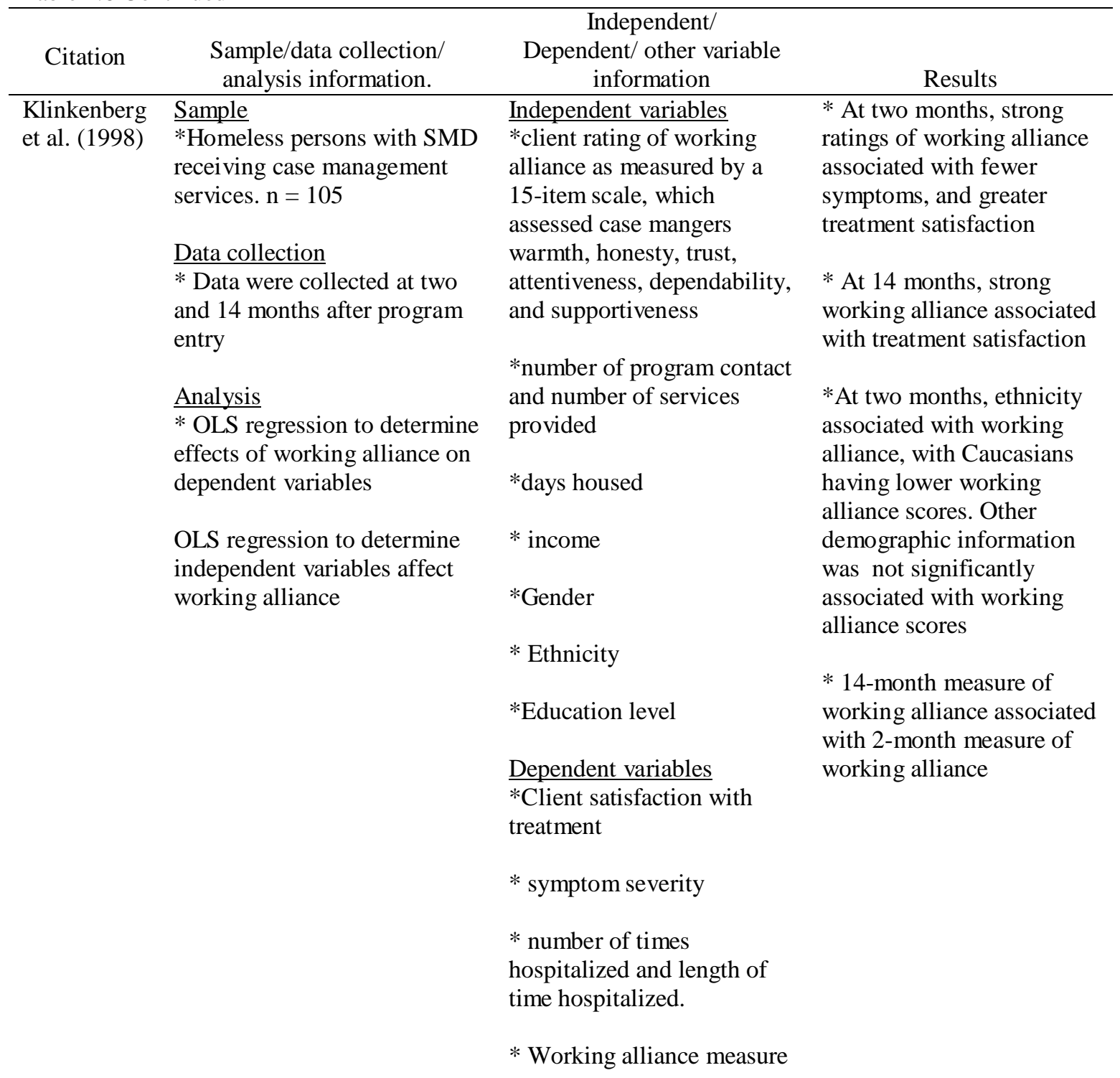

Table 2.6 Continued 
Table 2.6 Continued

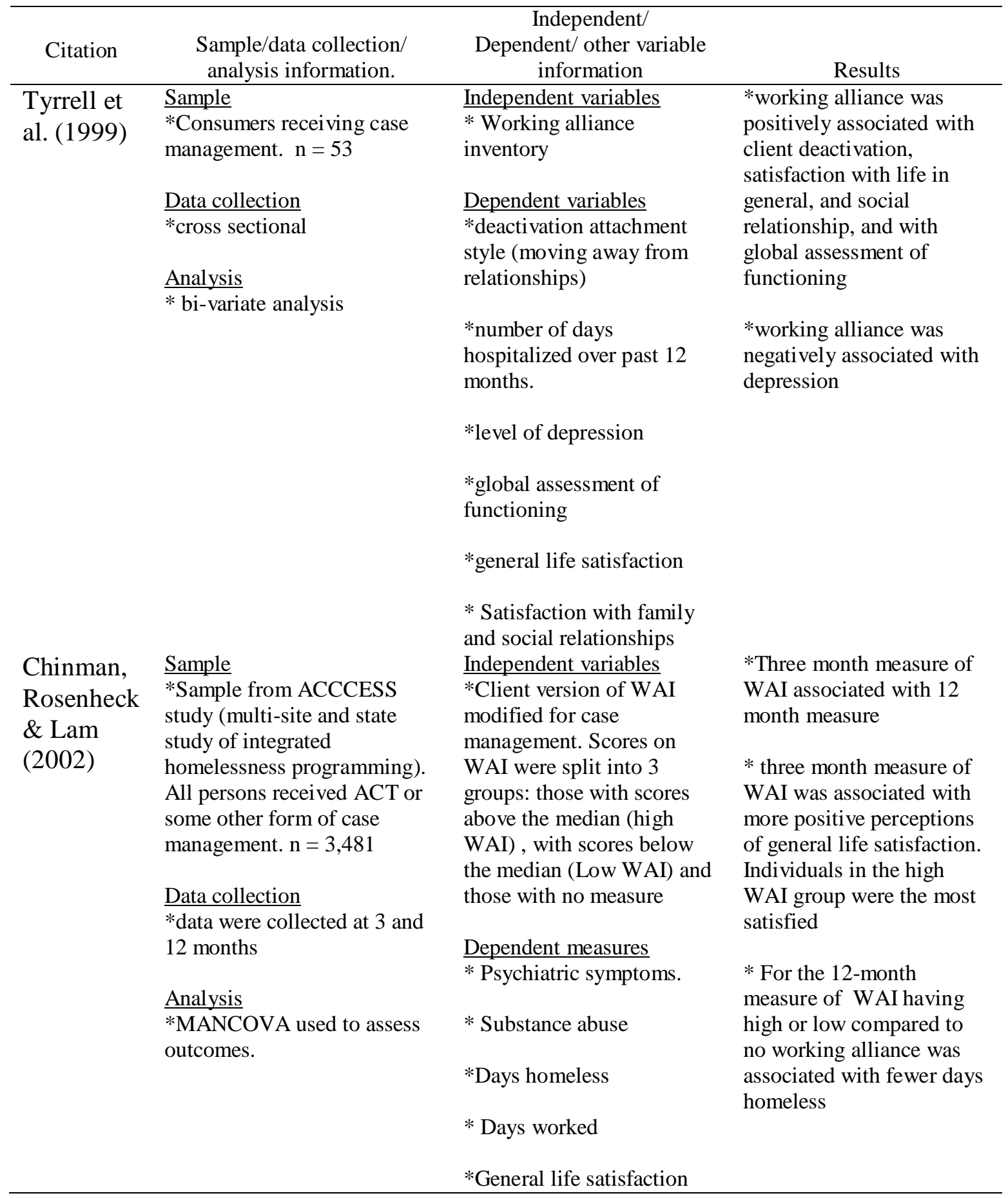




\section{CHAPTER 3:}

\section{METHODS}

\section{Research Design:}

The purpose of this study was to explore the relationships between working alliance, mental health self-stigma, and these variables' effects on the quality of life among consumers of Assertive Community Treatment (ACT) teams. The first research question asked if the self-stigma related variables and working alliance were independently related to subjective quality of life. The second research question asked if working alliance mediated the relationship between the self-stigma related variables and subjective quality of life.

The researcher employed a cross-sectional design. The cross-sectional nature of this study precluded the ability to establish a causal relationship between working alliance, self-stigma related variables, and quality of life. In order to establish causation, the research needs to: a) show that the independent variable precedes the dependent variables in time; b) show that the independent variables and the dependent variables are correlated; and c) show that no other rival hypotheses are tenable. The current research design allowed for the assessment of relationships between the independent and dependent variables. The current design allowed for the control of potential rival 
variables. The current research design did not allow for a time ordering of the independent and dependent variables. The goal of this study was to explore the relationships between these variables and to establish a tentative understanding of the suggested relationships. The cross-sectional design did allow for the development of a tentative understanding of the theoretical relationships between the independent variables and the dependent variable.

Pedhazur and Pedhazur-Schmelkin (1991) stated that one control for crosssectional studies is the statistical control of potential confounding variables. The authors argued that theory and common sense should govern selection of potential control variables. The current study included six potential control variables: gender, race, psychiatric diagnosis, the presence of a secondary alcohol or drug diagnosis, psychiatric symptom distress, and current case manager. Table 3.1 provides information on theoretical and statistical rationales for inclusion of each of these control variables. With the exception of the variable case manager, past research on all of the other control variables showed each of the control variables was significantly related to subjective quality of life. In addition, psychiatric diagnosis, a secondary alcohol and other drug diagnosis, and symptom distress represent rival hypotheses for the effects of self-stigma related variables (Gove, 1970). Gove argued that symptom distress and diagnoses, and the bizarre behaviors associated with these variables, explain differences in outcome such as differences in subjective quality of life, and also made the point that stigma and selfstigma are not adequate explanation for differences in outcomes. Finally, case mangers are a potential source of confounding co-variation. Ryan et al. (1994) stated that studies of case management have not accounted for the hierarchical, or nested, nature of case 
management programs. Ryan et al. (1994) found that case managers explained a significant amount of variance in the length of time during which a consumer received treatment. In the current study, consumers were nested within case managers.

\section{Measurement}

The primary variables of interest in this study were self-stigma, working alliance, and subjective quality of life. The variables related to self-stigma and to the working alliance were the independent variables for this study and subjective quality of life was the dependent variable for this study. Information from the independent and dependent variables came from face-to-face interviews with research participants. Appendix five provides the interview schedule used and specific questions asked for the independent and dependent variables.

\section{Measurement: independent and dependent variables}

Self-Stigma was defined using three concepts associated with modified labeling theory of mental illness: devaluation and discrimination (Link, 1987), stigma withdrawal (Link et al., 1989), and stigma related emotions of feeling different and ashamed (Link et al., 2002). Each of these three variables represents one aspect of the stigma process. Modified labeling theory hypothesizes that individuals will adopt negative stereotypes of mental illness as self-defining, and will engage in coping strategies to counter these perceptions (Link et al., 1989). In addition, labeled individuals develop negative emotional responses to their labeled status (Link et al., 2002; Scheff, 1999). Modified labeling theory focuses on a social psychological process that operates within the labeled 
individual that can exist in the absence of actual experiences of discrimination from others (Link and Phelan., 2001).

Devaluation and discrimination is defined as “...expectations as to whether most people will reject an individual with a mental illness as a friend, employee, neighbor, or intimate partner, and whether most people will devalue a person with a mental illness as less trustworthy, intelligent, and competent" (Link and Phelan, 2001). The devaluation and discrimination scale relates to the negative societal stereotypes about mental illness learned by members of society, including persons with SMD. Link and colleagues (1989) argued that individuals learn early in life how society views persons with a SMD, which is analogous to Mead's (1934) concept of the generalized other. Mead (1934) posited that individuals learn and adopt societal based attitudes towards social objects, including SMD. Individuals develop expectations for how persons with a SMD are usually treated by members of one's community. Link argued that these expectations, or stereotypes, about how the public will treat persons with SMD become meaningful for persons receiving psychiatric treatment (Link, 1987). The activation of these expectations, which occurred when a person with SMD was officially labeled, was hypothesized to lead to reduced life chances for persons with SMD (Link, 1989).

Devaluation and discrimination was operationally defined using the mean item score from Link's 12 item devaluation and discrimination scale, which are the first 12 questions of the stigma scales in Appendix five (Link et al., 2002). Items from the devaluation and discrimination scale ask respondents about stereotypes of SMD associated with employment, relationships (including intimate relationships), trustworthiness, and intelligence. Respondents were asked to strongly agree (4), agree 
(3), disagree (2), or strongly disagree (1) with each of the 12 statements. Each individual's responses to the 12 items were summed and divided by 12 to arrive at a mean item score. Potential mean item scores for the 12-item scale ranged from one to four. Higher scores on the devaluation and discrimination scale indicate greater understanding of the negative stereotypes of SMD. Link and colleagues (1989) noted that the use of an average item score allows the mean item score to be placed on a fourpoint scale and be compared to the midpoint of the scale. The midpoint of the devaluation and discrimination scale was 2.5 . If the mean item score for an individual was below 2.5, then that individual, on average, disagreed that individuals with a SMD will be devalued and discriminated against. If the mean item score for an individual was above 2.5 , then that individual, on average, agreed that individuals with a SMD would be devalued and discriminated against. Link's devaluation and discrimination scale has shown acceptable internal consistency reliability within samples of persons with a SMD, with coefficient alphas ranging from .82 (Link et al., 1991) to .88 (Link et al., 2002). Nunnally (1967) argued that internal consistency reliability estimates of .7 are acceptable. The internal consistency reliability coefficient for the present study was .83 .

Link et al. (2004) maintained that the devaluation and discrimination scale demonstrated construct validity. They argued that studies have shown that the devaluation and discrimination measure relates in theoretically hypothesized directions with outcome measures, including being negatively associated with self-esteem (Link,et al.,, 2001, 2002) and quality of life (Rosenfield, 1997) and positively associated with depressive symptoms (Link, et al., 1997; Link, et al., 2002) 
Stigma withdrawal is a coping mechanism that persons with SMD use to deal with their labeled status. Stigma withdrawal is the extent to which labeled individuals selectively avoid contact with individuals who do not know of their labeled status for fear of being rejected (Link et al., 1991). Link and colleagues (1991) have likened this coping mechanism to Goffman's (1963) conception of the "own and the wise." Goffman (1963) theorized that stigmatized individuals cope with their tainted status by avoiding normal social interaction and limiting their social interactions to those who know of and accept their devalued status, or the own and the wise. Link and colleagues have articulated four other coping orientations, including secrecy, educating others (Link et al., 1991), challenging stigmatizing statements and behaviors, and distancing from others. (Link et al., 2002). However, measures of these other stigma-coping orientations have not been as strongly related to outcomes as stigma withdrawal. In one study of self-stigma coping orientations, Link et al. (1991) found that stigma withdrawal and not stigma secrecy or stigma education was associated with demoralization and unemployment. In a more recent study, Link and colleagues (2002) found stigma withdrawal was associated with feeling misunderstood, with feeling different and ashamed, with reductions in selfesteem, and with increased depressive symptoms. None of the other coping variables was associated with more than one of the outcomes found to be associated with stigma withdrawal.

Stigma withdrawal was operationally defined using the mean item score from Link's 9-item stigma withdrawal scale (Link et al., 2002). The stigma withdrawal scale questions are questions 13-21 of the stigma scales in Appendix five. Items from the stigma withdrawal scale ask about the extent to which participants limit interaction with 
others who do not know of their tainted status and the extent to which consumers limit contact to other persons with SMD. Respondent were asked to strongly agree (4), agree (3), disagree (2), or strongly disagree (1) with nine statements that relate to the use of withdrawal as a coping mechanism. Each individual's responses to the nine statements were summed and divided by nine to arrive at an average items score. Total possible scores range from one to four, with greater scores associated with the endorsement of withdrawal as a stigma coping mechanism. Link and colleagues (1989) found an internal consistency reliability of .70 for the scale. In the current study, the alpha for stigma withdrawal scale was .60. This alpha suggested that the reliability of stigma withdrawal is less than in past studies.

Link and colleagues $(1989,2002)$ have tentatively demonstrated construct validity for the stigma withdrawal scale. The stigma withdrawal scale has operated in theoretically predicted relationships with outcome variables including reductions in selfesteem and reduced economic success (Link et al., 1989, 2002).

Feeling different and ashamed is defined as how psychiatrically labeled individuals" "experiences of mental illness and mental hospitalization make them feel set apart, different from other people, and ashamed" (Link et al., 2002, p. 211). Link and colleagues' (2002) articulation of the stigma-related feelings drew, in part, on the theoretical work of Scheff (1999). Scheff discussed the powerful and harmful role that negative feelings associated with having SMD, including shame and embarrassment, can have on psychiatrically labeled individuals. While Link and colleagues (2002) have articulated two different types of emotional responses, including feeling different and ashamed and feeling misunderstood by others, the variable feeling different and ashamed 
has been associated with lower self-esteem and greater depressive symptoms, while feeling misunderstood by others has not (Link et al., 2002). In addition, Link and colleagues (2002) found that feeling different and ashamed and feeling misunderstood by others were modestly correlated $(\mathrm{r}=.33)$, which indicated the two scales shared variance.

Feeling different and ashamed was operationally defined using the mean item score from the four item feeling different and ashamed scale developed by Link and colleagues (2002). The feelings of different and ashamed scale questions are questions 22-24 of the stigma scales in Appendix Five. Items from the feeling different and ashamed scale ask respondents about feeling different, ashamed, and set apart from others as a result of having SMD. Two of the questions specifically asked about feelings associated with past experiences of psychiatric hospitalization. Respondents were asked to strongly agree (4), agree (3), disagree (2), or strongly disagree (1), with four statements that relate to feeling different and ashamed. Each individual's responses to the four questions were summed and divided by four to arrive at an average items score. Total possible scores range from one to four, with greater scores associated with endorsement of feelings of different and ashamed. Internal consistency reliability for this scale has been mixed, with alphas ranging from $.58-.70$ in the first study that used this measure (Link et al, 2002). The higher alpha was associated with the base-line measurement of this scale and the alpha of .58 was associated with the 24 month follow-up measurement (Link et al., 2002). These low internal consistency reliability scores might be associated with the limited number of statements used to assess this variable. Internal consistency reliability scores are related to the number of items used to measure a construct, with increases in the number of items associated with greater reliability scores. No internal 
consistency reliability estimate was calculated for this variable, because too few persons provided answers to all of the questions. The feelings of different and ashamed scale, although collected during the face-to-face interview, was not used in the analysis.

Working alliance was defined using Bordin's (1979) pan-theoretical definition of the construct. Bordin (1979) defined the working alliance with three components: a) the positive bond that exists between the treatment provider and client, $b$ ) the agreement between the treatment provider and the client on treatment goals, and c) the agreement between the treatment provider and the client on treatment tasks. Horvath (1994) further defined these three components:

Task refers to the in-therapy activities that form the substance of the therapeutic process. In a well-functioning relationship, both parties must perceive these tasks as relevant and effective; furthermore, each must accept the responsibility to perform these acts. Goal refers to the therapist and client mutually endorsing and valuing the aims (outcomes) that are the target of the intervention. Bond embraces the complex network of positive personal attachments between client and therapist including issues such as trust, acceptance, and confidence (p.110-111).

While Horvath's definition of these three components of the working alliance stressed the relationship between a therapist and client, Bordin (1979) argued that his definition of the working alliance was applicable to any change-oriented activity. Indeed, if the words therapy and therapist were changed to community support/case management and case manager/ACT worker, Horvath's definition of the three components could be easily applied to case management.

Working alliance was operationally defined using the average item score from an adapted version of the short form of the "Working Alliance Inventory" (WAI) (Horvath \& Greenberg, 1989). The WAI consists of three sections that reflect Bordin's conceptualization of the working alliance: the bond, goals, and tasks sections. Each of 
these three sections has four items designed to measure a specific aspect of the working alliance. The WAI scale questions are all of the questions of the working alliance scale in Appendix Five. For each statement, respondents were asked to respond: never (1), rarely (2), occasionally (3), sometimes (4), often (5), very often (6), always (7). Each individual's score on the WAI was transformed into an average item score. As with the self-stigma scales, this transformation allowed for an interpretation of the WAI in relation to the mid-point of the scale. The midpoint of the WAI was four. Individuals with scores greater than four had favorable impressions of their working alliance with their case manager, and individuals with scores less than four had unfavorable impressions of their working alliance with their case manager.

The researcher used a modified version of the WAI in the current study. The researcher modified the WAI to reflect the use of the instrument in case management rather than therapy. The researcher modified the short form of the WAI by replacing the word "therapy" with "case management." To facilitate the face-to-face interview format of data collection, the researcher also changed the wording of items from the first person declarative to the second person interrogatory. Neale and Rosenheck (1995) made the same change when they adapted the long version of the WAI for their study of the working alliance within case management. For example, the original item, “ and I agree about the things I will need to do in therapy to help improve my situation," was changed to " How often do and you agree about the things you will need to do in case management to help improve your situation?" As with Neale and Rosenheck (1995), response categories were not changed. 
For the general population of individuals receiving psychotherapy, the WAI has demonstrated acceptable internal consistency reliability. In his review of the literature on the WAI, Horvath (1994) reported internal consistency reliability for the WAI that range from $.84-.93$. Among case management/ACT studies that used an adapted version of the consumer WAI for case management, Chinman et al. (2000) reported internal consistency reliability coefficients ranging from $.89-.90$. Neale and Rosenheck (1995) reported an internal consistency reliability coefficient of .93, and Solomon et al. (1995) reported an internal consistency reliability coefficient of .89 . The WAI internal consistency reliability for the current study was .95 .

Working alliance researchers have explored the construct validity of the WAI. The construct validity of the WAI has been tentatively supported. Tracy and Kokotvic (1989) conducted a confirmatory factor analysis of the WAI. They found working alliance was understood through a second-order factor model with each of the three subscales of the WAI (bond, tasks, goals) reflecting three unique latent factors. Together these three subscales defined a larger working alliance factor. Tracy and Kokotvic (1989) developed the short form of the WAI by taking four items from each of the three subscales that loaded highest on each of the three factors (Tracy \& Kokotovic, 1989). Tracy and Kokotvic (1989) found that the short form of the WAI had the same theoretical second-order factorial structure as the longer form. Horvath (1994) reported the WAI has demonstrated both convergent and discriminant validity; the WAI was correlated with other similar measures of working alliance, and not with other aspects of the relationship between therapists and clients distinct from the working alliance as defined by the WAI. 
Studies of the WAI within research on case management/ACT have demonstrated that the WAI performed in theoretically predicted directions with outcome variables, including being associated with fewer psychiatric symptoms and number of days homeless, and more positive perceptions of quality of life (Chinman et al., 2000; Neale \& Rosenheck, 1995; Solomon et al., 1995). The confirmation of the factor structure of the WAI, and the theoretically predicted relationships between the WAI and other alliance and outcome measures lend support to the construct validity of the WAI.

Subjective quality of life was defined as "the sense of well-being and satisfaction experienced by people under their current life conditions" (Lehman, 1982, p. 143) and related specifically to how persons feel about their living situation, daily activities, family relations, social relations, finances, work, safety, and health as well as their life in general. Frisch and colleagues (1992) posited that measures of subjective quality of life allow the comparison of individuals' assessment of their quality of life aspirations relative to their current life situation. The sense of well-being or satisfaction an individual has regarding quality of life in general or within each domain is reflective of the concordance between where an individual wishes to be within each of the domains of quality of life and where they perceive they actually are within each domain. Positive perceptions of quality of life reflect greater concordance between where a person is and where they want to be and negative perceptions reflect lesser concordance between where a person is and where they want to be.

Subjective quality of life was operationally defined using the subjective quality of life scales from "Lehman's Quality of Live Interview" (LQOLI) (Lehman, 1988). The LQOLI is a three component model of quality of life and includes both subjective and 
objective indicators of quality of life. The researcher used only the subjective quality of life sections for the current study. The subjective sections of the LQOLI assessed subjective well-being with eight life domain specific subscales and an overall quality of life subscale. The eight domains include satisfaction with living situation (6 questions), daily activities (6 questions), family support (4 questions), social relations (6 questions), finances (4 questions), work (5 questions), safety (5 questions), and health (6 questions). Overall quality of life was assessed using two questions in which respondents rate their overall quality of life at the beginning and end of the overall quality of life interview. Because of unacceptable item response rates on the work subscale, the researcher did not include the work subscale in the analysis.

The subjective quality of life subscale questions are in the subjective quality of life section of appendix six. For each question, respondents were asked to rate their responses using the terrible/delighted seven point likert-type scale. The terrible/delighted scale includes terrible (1), unhappy (2), mostly dissatisfied (3), mixed (4), mostly satisfied (5), pleased (6), and delighted (7). Using Solomon, Draine, and Delaney's (1995) strategy, the researcher treated the subjective quality of life as one total scale, rather than analyzing each of the domain subscales separately. The researcher used an average item score for the subjective quality of life scale. The midpoint for the scale was four. Scores above the mid-point of four indicated the respondents had favorable appraisals of their subjective quality of life and scores of less than four pointed to negative appraisals of their subjective quality of life.

The subjective scales of the LQOLI have shown acceptable levels of internal consistency reliability. In a sample of persons with a SMD, internal consistency 
reliability estimates for each of the subscales ranged from .79 for the overall QOL subscale to .88 for the living situations subscales (Lehman, 1988). The researcher calculated the internal consistency reliability coefficient for the whole scale, because a total subjective quality of life scale was used as the dependent variable. The coefficient alpha for the current study was .94 .

Lehman (1988) calculated the test retest-reliability of the LQOLI. The one week test-retest reliability estimates, a measure of a construct's stability over time, range from .41 for the safety subscale to .95 for the work subscale (Lehman, 1988). Lehman's finding about the test-retest reliability estimate suggests that the construct, subjective quality of life, has stability over short time periods.

Researchers studied the validity of Lehman's subjective quality of life subscales. Their findings suggest the LQOLI has demonstrated construct validity. Using factor analysis, Lehman (1998) found that each of the subscales represented a distinct latent factor. Further, Lehman (1988) discovered a modest relationship between the subjective subscales and their related objective subscales. Lehman and colleagues (1993) found modest convergent validity coefficients when the overall QOL, family relations, and social relations subscales of the LQOLI were compared with similar measures of satisfaction form the Heintrich-Carpenter Quality of Life scales. The convergent validity coefficients ranged from .26 for the overall QOL subscales and .43 for the social relations subscales. Further, Lehman found that the subjective measures from the LQOLI were distinct from measures of psychopathology (Lehman, 1983), although in another study overall QOL was negatively related to symptoms of depression and anxiety, but not to thought disorders (Lehman, 1988). 


\section{Measurement: control variables}

The researcher also collected information on the consumer's ethnicity, gender, current symptom distress, current psychiatric diagnosis, presence of a secondary alcohol or other drug diagnosis and current case manager as potential control variables. Table 3.1 provides statistical and theoretical rationales for use of each of the control variables. The following discussion provides additional information about each of these variables. Information from these control variables came from consumer records housed at Southeast. This information is collected as a routine part of the agency's assessment process and as part of the Ohio Mental Health Consumer Outcome System (The Ohio Department of Mental Health [ODMH], 2005). Information on ethnicity, age, gender, and symptom distress were collected on Consumer form A, which was developed by ODMH to track consumer outcomes as part of the consumer outcome system. Consumers complete this form when they first enter treatment. Consumers also complete this form at six months, a year, and every year thereafter. Southeast stores and tracks the information collected from Consumer form A in CATT, a Microsoft Access based program that was designed for storing and tracking behavioral health outcome data. Information on psychiatric diagnosis and the presence of a secondary alcohol or other drug diagnosis is not collected on Consumer form A, but is collected and stored in CATT by Southeast. The participant's current case manager was determined during the face-to-face interview by consumer self-report.

Ethnicity/race was defined as the subject's self-identification with a specific ethnic/racial group. Respondents could select white, Native American/Pacific Islander, Black/African-American, Hispanic/Latino, Asian, and Other. For the purposes of 
analysis, this variable has been coded as white, African-American, and other. The other category was used because of low numbers of Hispanic/Latinos and Asians in the population and sample.

Gender was defined as the subjects' self-identification with a particular gender and respondents had a choice of male of female.

Current symptom distress was defined as the subject's perceived level of distress caused by the severity of their psychiatric symptoms. Current symptom distress was operationally defined as the mean item score from the Symptom Distress Scale (SDS) of Consumer form A (ODMH, 2005). This scale consists of 15 questions; ten questions came from the Symptoms Checklist-10 (SCL-10) (Nguyen et al., 1983) and five questions from the SCL-90 (Derogatis \& Cleary, 1977). Respondents were asked how "distressed" or "bothered" they have been over the past seven days by 15 symptoms, such as nervousness or shakiness inside, feeling fearful, and being suddenly scared for no reason. For each question, consumers responded not at all (1), a little bit (2), some (3), quite a bit (4), or extremely (5). Possible scores ranged from one to five.. Higher scores on the SDS indicate greater symptom distress. The internal consistency reliability of this scale has been assessed at $.93(\mathrm{n}=1,479)(\mathrm{ODMH}, 2005)$. This researcher calculated the internal consistency reliability for symptom distress, which was .91. Because the SDS came from Southeast and may have been collected up to a year before the face-to-face interview, the results related to symptom distress scale may no longer be valid. The time difference between face-to-face data collection and Southeast's data collection of the symptom distress scale may serve as a source of bias in the estimation of the effect of the stigma distress scale. The relationships between other independent variables and 
subjective quality of life may also be biased. The errors associated with the time of measurement of SDS may bias the covariant structure between the independent variables and subjective quality of life

Current psychiatric diagnosis was defined as the patient's current DSM -IV (American Psychiatric Association, 1994) or DSM-IV TR (쓰erican Psychiatric

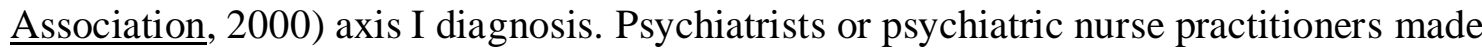
the diagnosis. Because individuals can hold more than one axis I diagnosis, only the client's primary diagnosis was used for this study. Based on the researcher's review of respondents' records, respondents were coded as living with schizophrenia, bipolar disorder, depression, and other illnesses (including an AODA primary diagnosis).

Secondary alcohol or other drug diagnosis was defined as the co-occurrence of a substance abuse disorder along with a primary diagnosis of SMD. Standards from the

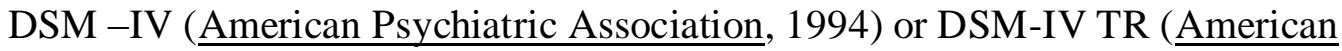
Psychiatric Association, 2000) were used to determine the presence of a co-occurring substance abuse disorder. Psychiatrists or psychiatric nurse practitioner made the diagnosis. Participants were identified as having or not having a secondary diagnosis of alcohol or other drug disorder.

The respondent's current case manager represented a final control variable. The respondent's current case manager was the person whom participants identified as providing them with services and support from Southeast. The researcher assigned each case manager a unique numeric code. This code and not the case manger's name was used in the analysis. Case manager information was also provided by Southeast. However, the researcher used the participant-identified provided case manager, because 
this was the case manager the participant was instructed to use in their assessment of their working alliance.

\section{Research site:}

Individuals with SMD who receive services from community-based treatment teams modeled on ACT were the primary population of interest for this study. An estimated 6.3 percent of the United States' population lives with a SMD during any given year (Kessler, Chiu, Demler, \& Walters, 2005). Of the national percentage of persons living with a SMD, 40.5 percent received services for emotional problems (Kessler, et al., 2005).

This study was situated in one community based mental health agency, Southeast Inc. (Southeast), in a large and mostly urban Midwestern county, Franklin county, Ohio. Southeast provides an array of services to individuals with SMD and/or alcohol or drug diagnoses, including services modeled on ACT. During fiscal year 2006, Southeast served over 6,000 consumers in all of their programs, including programming other than ACT. Of the 6,000 consumers who receive services from Southeast, 2,771 receive services modeled on ACT.

Southeast has 20 community-based case management teams. Most of these provide general community based treatment modeled on a hybrid ACT model. Two of these teams provided specialty services to persons who have had involvement with the criminal justice system. One team provides services to deaf persons and another team provides services to persons who live with both developmental disabilities and SMD. An additional three teams specialize in working with homeless persons. Further, three of the 
teams provide services modeled on Integrated Dual Disorder Treatment (IDDT), which provided comprehensive services to person living with SMD and alcohol and other drug diagnoses. The researcher recruited subjects from all case management teams with the exception of the deaf team; language barriers precluded deaf persons' involvement in the interview process.

\section{Subject recruitment}

The researcher used a convenience sample. Kazdin (2003) stated, "A sample of convenience is a sample of subjects that is studied because they are present in a convenient situation (waiting room, hospital ward) or are available for a quite different purpose (participation in another experiment that requires a special population)" (p 153). Ideally, the researcher would have used a probability sampling strategy. However, no accessible sampling frame of consumers who received services at Southeast was available to the researcher. The non-probability method does not allow for accurate estimation of sampling error and precludes the ability to draw inferences made from the collected data back to the population of interest (Pedhazur \& Pedhazur-Schmelkin, 1991). Findings here are limited to those individuals who participated in the study.

To be eligible to participate in the study, subjects had to be a current consumer of Southeast and had to be enrolled in one of the agency's ACT or ACT-like case management teams. All participants had to have a diagnosed SMD or alcohol or drug disorder. The researcher did not screen potential participants for the presence of a SMD because Southeast requires that consumers of their services must have a diagnosed SMD or alcohol or drug disorder. In addition, consumers had to consent to participate in this study. Not all consumers of Southeast were legally able to provide informed consent to 
participate. Potential participants who were not their own guardian were unable to provide informed consent and were not able to participate in the study. The researcher screened consumers to determine if they were their own guardian before beginning the consent process. Before beginning the consent process, he asked potential subjects if they were their own guardian.

Either the primary researcher or an assistant recruited subjects at three different Southeast locations. The majority of subject recruitment took place in Southeast's main lobby. The researcher set up an information table and placed advertisement signs in the main lobby of Southeast. He provided potential participants with written and verbal information about the study. The researcher asked interested consumers if they wanted to participate in the study that day or if they wanted to schedule a time to participate at a later date and time. All participants were consented and interviewed in a private location within Southeast. During the interview, the researcher provided participants with more information about the study, including information about the voluntary nature of the study and participants' rights. He read and had consumers read the informed consent form. The researcher answered any questions consumers had about the study. He provided coffee and donuts to all participants who came back to the private location, regardless of whether they actually participated in the face-to-face interview. The researcher was on-site Mondays, Tuesdays, and Wednesdays from 8:15 am to noon from June 14, 2005 to June 23, 2006 and from October 18, 2006 to January 19, 2007. The researcher was on site Mondays, Tuesdays, and Wednesdays from 1:00 pm to 4:00pm from January 22, 2007 to June 42007. 
The other two locations for interviews were two group homes operated by Southeast. The researcher added data collection at the two group homes because of a diminishing number of consenting participants over time at the primary research location. The assistant recruited subjects at the two group homes, setting up an information table and placing advertisement signs in the common area of the two group homes. She provided interested consumers with written and verbal information about the study. The assistant carried out interviews in a private location at each group home. During the interview, the assistant provided participants with more information about the study, including information about the voluntary nature of the study and participants' rights. She had consumers read the informed consent form. The assistant answered any questions consumers had about the study. The assistant provided coffee and donuts to all participants who came back to the private location, regardless of whether they actually participated in the face-to-face interview. The assistant was available for interviews Mondays and Tuesdays from May 14, 2007 to May 22, 2007.

Kazdin (2003) stated having more than one interviewer can serve as a potential sources of measurement error. To guard against potential issues with measurement error, the researcher trained the assistant from April 23, 2007 to May 7, 2007. The assistant conducted three interviews under the supervision of the researcher. In addition, the researcher statistically tested for the interviewer (researcher versus assistant) as a source of measurement bias. The researcher used independent t-tests to determine if the primary researcher and the assistant had participants with different mean scores on the devaluation and discrimination scale $(\mathrm{t}=-.851, \mathrm{df}=158, \mathrm{p}=.40)$, the stigma withdrawal scale $(\mathrm{t}=-.01, \mathrm{df}=158, \mathrm{p}=.99)$, the working alliance inventor $(\mathrm{t}=-.68, \mathrm{df}=158, \mathrm{p}=$ 
$.50)$, and the subjective quality of life scale $(\mathrm{t}=.18, \mathrm{df}=158, \mathrm{p}=.86)$. The researcher found no significant differences between the two interviewers on all scales. The statistical evidence does not support the hypotheses that interviewers served as a source of measurement error or bias.

The researcher and a non-clinical Southeast staff member retrieved information on the control variables from CATT. The non-clinical staff member did not have direct client contact. Data on the control variables were collected after the interviews and with the written permission of the participants. Only the researcher had access to both the face-to-face interview data and control variable data before the identifying information was purged from the researcher-developed dataset. The researcher removed participant names from the researcher-developed SPSS v. 15.0 database after he linked information from CATT to the SPSS v 15.0 database. The researcher assigned each participant with a unique client identification number. The Ohio State University's and Southeast's Institutional Review Boards (IRB) approved the sample recruitment, face to face and control variable data collection strategies.

\section{Pilot study}

The researcher conducted a pilot study before beginning the main study to determine if the interview schedule was understandable and the subject selection process was feasible. He conducted recruitment for the pilot study in the main lobby of Southeast and used the recruitment process discussed above. The researcher recruited 19 subjects for the pilot study. He recruited subjects on Mondays, Tuesdays, and Wednesdays from 8:15 am to noon from June 14, 2006 to June 23, 2006. The researcher informally asked consumers to comment on the ease of understanding the questions. All but one consumer 
stated that the interview questions were easy to understand. Based on consumer remarks, the researcher determined the interview schedule was easy to understand. The researcher also determined that the process of subject recruitment was feasible, because 19 participants were recruited over a two-week span of time. Because no changes in procedures were needed, the researcher included the 19 pilot participants as part of the overall study sample.

\section{Sample size}

The researcher initially set the minimum required sample size at 175 participants, based on the statistical power of finding a two percent variance explained in the dependent variable by the linear combination of all independent variables. Two percent variance explained is a small effect size (Cohen, 1988). Specifically, the researcher determined power based on type I error of .05 , an expected $\mathrm{R}^{2}$ of .2 and power of 80 percent, based on multiple regression as the analytic strategy.

During data collection, the researcher and his assistant conducted a total of 190 complete interviews. A few individuals -- eight with the researcher and five with the assistant -- began the interview but did not complete it. Thus, the interview noncompletion rate was $13 / 203$, or about six percent. Because demographic information was obtained from client records only on individuals who completed the interview, it is unknown whether completers differed from non-completers in any other appreciable way.

Of the 190 completed interviews, 15 later were excluded from the analysis because they were interviews conducted with someone who was not a consumer of Southeast $(\mathrm{n}=$ 9) or had been interviewed previously $(n=6)$. For individuals interviewed more than 
once, data from their earliest interview were used in the analysis. The available sample for the analysis included data from 175 persons, which was about six percent of persons receiving case management services at Southeast.

The use of a non-probability sampling technique limited the external validity of the research findings. Knowing differences and similarities between the sample and the population from which the sample was drawn can add a degree of confidence that the sample represents the population (Miller \& Smith, 1983). However, Pedhazur and Pedhazur-Schmelkin (1991) caution that, even if the sample and population are similar on known characteristics, the findings cannot be generalized back to the population of interest.

The researcher explored the differences between the sample of 175 consumers and the population of persons receiving ACT or ACT-like services from Southeast on gender, ethnicity, age, education, and primary psychiatric diagnosis. For analytic purposes, all variables were treated as dichotomous or multichotomous variables. The research used a one-way Chi-square test to determine if there was evidence to suggest that the sample was similar to the population of persons receiving case management services from Southeast during fiscal year 2006. The researcher calculated the Chi-square using the valid-percent from the sample data as the frequency observed. The researcher used available demographic data from Southeast as the frequency expected. The statistical, or null, hypotheses for each of the comparisons were that the distribution of data from the sample was no different from the distribution of data from the clients of Southeast. The probability of making a type I error was set at .05 . Table 3.2 provides a demographic comparison between the sample and Southeast 
With the exception of age $\left(\chi^{2}=6.81 \mathrm{df}=3, \mathrm{p}>.05\right)$, the null hypotheses for each of the other demographic variables were rejected. The distributions of race $\left(\chi^{2}=2.08 \mathrm{df}=2, \mathrm{p}\right.$ $<.05)$, gender $\left(\chi^{2}=4.23, \mathrm{df}=1, \mathrm{p}<05\right)$, education $\left(\chi^{2}=54.9 \mathrm{df}=3, \mathrm{p}<.05\right)$, and primary diagnosis $\left(\chi^{2}=12.51 \mathrm{df}=3, \mathrm{p}<.05\right)$ for the sample were different from the distributions of the same variables for Southeast. The sample had a higher proportion of whites and a smaller proportion of African Americans than the population of Southeast clients. The sample had a higher proportion of males. The sample had a higher percentage of persons who had some college or completed college and smaller percentage or persons who attended grades 10 or 11 than did all persons receiving case management services from Southeast. Finally, the sample had a higher proportion of persons with a diagnosis of major affective disorder and fewer persons with a primary diagnosis of alcohol or other drug disorder than did persons receiving case management services from Southeast. Thus, the sample of persons used in this study was significantly different from the population of persons who receive services from Southeast.

\section{Data analysis}

The research used multilevel modeling, also called hierarchical linear modeling, to assess the statistical relationships between the independent variables and dependent variable. Multilevel modeling is the appropriate statistical analysis for nested data structures (Luke, 2002). Data in the current study were in a nested structure. Clients were nested within case managers. Data from clients were the level-1 data and data from case managers were the level-2 data. Figure 3.1 provides a graphical depiction of the nested data structure. 
The use of single level statistical analysis, such as ordinary least square regression, in situations where there is a nested data structure is not appropriate. For the current study, consumer data may depend on their case manager. Case managers may exert an influence on consumers and subsequently on consumers' outcomes. One of the assumptions of ordinary least square regression is that error terms are not correlated, that there is no evidence of autocorrelation (Berry, 1993). Autocorrelation is the extent to which errors associated with one observation are correlated with another observation (Berry, 1993). Autocorrelation is particularly problematic when observations are associated with some unknown or unmeasured grouping variable. In the current study, case managers represent this grouping variable. Multilevel modeling accounts for these grouping variables by splitting the error term between the two levels.

A second and related problem with the use of ordinary least squares regression for nested data structures relates to the estimation of standard errors. Ordinary least square regression pools together level-2 and level-1 errors (Luke, 2002). Pooling the error terms together can result in underestimated standard errors (Hox, 2002). Reduced standard errors can result in an increased chance of making a type I error, or finding a significant relationship between variables when a true relationship does not exist.

Multilevel modeling controls for potential issues with autocorrelation and reduced standard errors by accounting for the potential grouping variable (Luke, 2002). Multilevel modeling simultaneously accounts for level-1 and level-2 effects by separating the effects of individual level variation and group level variation on dependent variables (Hox, 2002). "Conceptually, it is useful to view multilevel regression models as a hierarchical system of regression equations" (Hox, 2002, p.11). Level-2 regression equations are used 
to estimate group level effects on the level-1 intercept and/or slopes. The level-1 regression equation is used to estimate individual level effects on the dependent variable, which is a level-1 variable.

Multilevel modeling does not use an ordinary least squares approach to model estimation. Rather, multilevel modeling uses a maximum likelihood (ML) estimation procedure to estimate both the fixed (parameter coefficients) and random components (variance components) of the model. ML uses an iterative approach to estimate parameters, which is based on the likelihood function. The likelihood function is "...the function that describes the probability of observing the sample data, given the specific values of the parameter estimation" (Hox, 2002, p. 16). ML estimation works by first estimating starting values for each of the estimated parameters, including the fixed and random components. A likelihood function is calculated for this initial model. The ML procedure re-estimates the values of the parameters until changes in the likelihood function are small, which means that the estimation process has finished and the results have converged. Specifically, the researcher used full maximum likelihood estimation (ML). Unlike other forms of ML estimation, such as restricted maximum likelihood estimation, ML allows for comparisons between models with the same dependent variable and samples at each level. ML estimation was used for all of the multilevel modeling analysis undertaken in this study.

The specific class of multilevel modeling used in the analysis was a one-way random effects analysis of covariance (ANCOVA). One-way random effects ANCOVA is similar to ANCOVA except that the one-way random effects ANCOVA separates variances between levels, which accounts for the hierarchical structure of the data. The 
researcher selected multilevel modeling based on the need to control for the potential effects of case managers on subjective quality of life. One-way random effects ANCOVA allowed for a test of the effects of the case managers on subjective quality of life, while still allowing for an estimation of the relationships between the self-stigma variables and the working alliance variable on subjective quality of life. The researcher used the statistical package, HLM v.6, to estimate each of the models.

Although there were fairly complete data on 175 persons, all of the analysis reported in the next chapter used a dataset restricted to 160 persons. A rule of thumb for multilevel modeling requires that all level-2 units have at least two level-1 units associated with them (University of Bristol, 2007). Level-2 units with only one level-1 unit obscure level-1 and level-2 effects. All 175 participants, or level-1 units, in the initial sample had a case manager, or level-2 unit; however, not all case managers had more than one client. For the current study, there were 175 consumers and 62 case managers. Of the 62 case managers, 15 had only one client represented in the sample, and 47 had more than one client. The fifteen participants with case managers with only one client represented in the sample of 175 consumers were excluded from the study. The final sample consisted of 160 consumers and 47 case managers. Case managers had an average of 3.4 consumers. The researcher assessed the degree to which the sample of 175 and sample of 160 differed, using a Chi-square test for independence (see table 3.3). The samples differed only with regard to psychiatric diagnosis $\left(\chi^{2}=35.44 \mathrm{df}=3, \mathrm{p}<.05\right)$. The sample of 160 participants consisted of fewer persons with a diagnosis of major affective disorder and more persons with an alcohol or other drug diagnosis than did the sample of 170 . 
Analytic strategy for answering the research question

The first research question was a test of the independent effects of the self-stigma related variables and the working alliance variable on quality of life (see figure 1.1). The first research questions was: to what extent do client perceptions of self-stigma and the working alliance between clients and their primary ACT worker independently affect client perceptions of subjective quality of life among consumers of ACT and ACT-like services? To test the independent effects of working alliance and self-stigma on subjective quality of life, the researcher estimated one statistical model that included the effects of the self-stigma related variables, devaluation and discrimination and stigma withdrawal, on subjective quality of life. The researcher interpreted the estimated parameter coefficients for each of the independent variables to determine each variables effect on subjective quality of life.

The second research question was a test of the mediating role of the working alliance variable between self-stigma related variables and the quality of life variable (See figure 1.2). The researcher employed Baron and Kenny's (1986) recommendations for testing mediating effects. Figure 3.2 provides a graphic depiction of mediation effects of working alliance between the self-stigma related variables and subjective quality of life. According to Baron and Kenny (1986), mediating relationships need three statistical requirements to be met: First, the independent variable, the self-stigma related variables, and dependent variable, subjective quality of life, must share variance - path B. Second, the independent variables must share variance with the mediating variable, working alliance - path A. Finally, when both the mediating variable and the independent variable are entered into the model together, the mediating variable must share variance 
with the dependent variable - path $\mathrm{C}$. And, in the model with both the independent variable and the mediating variable entered, path B should be smaller than that of the model with only the independent variables entered.

The researcher ran two additional analyses to test the mediating relationship of working alliance between the self-stigma related variables and subjective quality of life. The first analysis tested the effects of the self-stigma related variables on working alliance - path A. In addition, the researcher assessed the impact of only the self-stigma variables on subjective quality of life - path $B$. The model used to test the independent effects of self-stigma related variables and working alliance on subjective quality of life was used to investigate path $\mathrm{C}$ and to determine if a difference existed between path $\mathrm{B}$ for the model without working alliance and with working alliance. 


\section{Tables and Figures}

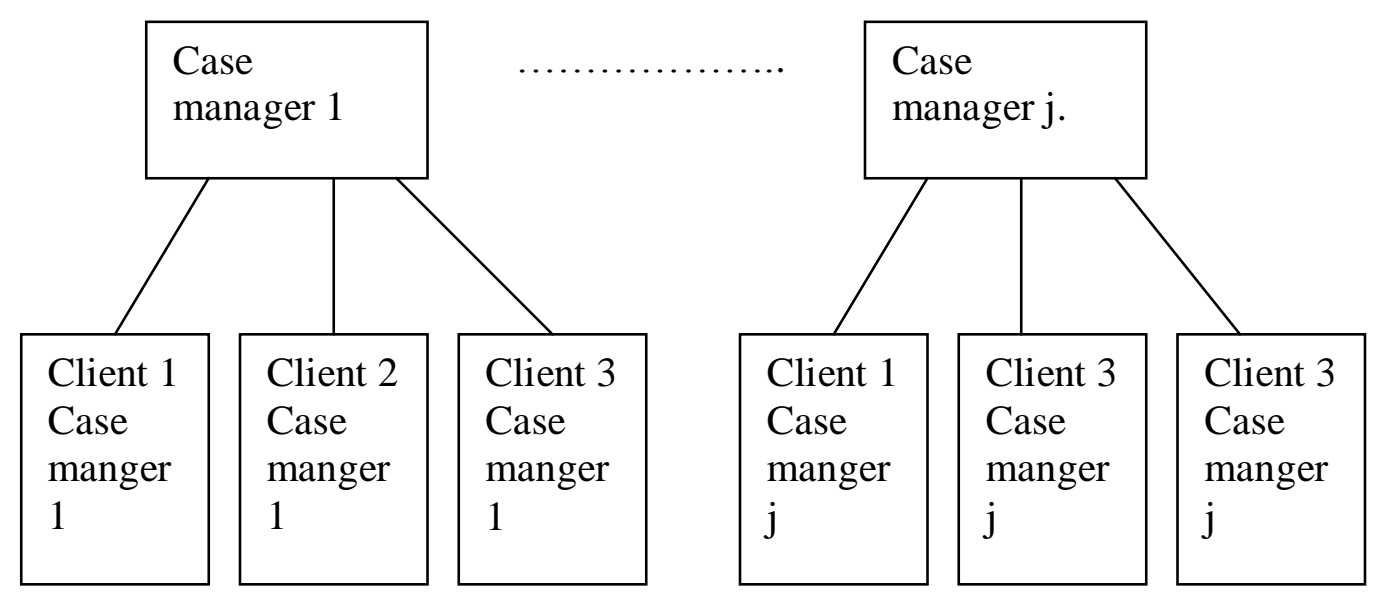

Figure 3.1: Graphical depiction of the nested data structure 


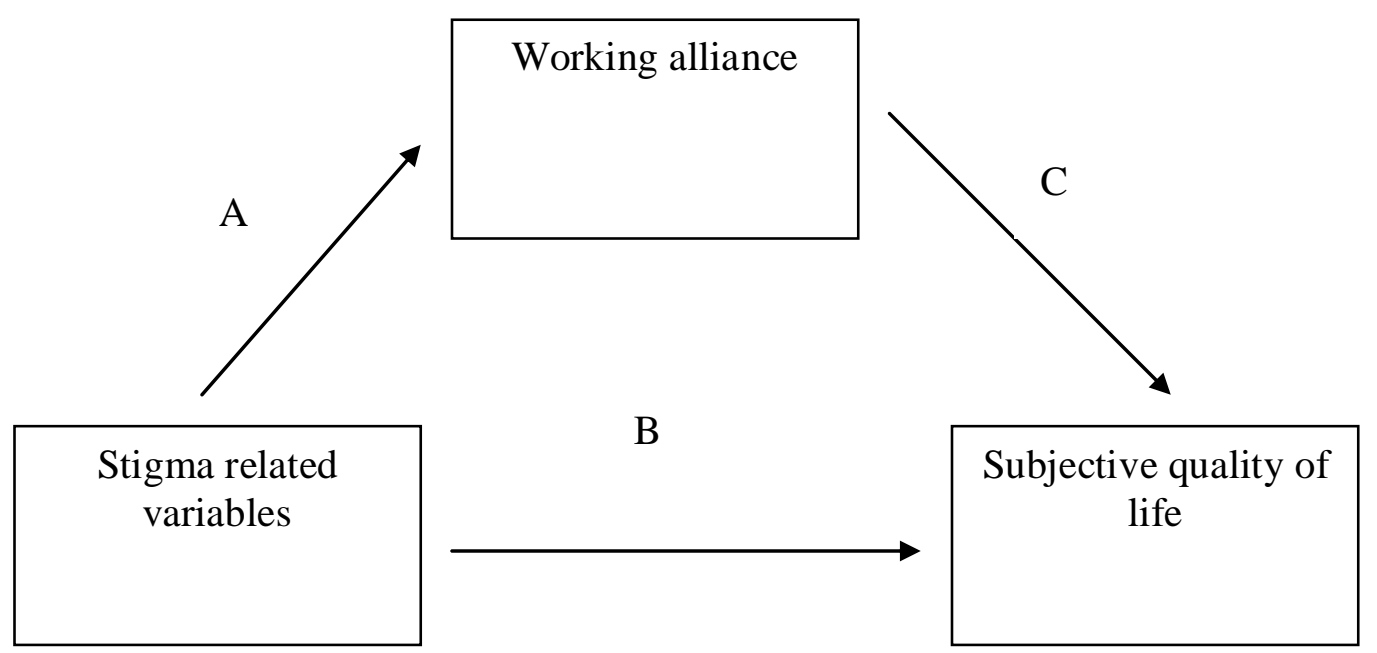

Figure 3.2: Graphic depiction of mediation effects of working alliance between stigma related variables and subjective quality of life. 


\begin{tabular}{|c|c|}
\hline Control variable & Rational for consideration as a control variable \\
\hline Gender & $\begin{array}{l}\text { *Lehman, Rachuba, \& Postrado (1995) found a relationship } \\
\text { between gender and subjective quality of life. Women } \\
\text { perceived their overall subjective quality of life, their safety } \\
\text { quality of life, daily activities quality of life and their family } \\
\text { quality of life more negatively than did men. }\end{array}$ \\
\hline Race & $\begin{array}{l}\text { *Lehman, Rachuba, \& Postrado (1995) found a relationship } \\
\text { between race and subjective quality of life. The authors } \\
\text { found that non-Caucasians reported significantly higher } \\
\text { satisfaction with their quality of life than Caucasians. }\end{array}$ \\
\hline Diagnosis & $\begin{array}{l}* \text { The behaviors associated with psychiatric diagnosis are a } \\
\text { potential rival explanation for the effects of stigma on } \\
\text { quality of life (Gove,1970). }\end{array}$ \\
\hline $\begin{array}{l}\text { Alcohol and drug } \\
\text { diagnosis }\end{array}$ & $\begin{array}{l}* \text { The behaviors associated with psychiatric diagnosis are a } \\
\text { potential rival explanation for the effects of stigma on } \\
\text { quality of life (Gove,1970). }\end{array}$ \\
\hline \multirow[t]{2}{*}{ Symptom distress } & $\begin{array}{l}\text { * The behaviors associated with psychiatric diagnosis are a } \\
\text { potential rival explanation for the effects of stigma on } \\
\text { quality of life (Gove,1970). }\end{array}$ \\
\hline & $\begin{array}{l}\text { * Eack and Newhill (2007) found that small effect for } \\
\text { symptom distress in their meta-analysis of correlates of } \\
\text { quality of life Symptoms negatively affected perceptions } \\
\text { of quality of life. }\end{array}$ \\
\hline \multirow[t]{2}{*}{ Case manager } & $\begin{array}{l}* \text { In the current study, consumers are nested within case } \\
\text { managers. Failure to account for the effects of case } \\
\text { managers could lead to violations of regression } \\
\text { assumptions. }\end{array}$ \\
\hline & $\begin{array}{l}\text { Ryan et al. (1994) found that case manages explained a } \\
\text { significant amount of variance in the length of time that } \\
\text { consumers received services from a case management } \\
\text { program. }\end{array}$ \\
\hline
\end{tabular}

Table 3.1: rational for inclusion of control variables. 


\begin{tabular}{|c|c|c|c|}
\hline Demographic & Curren & Study & Southeast (current) \\
\hline & Actual & (Valid) & \\
\hline Race & & & \\
\hline$\left(\chi^{2}=10.92 \mathrm{df}=2, \mathrm{p}<.05\right)$ & & & \\
\hline White & $33.7 \%$ & $(37.3 \%)$ & $53 \%$ \\
\hline African American & $51.4 \%$ & $(57 \%)$ & $44 \%$ \\
\hline Other & $5.1 \%$ & $(5.7 \%)$ & $3 \%$ \\
\hline Missing & $9.7 \%$ & & $0 \%$ \\
\hline Gender & & & \\
\hline$\left(\chi^{2}=7.47, \mathrm{df}=1, \mathrm{p}<.05\right)$ & & & \\
\hline Female & $30.3 \%$ & $(31.4 \%)$ & $45 \%$ \\
\hline Male & $66.3 \%$ & $(68.6 \%)$ & $55 \%$ \\
\hline Missing & $3.4 \%$ & & $0 \%$ \\
\hline Age & & & \\
\hline$\left(\chi^{2}=6.81 \mathrm{df}=3, \mathrm{p}>.05\right)$ & & & \\
\hline 30 and younger & $10.9 \%$ & $(13.2 \%)$ & $16 \%$ \\
\hline $31-40$ & $22.3 \%$ & $(28.7 \%)$ & $21.7 \%$ \\
\hline $41-50$ & $49.1 \%$ & $(35.6 \%)$ & $35.8 \%$ \\
\hline 51 and older & $17.1 \%$ & $(17.2 \%)$ & $26.8 \%$ \\
\hline Missing & $1.1 \%$ & & \\
\hline Education & & & \\
\hline$\left(\chi^{2}=54.3 \mathrm{df}=3, \mathrm{p}<.05\right)$ & & & \\
\hline Grade 9 or less & $13.1 \%$ & $(13.2 \%)$ & $28.2 \%$ \\
\hline Grade 10 or 11 & $28.6 \%$ & $(28.7 \%)$ & $56.9 \%$ \\
\hline High School Diploma & $17.7 \%$ & $(17.8 \%)$ & $3.3 \%$ \\
\hline Some College or more & $34.4 \%$ & $(35.6 \%)$ & $10.7 \%$ \\
\hline Missing & $.6 \%$ & & \\
\hline $\begin{array}{l}\text { Primary Diagnosis } \\
\left(\chi^{2}=35.44 \mathrm{df}=3, \mathrm{p}<.05\right)\end{array}$ & & & \\
\hline Schizophrenia & $30.9 \%$ & $(34 \%)$ & $27 \%$ \\
\hline Major Affective & $40 \%$ & $(44.1 \%)$ & $21.4 \%$ \\
\hline Alcohol/drug disorder & $7.4 \%$ & $(8.25)$ & $22.5 \%$ \\
\hline Other & $12.6 \%$ & $(13.8 \%)$ & $2.7 \% \%$ \\
\hline Missing & $9.1 \%$ & & \\
\hline
\end{tabular}

Table 3.2 Demographic comparison between sample of 175 and Southeast 


\begin{tabular}{|c|c|c|c|c|}
\hline \multirow[t]{2}{*}{ Demographic } & \multicolumn{2}{|c|}{ Sample size of 175} & \multicolumn{2}{|c|}{ Sample size of 160} \\
\hline & Actual & (Valid) & Actual & (Valid) \\
\hline \multicolumn{5}{|l|}{$\begin{array}{l}\text { Race } \\
\left(\chi^{2}=.209 \mathrm{df}=2, \mathrm{p}>.05\right)\end{array}$} \\
\hline White & $33.7 \%$ & $(37.3 \%)$ & $34.4 \%$ & $(38.2 \%)$ \\
\hline African American & $51.4 \%$ & $(57 \%)$ & $51.3 \%$ & $(56.9 \%)$ \\
\hline Other & $5.1 \%$ & $(5.7 \%)$ & $4.4 \%$ & $(4.9 \%)$ \\
\hline Missing & $9.7 \%$ & & $10 \%$ & \\
\hline \multicolumn{5}{|l|}{$\begin{array}{l}\text { Gender } \\
\left(\chi^{2}=.092, \mathrm{df}=1, \mathrm{p}>.05\right)\end{array}$} \\
\hline Female & $30.3 \%$ & $(31.4 \%)$ & $33.1 \%$ & $(33.1 \%)$ \\
\hline Male & $66.3 \%$ & $(68.6 \%)$ & $66.9 \%$ & $(56.9 \%)$ \\
\hline Missing & $3.4 \%$ & & 0 & \\
\hline \multicolumn{5}{|l|}{$\begin{array}{l}\text { Age } \\
\left(\chi^{2}=6.4 \mathrm{df}=3, \mathrm{p}>.05\right)\end{array}$} \\
\hline 30 and younger & $10.9 \%$ & $(13.2 \%)$ & $10.0 \%$ & $(10.1 \%)$ \\
\hline $31-40$ & $22.3 \%$ & $(28.7 \%)$ & $23.8 \%$ & $(23.9 \%)$ \\
\hline $41-50$ & $49.1 \%$ & $(35.6 \%)$ & $49.1 \%$ & $(49.2 \%)$ \\
\hline 51 and older & $17.1 \%$ & $(17.2 \%)$ & $16.9 \%$ & $(17 \%)$ \\
\hline Missing & $1.1 \%$ & & $1.1 \%$ & \\
\hline \multicolumn{5}{|l|}{$\begin{array}{l}\text { Education } \\
\left(\chi^{2}=0 \mathrm{df}=3, \mathrm{p}>.05\right)\end{array}$} \\
\hline Grade 9 or less & $13.1 \%$ & $(13.2 \%)$ & $13.1 \%$ & $(13.2 \%)$ \\
\hline Grade 10 or 11 & $28.6 \%$ & $(28.7 \%)$ & $28.6 \%$ & $(28.7 \%)$ \\
\hline High School Diploma & $17.7 \%$ & $(17.8 \%)$ & $17.7 \%$ & $(17.8 \%)$ \\
\hline Some College or more & $34.4 \%$ & $(35.6 \%)$ & $34.4 \%$ & $(35.6 \%)$ \\
\hline Missing & $.6 \%$ & & $.6 \%$ & \\
\hline \multicolumn{5}{|l|}{$\begin{array}{l}\text { Primary Diagnosis } \\
\left(\chi^{2}=16.01 \mathrm{df}=3, \mathrm{p}<.05\right)\end{array}$} \\
\hline Schizophrenia & $30.9 \%$ & $(34 \%)$ & $29.4 \%$ & $(32.0 \%)$ \\
\hline Major Affective & $40 \%$ & $(44.1 \%)$ & $24.4 \%$ & $(26.5 \%)$ \\
\hline Alcohol/drug disorder & $7.4 \%$ & $(8.25)$ & $16.3 \%$ & $(17.7)$ \\
\hline Other & $12.6 \%$ & $(13.8 \%)$ & $21.9 \%$ & $(23.8 \%)$ \\
\hline Missing & $9.1 \%$ & & $9.1 \%$ & \\
\hline
\end{tabular}

Table 3.3: demographic comparisons of the sample of 175 and the sample of 160. 


\section{CHAPTER 4}

\section{RESULTS}

Missing/unknown value analysis

Missing and unknown data frequently occur in social work research but are often not attended to researchers (Saunders et al., 2006). Missing data could serve as a potential source of measurement bias and could distort relationships between independent and dependent variables (Schafer \& Graham, 2002). The researcher first identified the extent of missing data. Next, the researcher took steps to mitigate the effects of missing data. Scales and subscales with items with missing data were eliminated from the analysis, or steps were taken to replace the missing values.

Not all participants of the study provided answers to all questions during the faceto-face interview. Participants were able to answer, "don't know," to any of the questions asked during the face-to-face interview. In addition, Southeast had incomplete data in CATT, which is the Southeast data system used to track consumer outcome data on some of their consumers. One concern over missing data is the potential for bias that may be associated with missingness (Schafer \& Graham, 2002). According to Schafer and Graham (2002), missing data can be classified as missing completely at random (MCAR), missing at random (MAR), and missing not at random (MNAR). MCAR assumes that missing values are not dependent on their values on the specific variable under investigation or some other measured variable. MAR assumes that missing values 
are not dependent on their values for the specific variable under investigation, but may depend, in part, on some other measured value. MNAR assumes that missing values are dependent on their values for the variable under consideration and on other measured variables.

Table 4.1 provides item-by-item counts and percentages of missing or unknown data. Items that comprise the self-stigma, working alliance, and quality of life variables, had relatively low levels of missing data. In most cases, less than 10 percent of respondents had missing data on an item. Two of the stigma feeling different and ashamed scale items has missing data greater than 10 percent. One item had 18.1 percent missing data and the other had 20.6 percent missing data. These two items are part of the four item stigma feelings of different and ashamed scale, which asked about negative feeling related to experiences of hospitalization. Not all participants had been hospitalized and therefore some respondents were unable to provide a response to these items. Quality of life family subscale had missing items that ranged from 10.6 percent to 11.3 percent. These items are the quality of life family relations subscale. All but one of the items of the symptom distress scale had 10.6 percent missing values. The symptom distress scale was one of the control variables collected from Southeast. Missing information from Southeast may be related to consumers' unwillingness to fill out the scale, the case manager not having turned in consumers' responses to the scale or the data entry person not having entered the data into the system (Personal communication with Richard Reynolds, February 21, 2008).

While the previous items had modest percentages of missing data, the quality of life work subscale had significant amounts of missing data. Eighty-eight percent of the 
quality of life work subscale items were missing data. These items did not have responses because 88 percent of participants identified themselves as unemployed

As suggested by Schafer and Graham (2002), missingness may be statistically related to collected data on one or more measured variables. To determine whether missing data might relate to information on one of the other measured variables, the researcher calculated the mean item scores for "devaluation and discrimination, stigma withdrawal, working alliance, quality of life, and symptom distress scales. If one item on the scale had missing information, the value for that scale was considered missing. The researcher developed another variable for devaluation and discrimination, stigma withdrawal, working alliance, quality of life, and symptom distress that was coded as 1 for missing and 0 for not missing. Using a Chi-square test for independence, the researcher investigated the extent to which missing information was related to race, gender, and psychiatric diagnosis. The null hypotheses for these tests were cases with missing values did not differ by race, gender or psychiatric diagnosis. Table 4.2 presents the results of this assessment. With the exception of working alliance and psychiatric diagnosis $\left(\chi^{2}=8.554, \mathrm{df}=3, \mathrm{p}<05\right)$, the null hypotheses for each of these comparisons were not rejected. However, missing values for the working alliance scale did differ by psychiatric diagnosis. Missing values on the working alliance scale suggest that the data were not MCAR. Evidence from the above analysis of the scales included in the analysis suggested that the distribution of missing values are conditionally MAR. 


\section{Missing/Unknown value corrections}

The researcher used two approaches for handling missing data. First, the researcher determined the extent to which an underlying process, unique to the variable, was responsible for missingness. Two groups of items were problematic. First, the stigma feelings of different and ashamed scale had two items with missing data above 10 percent. These two items were related to experiences of hospitalization. Rather than measuring stigma feelings of different and ashamed, the pattern of missing data suggested that this scale might also be measuring hospitalizations. This self-stigma scale was eliminated from the analysis, based on this concern. Likewise, the subjective quality of life work subscale contained missing data that were patterned on persons not working; 88 percent of the sample was unemployed. This scale was eliminated from the analysis, because it might also be measuring employment status and not satisfaction with work. In addition, both of these scales had items with greater than 20 percent missing data. Therefore, a rule of thumb for including variables with missing data in the analysis is that variables with missing data should have less than 20 percent missing data (Saunders et al., 2006).

One approach for replacing missing data that are MAR is a regression imputation approach. Hill (1997) states that regression imputation approaches provide a relatively unbiased estimation of missing values when data are conditionally MAR. Regression imputation approaches predict missing values using the linear combination of a set of independent, or predictor, variables. The choice of predictor variables should be based on observed statistical relationships between the predictors and the variables with missing values. In regression imputation, "(c)ases with complete date for the predictor variables 
are used to generate the regression equation; the equation is then used to predict missing values for incomplete cases" (Saunders et al., 2006). Further, the approach models prediction error by adding a random residual value to each predicated value from a randomly selected case with complete data (Hill, 1997).

The researcher replaced missing values at the item level. Using the high levels of internal consistency reliability, which is a measure of systematic variance, between items within devaluation and discrimination scale $(\alpha=.83)$, stigma withdrawal scale $(\alpha=.6)$, working alliance scale $(\alpha=.95)$, subjective quality of life scale $(\alpha=.94)$, and symptom distress scale $(\alpha=.91)$ scales, the researcher replaced missing items within each subscale using known information from all items within the subscale. The high levels of internal consistency reliability suggested the items were inter-correlated, which suggested that information on an item within a subscale was related to information on other items within the same subscale. The researcher used the power of these relationships to predict missing values. For each item, a unique regression equation was estimated using all the other items in the sub-scale as a predictors. For example, if a person had missing data on the third item from a 12-item scale, a unique regression equation for that item, which used the other 11 items as predictor variables, was used to estimate the missing value on the third item. The researcher calculated missing values for the devaluation and discrimination scale, stigma withdrawal scale, working alliance inventory, subjective quality of life scale, and the symptom distress scale. The researcher used an SPSS v 15.0 based regression imputation approach. Table 4.3 provides means and standard deviations for the estimated values. 


\section{Descriptive analysis}

The researcher calculated means and standard deviations for all of the scale level variables and percentages within each category for the nominal variables. Table 4.4 provides this descriptive information. The sample was comprised of more African Americans (51.3 percent) than all other races and more males (66.9\%) than females. A plurality of the sample had schizophrenia (29.4 percent) followed by mood disorder $(24.4$ percent). A majority of the sample did not have a secondary alcohol or other drug diagnosis (65 percent). The mean item symptom distress scale score was $2.47(\mathrm{SD}=$ .86), which was below the scale's mid-point value of four. On average, participants reported that they were not affected by symptoms. The mean item devaluation and discrimination score was $2.71(\mathrm{SD}=.46)$, which was above the mid-point value of 2.5 . On average, participants endorsed knowledge of stereotypes of persons with SMD. The mean item stigma withdrawal score was $2.79(\mathrm{SD}=.35)$, which was above the mid-point value of 2.5 for the stigma withdrawal scale. Participants endorsed using withdrawal as a stigma coping mechanism. The mean item score for the working alliance scale was 5.12 ( $\mathrm{SD}=1.49)$, which was slightly above the mid-point of four for the working alliance scale. On average, participants endorsed having a strong working alliance with their case managers. Finally, the mean item subjective quality of life scores was $4.32(\mathrm{SD}=1.09)$, which was above the mid-point value of four. On average, participants reported being satisfied with their quality of life.

Table 4.5 provides comparisons between mean values for the sample and mean values reported in the literature for devaluation and discrimination, working alliance, and subjective quality of life scales. In all cases, the means from the sample for the current 
study and the samples used in the literature were above each scale's respective mid-point. In addition, differences between the sample means for the current study and the sample means reported in the literature ranged from .01 for the stigma withdrawal scale, to .62 for the subjective quality of life scale. Descriptive findings for this study were comparable to past research.

\section{Bivariate comparisons}

The researcher explored bivariate relationships between all variables used in the analysis. First, he explored the relationships between the nominal level variables and the scale level variables. The researcher used t-tests for nominal independent variables that were comprised of two categories and one-way ANOVA tests for nominal independent variables that were comprised of more than two categories. The null hypotheses for these tests were there was no association between the nominal variables and the scale level variables. Results are summarized in table 4.6. Results indicate that the null hypotheses for each of the tests were not rejected, with the exception of the relationship between gender and stigma withdrawal $(\mathrm{t}=2.43, \mathrm{df}=152, \mathrm{p}<.05)$. Women $($ mean $=2.88, \mathrm{SD}=$ .38) typically reported higher endorsement of stigma withdrawal as a coping mechanism than did men $($ mean $=2.73, \mathrm{SD}=.33)$.

The researcher also explored the bivariate relationships among the scale level measures. The researcher used Pearson product moment correlations to explore these relationships. Table 4.7 provides the correlations between devaluation and discrimination, stigma withdrawal, working alliance, subjective quality of life, and symptom distress scales. Symptom distress was negatively associated with subjective quality of life $(\mathrm{r}=-.164, \mathrm{n}=160)$; greater symptom distress was associated with more 
negative appraisals of subjective quality of life. Symptom distress and subjective quality of life shared 2.7 percent variance, which, according to Cohen (1988), is a small effect size. Devaluation and discrimination was positively associated with stigma withdrawal (r $=.160, \mathrm{n}=160)$ and symptom distress $(\mathrm{r}=.274, \mathrm{n}=160)$; stronger endorsement of devaluation and discrimination was associated with stronger endorsement of stigma withdrawal as a coping mechanism and greater symptom distress. Devaluation and discrimination shared 2.6 percent of the variance with stigma withdrawal and 7.5 percent with symptom distress, both of which are small effect size (Cohen, 1988). Devaluation and discrimination was negatively associated with subjective quality of life $(\mathrm{r}=-.380, \mathrm{n}=$ 160). Greater endorsement of devaluation and discrimination was related to more negative perceptions of subjective quality of life. Devaluation and discrimination and subjective quality of life shared 14.4 percent variance, which is a medium effect size (Cohen, 1988). Working alliance was positively associated with subjective quality of life $(\mathrm{r}=.330, \mathrm{n}=.220)$, with stronger endorsement of a positive working alliance associated with positive perceptions of quality of life. Working alliance and subjective quality of life shared 11 percent variance, which is a medium effect size (Cohen, 1988). Relative to the primary research questions for this study, these bivariate findings suggest that devaluation and discrimination and working alliance are associated with subjective quality of life. However, these findings also suggest that stigma withdrawal is unrelated to subjective quality of life $(r=-.099, \mathrm{n}=160)$. Stigma withdrawal accounts for less than one percent of the variance in subjective quality of life. 


\section{Model building}

A fundamental rule of multilevel model building, as with other methods of statistical model building, is model parsimony (Hox, 2002). The model with the fewest number of predictor/independent variables, which explains the greatest amount of variance in the dependent variable, is better than a model with all possible predictor variables. Raudenbush and Bryk (2002) wrote:

Intuitively, there is only a fixed amount of variation to be explained. If one overfits the model by specifying too many random level-one coefficients, the variation is partitioned into many little pieces, none of which is of much significance. The problem is analogous to focusing a projector. If one moves beyond the proper range, the image loses focus. (p. 275)

Raudenbush and Bryk (2002) argue the probability of finding a significant relationship in multilevel models is partly related to the number of included predictor variables and the sample size. Adding too many predictor variables might lead to type II error, or not finding a significant relationship when a true relationship exists. The authors suggest theory and statistical considerations should govern decisions about inclusion of independent variables, including control variables, into the model.

In the interest of model parsimony, the researcher sought the smallest number of relevant control variables. The researcher used a method suggested by Early (1994). He explored the variance explained in quality of life by each individual control variable, controlling for all other potential control variables. He used hierarchical, ordinary least squares regression to assess the impact of each of the control variables on quality of life. The researcher used a two-step process. He first entered all control variables minus one control variable into a regression model. In the second step, he added the final control variable, the variable left out of the first step. The researcher interpreted the increment in 
variance explained by the added control variable in step two (the $\mathrm{R}$-squared change statistic). He kept control variables that uniquely explained one percent of the variance in subjective quality of life. According to Cohen (1988), one percent variance explained is a small effect size. The possible control variables included in the model were gender, race, psychiatric diagnosis, secondary alcohol or other drug diagnosis, and symptom distress. These potential control variables were selected based on theoretical considerations (see table3.1). Table 4.8 provides the results of this analysis.

The control variables that had at least a small effect on subjective quality of life were gender (1.5 percent variance explained), race (2.4 percent variance explained), and symptom distress (3.7 percent variance explained). The researcher entered these three control variables in models predicting quality of life to rule out these variables as alternative explanations of the relationship between the self-stigma related variables and the working alliance variable and subjective quality of life.

The analytic strategy for the second research question required working alliance to be treated as a dependent variable for one of the statistical analyses. The researcher used the same process for determining which of the control variables to include in the model predicting working alliance. Table 4.9 provides results for this analysis. The control variables that had at least a small effect on working alliance were race (one percent variance explained), psychiatric diagnosis (2.9 percent variance explained), and a secondary alcohol or other drug diagnosis (1.6 percent variance explained). The researcher included these three control variables in the model predicting working alliance in an effort to rule out these variables as alternative explanations between the independent and dependent variables. 
Two additional model-building considerations need to be presented before discussing model estimation. The first consideration is grand mean centering. Grand mean centering is used in multilevel models because the intercept is an outcome for the level-2 variables, and grand mean centering allows for the effects of level-2 variation to be interpretable (Raudenbush \& Bryk, 2002). All of the independent and control variables for each of the multilevel estimated models were grand mean centered. Grand mean centering is the linear transformation of an independent variable by subtracting from that variable the mean of the variable (Luke, 2002). Values for the newly created mean centered variable represents the difference between that value for the variable and the variables mean. The interpretation of estimated parameter coefficients also changes because of grand mean centering. The new values for the parameter coefficients are interpreted as change in the dependent variable associated with a one-unit change from the mean score of that independent variable. In addition, the intercept is interpreted as the expected value in the dependent variable, when participants have the mean value for all independent variables.

A second issue is the use of dummy coding of nominal, non-continuous, independent variables. One of the assumptions of linear forms of regression is that independent variables must be scale level of measurement (Berry, 1993). Two variables in the models predicting subjective quality of life were nominal: gender and race. Dummy coding is a mathematical fix for categorical variables and was used to transform nominal variables for analysis. "Dummy coding consists of 1's and 0's. with one signifying membership in a category under consideration and zero signifying no member in that category" (Pedhazur \& Pedhazur-Schmelkin, 1991). The number of dummy 
coded variables created for the analysis is equal to the number of categories of a particular nominal variable minus one. In dummy coding, one category of an independent nominal variable receives all zeros and this category is known as the comparison or reference group. Information on the other coded variables was compared to the reference group. For gender, the reference group was males. The gender variable used in the analysis represents the effects of being female. For race, the reference group was Caucasians. Two race variables were included in the analysis; the first was raceblack, which were persons who identified themselves as being African American, and race-other, which were persons who identified themselves as being other than Caucasian or African American.

For two of the estimated models, working alliance was treated as the dependent variable. These two models required the consideration of different control variables. The control variables for this model were race, psychiatric diagnosis, and secondary alcohol or other drug diagnosis. These three control variables were nominal in scale of measure and required dummy coding. For race, Caucasians were the reference category and raceblack and race-other were the dummy coded variables. For psychiatric diagnosis, schizophrenia was the reference category, and bipolar, depression and other diagnosis were the dummy coded variables. For secondary alcohol or other drug diagnosis, the reference category was not having a secondary diagnosis and the dummy coded variable was the presence of a secondary diagnosis. 
Statistical Analysis for research question one.

The purpose of this study was to answer two research questions. The first research question was: "To what extent do client perceptions of self-stigma related variables and the working alliance between clients and their primary ACT worker independently affect client perceptions of subjective quality of life among consumers of ACT and ACT-like services?" The researcher developed one statistical model to answer this question. The model assessed the independent effects of devaluation and discrimination, stigma withdrawal, and working alliance on subjective quality of life Multilevel model of the effects of devaluation and discrimination, stigma withdrawal and working alliance on subjective quality of life.

The first model assessed the independent effects of devaluation and discrimination, stigma withdrawal, and working alliance on quality of life, controlling for the effects of gender, race, symptom distress and case manager.

Assessing model assumptions. According to Luke (2002), it is important to test two model assumptions in a multilevel model. These assumptions are“...(a) that the level-1 (within-group) errors are independent and normally distributed with a mean of zero; and (b) that the random effects are normally distributed with a mean of zero...." (Luke, 2002, p 38). The researcher assessed each of these two assumptions. To test the assumption about the level-1 errors, the researcher used the normal quantile-quantile plot (QQ plot) (Luke, 2002). In QQ plots, data are plotted against a diagonal line. To the degree the data fall on the diagonal line, the data can be considered normally distributed. The researcher used a QQ plot to test if the level one errors were normally distributed. After inspecting the QQ-plot, the researcher determined the errors for the current model 
assessing the effects of devaluation and discrimination and working alliance on subjective quality of life were normally distributed. The research also investigated the mean residual value for the distribution of level-1 errors; the mean of the level-1 error terms was zero. The researcher determined the first model assumption was met.

There was only one random effect in the model, which was the effect of level-2 information on the intercept. The researcher assessed the degree to which random effects for the intercept were normally distributed. The researcher used a QQ-plot to assess if these level-2 variance component error terms of the intercept were normally distributed. The QQ plot suggested dramatic departures from normality. The mean of the level-2 errors was zero. Hox (2002) stated issues with normality are often associated with a miss-specified model, a model that does not include all necessary predictor variables. Residual plots are a useful tool for determining whether other predictor variables should be entered into the model. Greater departures from normality suggest the need to add more predictor variables. A limitation of this study was a lack of information about the level-2 units, case managers. The research did not have access to basic demographic information about case managers, such as level of education, years of experience, or gender. Including level-2 information might result in more normally distributed level-2 variance component errors. However, "Estimation of the fixed effects will not be biased by a failure of the normality assumption at level 2" (Raudenbush \& Bryk, 2002). The consequence of a failure of the normality assumption could affect the validity of hypothesis tests. Particular attention should be paid to the strength of the relationship between independent variables and the dependent variable. 
Intraclass correlation: variance in subjective quality of life accounted for by case managers. Table 4.10 provides statistical information for the first estimated model, which assessed the effects of devaluation and discrimination and working alliance on quality of life controlling for potential sources of confounding variance. Initial assessment of this model focused on the unconditional model, or null model. The unconditional model is a one-way random effects ANOVA and can be used to test the proportion of total variance in the dependent variable, subjective quality of life, accounted for by the level-2 units, or case managers. The statistic for the level-2 variance is the intraclass correlation (ICC). The ICC for this model was .008, which was interpreted as case managers accounted for .8 percent of the variance in subjective quality of life.

Model goodness-of-fit. The researcher used three statistics to assess model goodness-of-fit. The first model fit statistic was the deviance statistic. The deviance statistic is a transformation of the likelihood function. Arithmetically, the deviance is the natural $\log$ of the likelihood function multiplied by negative two. The deviance statistic is relative and is only interpretable when comparing two or more models. For the current analysis, the deviance statistic for the final model was calculated and compared to the unconditional model, which was the model with no predictor variables entered. The model with the lowest deviance statistic was interpreted as the better fitting model (Hox, 2002).

A second model fit statistic used in the current study was the Akaike's Information Criteria (AIC). The number of estimated parameters adversely affects the deviance statistic (Hox, 2002). As the number of estimated parameters increases, the 
deviance statistic necessarily decreases (Luke, 2002). Models with more parameters are likely to have lower deviance scores than model with fewer parameters. The AIC accounts for the number of parameters used to estimate the model by adding the deviance statistic to two times the number of estimated parameters. As with the deviance statistic, the AIC for the full model was compared to the unconditional model. The model with the lowest AIC was interpreted as the better fitting model.

The third goodness-of-fit statistic is the proportional reduction of prediction error of individual outcomes. The proportional reduction in prediction error for individual outcomes is the reduction in unexplained variance in the unconditional model explained by the addition of predictor variables in the full model (Luke, 2002).

For the model of the effects of devaluation and discrimination, stigma withdrawal and working alliance on subjective quality of life, the unconditional model, with no level1 or level-2 predictors, had a deviance of 480.94 and an AIC of 486.94. The full model, with devaluation and discrimination, working alliance and control variables entered, had a deviance of 367.97 and an AIC of 387.97. Both the deviance and the AIC are lower in the full model than in the unconditional model. These goodness-of-fit statistics suggested that the full model, with devaluation and discrimination, working alliance, and control variables included as predictors, was a better fitting model than the null model. In addition, the full model explained 27.5 percent of the unexplained variance in subjective quality of life associated with the unconditional model.

Parameter estimation. The regression coefficient, or slope, of each of the independent variables, provides information about the relationship between the independent variable and the dependent variable, controlling for all other included 
independent variables. The hypothesis test statistic for the parameters is the t-test. The null hypothesis is that each of the regression coefficients is equal zero. As table 4.9 shows, four of the independent variables were significantly related to subjective quality of life. These four independent variables were devaluation and discrimination $(\beta=-.94$, $\mathrm{t}=-4.48, \mathrm{df}=132, \mathrm{p}=.001)$, working alliance $(\beta=.12, \mathrm{t}=2.26, \mathrm{df}=132, \mathrm{p}=.025)$, raceother $(\beta=.69, \mathrm{t}=2.09, \mathrm{df}=132, \mathrm{p}=.038)$, and gender $(\beta=-.43, \mathrm{t}=-3.20, \mathrm{df}=132, \mathrm{p}=$ $.002)$. Stigma withdrawal $(\beta=-.17, \mathrm{t}=-0.63, \mathrm{df}=132, \mathrm{p}>.05)$ was unrelated to subjective quality of life. Devaluation and discrimination was negatively related to subjective quality of life. Stronger endorsement of devaluation and discrimination was associated with negative appraisals of quality of life. Working alliance was positively related to subjective quality of life. Perceptions of a strong working alliance were associated with positive appraisals of quality of life. Persons who identified with being a race other than Caucasian and African American had more positive appraisals of their quality of life than individuals who identify as being Caucasian. Finally, women had more negative appraisals of their quality of life than did men.

\section{Statistical analysis for research question two}

The second research question asked: To what extent do client perceptions of the working alliance between clients and their primary ACT worker mediate the relationship between perceptions of self-stigma related variables and client perceptions of subjective quality of life among consumers of ACT and ACT-like services? The second research question required a test of the mediating effects of working alliance. The researcher tested the mediating role of the working alliance using recommendations of Baron and 
Kenny (1986). In addition to the previous model presented, the researcher ran two additional models. The first model tested the effects of the self-stigma related variables on working alliance. The second model tested the effects of the self-stigma related variables on subjective quality of life without controlling for the working alliance variable.

Multilevel model of the effect of devaluation and discrimination and stigma withdrawal on working alliance:

The next model assessed the effects of the two self-stigma variables on working alliance.

Intraclass correlation Table 4.11 provides statistical information for the effects of devaluation and discrimination and stigma withdrawal on working alliance. The intraclass correlation for the effects of case managers on working alliance was .096. Case managers, the level- 2 unit, explained about 10 percent of the variance in working alliance. Case managers represent a significant predictor of working alliance scores.

Assessing model assumptions. The researcher assessed the model assumption that level-1 errors were normally distributed and had a mean of zero. A QQ-plot of level-1 errors showed the error terms were not normally distributed. Investigation of a histogram of the error terms revealed the error terms were negatively distributed. As Hox (2002) suggested, one explanation for issues with normality is that the model did not include enough predictor variables. Other, unmeasured variables, might better predict working alliance. Failure to include these other unmeasured variables could result in biased estimation of the fixed effects of included independent variables. 
The researcher assessed the model assumption that level-2 errors were normally distributed and had a mean of zero. The QQ plot of the level-2 variance component errors of the intercept revealed dramatic departures from normality. The mean of the variance component errors of the intercept was .098. As with the previous model, failure to include level-2 explanatory variables is a limitation of this study and is the likely cause of these departures from normality.

Model goodness-of-fit. The researcher compared the deviance and AIC statistics for the unconditional, or null, model and the model containing devaluation and discrimination, stigma withdrawal, and control variables. The deviance statistic was 579.35 and the AIC was 585.35 for the unconditional model. For the full model, the deviance statistic was 474.07 and the AIC was 496.07. The full model was a better fitting model than the unconditional model. The full model explained four percent of the unexplained variance of working alliance associated with the unconditional model.

Parameter estimation. None of the independent variables were significantly related to working alliance. Devaluation and discrimination $(\beta=-.42, \mathrm{t}=-1.43, \mathrm{df}=124$, $\mathrm{p}=.153)$ and stigma withdrawal $(\beta=-.40, \mathrm{t}=-1.21, \mathrm{df}=124, \mathrm{p}=.228)$ were not significantly related to working alliance.

Multilevel statistical model of the effects of devaluation and discrimination, and stigma withdrawal on subjective quality of life.

The next model assessed the separate effects of devaluation and discrimination and stigma withdrawal on subjective quality of life.

Assessing model assumptions The researcher assessed the degree to which level-1 errors were normally distributed and had a mean of zero. Inspection of the QQ plot of the 
level-1 errors revealed that the errors were normally distributed. The mean of the error terms was zero. The researcher also assessed the degree to which level-2 variance component errors of the intercept were normally distributed and had a mean of zero. The level-2 errors were not normally distributed. The mean of the level-2 errors was .079.

Model goodness-of-fit Table 4.12 provides statistical information for the effects of devaluation and discrimination and stigma withdrawal on subjective quality of life. The researcher compared the deviance and AIC for the unconditional and full models. The unconditional model had a deviance of 480.94 and an AIC of 486.94. The full model had a deviance statistic of 372.84 and an AIC of 390.84. The full model fit the data better than did the unconditional model. The full model explained 25.6 percent of the unexplained variance of subjective quality of life associated with the unconditional model.

Parameter estimation. Three of the independent variables were significantly related to subjective quality of life. Devaluation and discrimination $(\beta=-1.00, \mathrm{t}=-4.32$, $\mathrm{df}=132, \mathrm{p}<.001)$, race other $(\beta=.69, \mathrm{t}=2.25, \mathrm{df}=132, \mathrm{p}=.026)$, and gender $(\beta=-$ $.43, \mathrm{t}=-3.15, \mathrm{df}=132, \mathrm{p}=.001)$ were significant predictors of subjective quality of life. Stigma withdrawal $(\beta=-.21, \mathrm{t}=-0.73, \mathrm{df}=132, \mathrm{p}>.05)$ was unrelated to subjective quality of life. Devaluation and discrimination was negatively related to subjective quality of life. Individuals who endorsed devaluation and discrimination perceived their subjective quality of life more negatively. Persons who identified themselves as being neither Caucasian or African American reported more positive subjective quality of life than did Caucasians. Women had more negative evaluations of their quality of life than did men. 


\section{Summary of results}

Results from this study indicate that devaluation and discrimination and working alliance independently affect subjective quality of life of persons with SMD. Perceptions of devaluation and discrimination are negatively related to subjective quality of life, and perceptions of a working alliance were positively related to subjective quality of life. Stigma withdrawal was unrelated to subjective quality of life. In addition, neither devaluation and discrimination nor stigma withdrawal were related to working alliance. However, case managers were, themselves, a source of variation in working alliance scores. 
Tables

\begin{tabular}{|c|c|c|c|c|c|}
\hline Item & $\begin{array}{l}\text { Number } \\
\text { missing/ } \\
\text { unknown }\end{array}$ & $\begin{array}{l}\text { Percent } \\
\text { missing/ } \\
\text { unknown }\end{array}$ & Item & $\begin{array}{l}\text { Number } \\
\text { missing/ } \\
\text { unknown }\end{array}$ & $\begin{array}{l}\text { Percent } \\
\text { missing/ } \\
\text { unknown }\end{array}$ \\
\hline Stigma 1 & 5 & 3.1 & QOL 3 & 6 & 3.8 \\
\hline Stigma 2 & 2 & 1.3 & QOL 4 & 2 & 1.3 \\
\hline Stigma 3 & 9 & 5.6 & QOL 5 & 1 & .6 \\
\hline Stigma 4 & 9 & 5.6 & QOL 6 & 0 & 0 \\
\hline Stigma 5 & 3 & 1.9 & QOL 7 & 2 & 1.3 \\
\hline Stigma 6 & 5 & 3.1 & QOL 8 & 1 & .6 \\
\hline Stigma 7 & 7 & 4.4 & QOL 9 & 2 & 1.3 \\
\hline Stigma 8 & 11 & 6.9 & QOL 10 & 2 & 1.3 \\
\hline Stigma 9 & 10 & 6.3 & QOL 11 & 2 & 1.3 \\
\hline Stigma 10 & 6 & 3.8 & QOL 12 & 0 & 0 \\
\hline Stigma 11 & 5 & 3.1 & QOL 13 & 4 & 2.5 \\
\hline Stigma 12 & 8 & 5 & QOL 14 & 17 & 10.6 \\
\hline Stigma 13 & 6 & 3.8 & QOL 15 & 18 & 11.3 \\
\hline Stigma 14 & 2 & 1.3 & QOL 16 & 17 & 10.6 \\
\hline Stigma 15 & 7 & 4.4 & QOL 17 & 17 & 10.6 \\
\hline Stigma 16 & 4 & 2.5 & QOL 18 & 2 & 1.3 \\
\hline Stigma 17 & 10 & 6.3 & QOL 19 & 1 & .6 \\
\hline Stigma 18 & 4 & 2.5 & QOL 20 & 7 & 4.4 \\
\hline Stigma 19 & 4 & 2.5 & QOL 21 & 1 & .6 \\
\hline Stigma 20 & 5 & 3.1 & QOL 22 & 11 & 6.9 \\
\hline Stigma 21 & 6 & 3.8 & QOL 23 & 3 & 1.9 \\
\hline Stigma 22 & 29 & 18.1 & QOL 24 & 1 & .6 \\
\hline Stigma 23 & 6 & 3.8 & QOL 25 & 1 & .6 \\
\hline Stigma 24 & 2 & 1.3 & QOL 26 & 3 & 1.9 \\
\hline Stigma 25 & 33 & 20.6 & QOL 27 & 2 & 1.3 \\
\hline WAI 1 & 0 & 0 & QOL 28 & 142 & 0 \\
\hline WAI 2 & 3 & 1.9 & QOL 29 & 142 & 88.8 \\
\hline WAI 3 & 8 & 5 & QOL 30 & 142 & 88.8 \\
\hline WAI 4 & 5 & 3.1 & QOL 31 & 142 & 88.8 \\
\hline WAI 5 & 1 & .6 & QOL 32 & 142 & 88.8 \\
\hline WAI 6 & 1 & .6 & QOL 33 & 142 & 88.8 \\
\hline WAI 7 & 10 & 6.3 & QOL 34 & 0 & 0 \\
\hline WAI 8 & 2 & 1.3 & QOL 35 & 0 & 0 \\
\hline WAI 9 & 4 & 2.5 & QOL 36 & 0 & 0 \\
\hline WAI 10 & 3 & 1.9 & QOL 37 & 2 & 1.3 \\
\hline WAI 11 & 4 & 2.5 & QOL 38 & 4 & 2.5 \\
\hline WAI 12 & 2 & 1.3 & QOL 39 & 0 & 0 \\
\hline QOL 1 & 0 & 0 & QOL 40 & 2 & 1.3 \\
\hline QOL 2 & 1 & .6 & QOL 41 & 1 & .6 \\
\hline
\end{tabular}

Table 4.1: Missing or unknown items

Continued 
Table 4.1 Continued

\begin{tabular}{lcc}
\hline \multicolumn{1}{c}{ Item } & $\begin{array}{c}\text { Number } \\
\text { missing/ } \\
\text { unknown }\end{array}$ & $\begin{array}{c}\text { Percent } \\
\text { missing/ } \\
\text { unknown }\end{array}$ \\
\hline QOL 42 & 8 & 5 \\
QOL 43 & 1 & .6 \\
QOL 44 & 2 & 1.3 \\
QOL 45 & 0 & 0 \\
Symptom 1 & 15 & 9.4 \\
Symptom 2 & 17 & 10.6 \\
Symptom 3 & 17 & 10.6 \\
Symptom 1 & 17 & 10.6 \\
Symptom 4 & 17 & 10.6 \\
Symptom 5 & 17 & 10.6 \\
Symptom 6 & 17 & 10.6 \\
Symptom 7 & 17 & 10.6 \\
Symptom 8 & 17 & 10.6 \\
Symptom 10 & 17 & 10.6 \\
Symptom 11 & 17 & 10.6 \\
Symptom 12 & 17 & 10.6 \\
Symptom 13 & 17 & 10.6 \\
Symptom 14 & 17 & 10.6 \\
Symptom 15 & 17 & 10.6 \\
Gender & 6 & 3.6 \\
Race & 16 & 10 \\
Primary & 13 & 8.1 \\
Diagnosis & & \\
Alcohol/ & 13 & 8.1 \\
drug & & \\
Case & 0 & 0 \\
manager & & \\
\hline & &
\end{tabular}




\begin{tabular}{|c|c|}
\hline & Devaluation and discrimination \\
\hline Gender & $\chi^{2}=.02, \mathrm{df}=1, \mathrm{p}>.05$ \\
\hline Race & $\chi^{2}=1.98, \mathrm{df}=2, \mathrm{p}>.05$ \\
\hline \multirow[t]{2}{*}{ Primary diagnosis } & $\chi^{2}=.557, \mathrm{df}=2, \mathrm{p}>.05$ \\
\hline & Stigma withdrawal \\
\hline Gender & $\chi^{2}=1.2, \mathrm{df}=1, \mathrm{p}>.05$ \\
\hline Race & $\chi^{2}=.907, \mathrm{df}=2, \mathrm{p}>.05$ \\
\hline \multirow[t]{2}{*}{ Primary diagnosis } & $\chi^{2}=.989, \mathrm{df}=3 \mathrm{p}>.05$ \\
\hline & Working alliance \\
\hline Gender & $\chi^{2}=.015, \mathrm{df}=1, \mathrm{p}>.05 \backslash$ \\
\hline Race & $\chi^{2}=1.099, \mathrm{df}=2, \mathrm{p}>.05$ \\
\hline \multirow[t]{2}{*}{ Primary diagnosis } & $\chi^{2}=8.554$, df $=3, p</ 05$ \\
\hline & Quality of life \\
\hline Gender & $\chi^{2}=.044, \mathrm{df}=1, p>.05$ \\
\hline Race & $\chi^{2}=.594, \mathrm{df}=2, \mathrm{P}>.05$ \\
\hline \multirow[t]{2}{*}{ Primary diagnosis } & $\chi^{2}=.399, \mathrm{df}=3, \mathrm{P}>.05$ \\
\hline & $\underline{\text { Symptom distress }}$ \\
\hline Gender & $\chi^{2}=.144, \mathrm{df}=1, p>.05$ \\
\hline Race & $\chi^{2}=.419, \mathrm{df}=2, \mathrm{P}>.05$ \\
\hline Primary diagnosis & $\chi^{2}=.3, \mathrm{df}=3, \mathrm{P}>.05$ \\
\hline
\end{tabular}

Table 4.2 Differences in missing values by gender, race, and primary diagnosis 


\begin{tabular}{|c|c|}
\hline & $\begin{array}{l}\text { Regression means and standard deviations } \\
\text { for estimated values }\end{array}$ \\
\hline \multicolumn{2}{|c|}{ Devaluation and discrimination } \\
\hline Stigma 1 & Mean $=2.42, \mathrm{SD}=.88$ \\
\hline Stigma 2 & Mean $=2.43, \mathrm{SD}=.84$ \\
\hline Stigma 3 & Mean $=2.28, \mathrm{SD}=.71$ \\
\hline Stigma 4 & Mean $=2.08, \mathrm{SD}=.78$ \\
\hline Stigma 5 & Mean $=2.51, \mathrm{SD}=.82$ \\
\hline Stigma 6 & Mean $=3.02, \mathrm{SD}=.72$ \\
\hline Stigma 7 & Mean $=2.88, \mathrm{SD}=.72$ \\
\hline Stigma 8 & Mean $=2.64, \mathrm{SD}=.77$ \\
\hline Stigma 9 & Mean $=2.88, \mathrm{SD}=.69$ \\
\hline Stigma 10 & Mean $=2.33, \mathrm{SD}=83$ \\
\hline Stigma 11 & Mean $=2.72, \mathrm{SD}=.86$ \\
\hline Stigma 12 & Mean $=2.83, \mathrm{SD}=.67$ \\
\hline \multicolumn{2}{|c|}{ Stigma withdrawal } \\
\hline Stigma 13 & Mean $=2.59, \mathrm{SD}=.81$ \\
\hline Stigma 14 & Mean $=2.86, \mathrm{SD}=.74$ \\
\hline Stigma 15 & Mean $=2.78, \mathrm{SD}=.74$ \\
\hline Stigma 16 & Mean $=2.80, \mathrm{SD}=.78$ \\
\hline Stigma 17 & Mean $=2.76, \mathrm{SD}=.70$ \\
\hline Stigma 18 & Mean $=2.65, \mathrm{SD}=.72$ \\
\hline Stigma 19 & Mean $=2.83, \mathrm{SD}=.61$ \\
\hline Stigma 20 & Mean $=2.99, \mathrm{SD}=.74$ \\
\hline Stigma 21 & Mean $=2.81, \mathrm{SD}=.90$ \\
\hline \multicolumn{2}{|c|}{ Working Alliance Inventory } \\
\hline WAI 1 & Mean $=5.19, \mathrm{SD}=1.73$ \\
\hline WAI 2 & Mean $=4.67, \mathrm{SD}=1.83$ \\
\hline WAI 3 & Mean $=5.37, \mathrm{SD}=1.89$ \\
\hline WAI 4 & Mean $=2.86, \mathrm{SD}=1.79$ \\
\hline WAI 5 & Mean $=5.43, \mathrm{SD}=1.87$ \\
\hline WAI 6 & Mean $=5.29, \mathrm{SD}=1.88$ \\
\hline WAI 7 & Mean $=5.18, \mathrm{SD}=1.97$ \\
\hline WAI 8 & Mean $=5.29, \mathrm{SD}=1.86$ \\
\hline WAI 9 & Mean $=5.25, \mathrm{SD}=1.95$ \\
\hline WAI 10 & Mean $=3.45, \mathrm{SD}=1.87$ \\
\hline WAI 11 & Mean $=5.09, \mathrm{SD}=1.88$ \\
\hline WAI 12 & Mean $=5.12, \mathrm{SD}=1.93$ \\
\hline
\end{tabular}

Table 4.3 Multiple imputation regression values used to replace unknown values continued 
Regression means and standard deviations for estimated values

\section{Quality of life}

QOL 1

QOL 2

QOL 3

QOL 4

QOL 5

QOL 6

QOL 7

QOL 8

QOL 9

QOL 10

QOL 11

QOL 12

QOL 13

QOL 14

QOL 15

QOL 16

QOL 17

QOL 18

QOL 19

QOL 20

QOL 21

QOL 22

QOL 23

QOL 24

QOL 25

QOL 26

QOL 27

QOL 28

QOL 29

QOL 30

QOL 31

QOL 32

QOL 33

QOL 34

QOL 35

QOL 36

QOL 37

QOL 38

QOL 39

Mean $=4.24, \mathrm{SD}=1.74$
Mean $=4.15, \mathrm{SD}=2.07$
Mean $=4.93, \mathrm{SD}=1.97$
Mean $=4.83, \mathrm{SD}=1.81$
Mean $=4.59, \mathrm{SD}=2.11$
Mean $=5.15, \mathrm{SD}=1.93$
Mean $=3.83, \mathrm{SD}=2.24$
Mean $=4.33, \mathrm{SD}=1.80$
Mean $=4.58, \mathrm{SD}=1.73$
Mean $=4.75, \mathrm{SD}=1.73$
Mean $=4.58, \mathrm{SD}=1.83$
Mean $=4.44, \mathrm{SD}=1.89$
Mean $=4.84, \mathrm{SD}=1.85$
Mean $=4.61, \mathrm{SD}=2.07$
Mean $=3.97, \mathrm{SD}=2.03$
Mean $=4.00, \mathrm{SD}=2.10$
Mean $=4.07, \mathrm{SD}=2.10$
Mean $=4.53, \mathrm{SD}=1.60$
Mean $=4.49, \mathrm{SD}=1.62$
Mean $=4.50, \mathrm{SD}=1.59$
Mean $=4.89, \mathrm{SD}=1.69$
Mean $=4.61, \mathrm{SD}=1.75$
Mean $=4.16, \mathrm{SD}=1.82$
Mean $=2.94, \mathrm{SD}=2.01$
Mean $=3.21, \mathrm{SD}=2.03$
Mean $=2.88, \mathrm{SD}=1.90$
Mean $=2.87, \mathrm{SD}=1.95$
Mean $=4.89, \mathrm{SD}=1.73$
Mean $=4.54, \mathrm{SD}=1.87$
Mean $=4.78, \mathrm{SD}=1.76$
Mean $=4.33, \mathrm{SD}=1.96$
Mean $=4.44, \mathrm{SD}=1.90$
Mean $=4.09, \mathrm{SD}=1.75$
Mean $=4.72, \mathrm{SD}=1.84$
Mean $=4.51, \mathrm{SD}=1.87$
Mean $=4.57, \mathrm{SD}=1.79$
Mean $=4.08, \mathrm{SD}=1.83$
Mean $=4.03, \mathrm{SD}=1.89$
Mean $=4.39, \mathrm{SD}=1.84$

Table 4.3 Continued 
Table 4.3 Continued

Regression means and standard deviations for estimated values

Symptom distress

Symptom 1

Symptom 2

Symptom 3

Symptom 4

Symptom 5

Symptom 6

Symptom 7

Symptom 8

Symptom 9

Symptom 10

Symptom 11

Symptom 12

Symptom 13

Symptom 14

Mean $=2.79, \mathrm{SD}=1.29$

Mean $=2.30, \mathrm{SD}=1.21$

Mean $=2.33, \mathrm{SD}=1.20$

Mean $=2.70, \mathrm{SD}=1.17$

Mean $=2.13, \mathrm{SD}=1.16$

Mean $=2.78, \mathrm{SD}=1.20$

Mean $=2.09, \mathrm{SD}=1.15$

Mean $=1.79, \mathrm{SD}=1.11$

Mean $=2.52, \mathrm{SD}=1.33$

Mean $=2.73, \mathrm{SD}=1.28$

Mean $=2.42, \mathrm{SD}=1.27$

Mean $=2.84, \mathrm{SD}=1.30$

Mean $=3.03, \mathrm{SD}=1.41$

Mean $=2.62, \mathrm{SD}=1.37$

Symptom 15

Mean $=2.01, \mathrm{SD}=1.23$ 
Race

$\begin{array}{rc}\text { White } & 34.4 \% \\ \text { African American } & 51.3 \% \\ \text { Other } & 4.4 \% \\ \text { Missing } & 10 \%\end{array}$

Gender

$\begin{array}{rc}\text { Female } & 33.1 \% \\ \text { Male } & 66.9 \% \\ \text { Missing } & 0\end{array}$

Primary Diagnosis
Schizophrenia
$29.4 \%$
Major Affective
$24.4 \%$
Alcohol/drug disorder
$16.3 \%$
$21.9 \%$
Missing
$9.1 \%$

Secondary Diagnosis of Alcohol or Other

Drug Abuse or Dependency

$\begin{array}{rr}\text { Yes } & 25 \% \\ \text { No } & 65 \% \\ \text { Missing } & 10 \%\end{array}$

Symptom distress

Devaluation and Discrimination

Stigma Withdrawal

Working Alliance

Subjective Quality of Life

$$
\begin{gathered}
\text { Mean }=2.47, \mathrm{SD}=.86 \\
\text { Mean }=2.71 \mathrm{SD}=.46 \\
\text { Mean }=2.79 \mathrm{SD}=.35 \\
\text { Mean }=5.12 \mathrm{SD}=1.49 \\
\text { Mean }=4.32, \mathrm{SD}=1.09
\end{gathered}
$$

Table 4.4: Descriptive statistics for all variables included in the study 
Stigma scales:

Devaluation and discrimination scale

Stigma withdrawal

Working alliance:

Working alliance

Quality of life scale:

QOL: Total
Current study

$\bar{x}=2.71$

$\bar{x}=2.79$

Current

$\bar{x}=5.12$

Current

$\bar{x}=4.3$
Link et al. (2002)

$\bar{x}=2.8$

$\bar{x}=2.8$

Goldberg et al.

(2004)

$\bar{x}=5.45$

Lehman et al.

(1986)

$\bar{x}=4.75$

Table 4.5. Comparison of mean and standard deviation between current sample and past samples 
Gender

Secondary Diagnosis of Alcohol and other

drug

Primary Diagnosis

Race

Gender

Secondary Diagnosis of Alcohol and other

drug

Primary Diagnosis

Race

Gender

Secondary Diagnosis of Alcohol and other drug

Primary Diagnosis

Race

Gender

Secondary Diagnosis of Alcohol and other

drug

Primary Diagnosis

Race

Gender

Secondary Diagnosis of Alcohol and other

drug

Primary diagnosis

Race
Devaluation and Discrimination

$\mathrm{t}=1.28, \mathrm{df}=152, \mathrm{p}>.05$

$\mathrm{t}=-1.74, \mathrm{df}=145, \mathrm{p}>.05$

$\mathrm{F}=.52, \mathrm{df}=3,143, \mathrm{p}>.05$

$\mathrm{F}=.42$, df $2,141, \mathrm{p}>.05$

$\underline{\text { Stigma Withdrawal }}$

$\mathrm{t}=2.43, \mathrm{df}=152, \mathrm{p}<.05$

$\mathrm{t}=-.99, \mathrm{df}=145, \mathrm{p}>.05$

$\mathrm{F}=1.70, \mathrm{df}=3,143, \mathrm{p}>.05$

$\mathrm{F}=.07, \mathrm{df} 2,141, \mathrm{p}>.05$

Working alliance

$\mathrm{t}=-.30, \mathrm{df}=152, \mathrm{p}>.05$

$\mathrm{t}=1.39, \mathrm{df}=145, \mathrm{p}>.05$

$\mathrm{F}=.91, \mathrm{df}=3,143, \mathrm{p}>.05$

$\mathrm{F}=.90$, df $2,141, \mathrm{p}>.05$

Subjective Quality of life

$\mathrm{t}=1.05, \mathrm{df}=152, \mathrm{p}>.05$

$\mathrm{t}=1.16, \mathrm{df}=145, \mathrm{p}>.05$

$\mathrm{F}=.088, \mathrm{df}=3,143, \mathrm{p}>.05$

$\mathrm{F}=1.20$, df $2,141, \mathrm{p}>.05$

$\underline{\text { Symptom distress }}$

$\mathrm{t}=1.20, \mathrm{df}=152, \mathrm{p}>.05$

$\mathrm{t}=-1.07, \mathrm{df}=145, \mathrm{p}>.05$

$\mathrm{F}=.23, \mathrm{df}=3,143, \mathrm{p}>.05$

$\mathrm{F}=1.09$, df $2,141, \mathrm{p}>.05$

Table 4.6: t-test and ANOVA comparisons 


\begin{tabular}{|c|c|c|c|c|c|}
\hline & $\begin{array}{l}\text { Devaluation } \\
\text { Discrimination }\end{array}$ & $\begin{array}{l}\text { Stigma } \\
\text { Withdrawal }\end{array}$ & $\begin{array}{l}\text { Working } \\
\text { Alliance }\end{array}$ & $\begin{array}{l}\text { Quality of } \\
\text { Life }\end{array}$ & $\begin{array}{l}\text { Symptom } \\
\text { distress }\end{array}$ \\
\hline $\begin{array}{l}\text { Devaluation } \\
\text { Discrimination }\end{array}$ & 1 & $.160 *$ & -.152 & $-.380 *$ & $.274 *$ \\
\hline $\begin{array}{l}\text { Stigma } \\
\text { Withdrawal }\end{array}$ & & 1 & -.072 & -.099 & -.106 \\
\hline $\begin{array}{l}\text { Working } \\
\text { Alliance }\end{array}$ & & & 1 & $.220 *$ & -.003 \\
\hline $\begin{array}{l}\text { Quality of Life } \\
\text { Symptom } \\
\text { distress }\end{array}$ & & & & & 1 \\
\hline$* \mathrm{p}<.05$ & & & & & \\
\hline
\end{tabular}

Table 4.7: Bi-variate Correlations $(\mathrm{n}=160)$

\begin{tabular}{ll}
\hline Control Variables & Change in R-squared \\
\hline Gender & .015 \\
Race & .024 \\
Diagnosis & .001 \\
Secondary diagnosis of Alcohol or other & \\
drug abuse or dependence & .006 \\
Symptom distress & .037 \\
\hline
\end{tabular}

Table 4.8: Regression of subjective quality of life on control variables

\begin{tabular}{ll}
\hline Control Variables & Change in R-squared \\
\hline Gender & .009 \\
Race & .01 \\
Diagnosis & .029 \\
Secondary diagnosis of Alcohol or other & .016 \\
drug abuse or dependence & \\
Symptom distress & .001 \\
\hline
\end{tabular}

Table 4.9 Regression of working alliance on control variables 


\begin{tabular}{l|lllll}
\hline & $\begin{array}{l}\text { Parameter } \\
\text { estimate }\end{array}$ & $\mathrm{SE}$ & $\mathrm{t}$ & $\mathrm{df}$ & P-value \\
\hline Intercept & 4.30 & 0.09 & 46.32 & 47 & $<.001$ \\
$\begin{array}{l}\text { Devaluation and } \\
\text { discrimination }\end{array}$ & -0.94 & 0.20 & -4.48 & 132 & $<.001$ \\
Stigma withdrawal & -0.17 & 0.27 & -0.63 & 132 & .528 \\
Working alliance & 0.12 & 0.05 & 2.26 & 132 & .025 \\
Race-Black & 0.05 & 0.16 & 0.32 & 132 & .749 \\
Race-Other & 0.69 & 0.33 & 2.09 & 132 & .038 \\
Gender-Female & -.43 & 0.13 & -3.20 & 132 & .002 \\
Symptom distress & -0.15 & 0.09 & -1.58 & 132 & .115 \\
\hline Fully unconditionat
\end{tabular}

Fully unconditional model without predictor variables

\begin{tabular}{ll} 
Level one variance & 1.182 \\
Level two variance & .001 \\
Total Variance & 1.183 \\
Intraclass correlation & .0008 \\
Number of parameters & 3 \\
Deviance & 480.94 \\
AIC & 486.94 \\
\hline Final estimated model with predictor variables \\
\hline Level one variance & 0.731 \\
Level two variance & 0.127 \\
Total variance & 0.858 \\
Number of parameters & 10 \\
Deviance & 367.97 \\
AIC & 387.97 \\
Proportional reduction in error & $27.5 \%$ \\
\hline
\end{tabular}

Table 4.10: final estimation for multilevel model of the effects of devaluation and discrimination, stigma withdrawal, working alliance on quality of life, controlling for demographic information and case managers 


\begin{tabular}{|c|c|c|c|c|c|}
\hline & $\begin{array}{l}\text { Parameter } \\
\text { estimate }\end{array}$ & $\mathrm{SE}$ & $\mathrm{t}$ & $\mathrm{df}$ & p-value \\
\hline Intercept & 5.11 & 0.12 & 39.53 & 47 & $<.001$ \\
\hline $\begin{array}{l}\text { Devaluation and } \\
\text { discrimination }\end{array}$ & -0.42 & 0.29 & -1.43 & 123 & .153 \\
\hline Stigma withdrawal & -0.40 & 0.33 & -1.21 & 123 & .228 \\
\hline Race-Black & 0.31 & 0.26 & 1.21 & 123 & .229 \\
\hline Race-Other & -0.21 & 0.26 & -.027 & 123 & .784 \\
\hline Diagnosis: Bipolar & 0.32 & 0.32 & 1.00 & 123 & .321 \\
\hline Diagnosis: Depression & 0.69 & 0.37 & 1.88 & 123 & .062 \\
\hline Diagnosis: Other & 0.38 & 0.33 & 1.15 & 123 & .252 \\
\hline $\begin{array}{l}\text { Alcohol/Drug secondary } \\
\text { (yes) }\end{array}$ & -2.27 & 0.26 & -1.00 & 123 & .319 \\
\hline \multicolumn{6}{|c|}{ Fully unconditional model without predictor variables } \\
\hline \multicolumn{6}{|c|}{ Level one variance $\quad 2.001$} \\
\hline \multicolumn{2}{|l|}{ Level two variance } & \multicolumn{2}{|c|}{0.213} & & \\
\hline \multicolumn{2}{|l|}{ Total Variance } & \multicolumn{2}{|r|}{2.214} & & \\
\hline \multicolumn{2}{|l|}{ Intraclass correlation } & \multicolumn{2}{|r|}{.096} & & \\
\hline \multicolumn{2}{|l|}{ Number of parameters } & \multicolumn{2}{|r|}{3} & & \\
\hline \multicolumn{2}{|l|}{ Deviance } & \multicolumn{2}{|r|}{579.35} & & \\
\hline \multicolumn{2}{|l|}{ AIC } & \multicolumn{2}{|r|}{585.35} & & \\
\hline \multicolumn{6}{|c|}{ Final estimated model with predictor variables } \\
\hline \multicolumn{2}{|c|}{ Level one variance } & \multicolumn{2}{|c|}{2.081} & & \\
\hline \multicolumn{2}{|l|}{ Level two variance } & \multicolumn{2}{|r|}{0.045} & & \\
\hline \multicolumn{2}{|l|}{ Total variance } & \multicolumn{2}{|r|}{2.126} & & \\
\hline \multicolumn{2}{|l|}{ Number of parameters } & \multicolumn{2}{|r|}{11} & & \\
\hline \multicolumn{2}{|l|}{ Deviance } & \multicolumn{2}{|r|}{474.07} & & \\
\hline \multicolumn{2}{|c|}{$\mathrm{AIC}$} & \multicolumn{2}{|r|}{496.07} & & \\
\hline \multicolumn{2}{|c|}{ Proportional reduction in error } & \multicolumn{2}{|r|}{$4 \%$} & & \\
\hline
\end{tabular}

Table 4.11: final estimation for multilevel model of the effects of devaluation and discrimination, and stigma withdrawal, on working alliance controlling for demographic variables and case manager 


\begin{tabular}{|c|c|c|c|c|c|}
\hline & $\begin{array}{l}\text { Parameter } \\
\text { estimate }\end{array}$ & $\mathrm{SE}$ & $\mathrm{t}$ & df & P-value \\
\hline Intercept & 4.29 & 0.09 & 46.32 & 47 & $<.001$ \\
\hline $\begin{array}{l}\text { Devaluation and } \\
\text { discrimination }\end{array}$ & -1.00 & 0.23 & -4.32 & 132 & $<.001$ \\
\hline Stigma withdrawal & -0.21 & 0.28 & -0.73 & 132 & .464 \\
\hline Race-Black & 0.09 & 0.17 & 0.53 & 132 & .591 \\
\hline Race-Other & 0.69 & 0.31 & 2.25 & 132 & .026 \\
\hline Gender-Female & -0.43 & 0.14 & -3.15 & 132 & .001 \\
\hline Symptom distress & -0.14 & 0.10 & -1.40 & 132 & .163 \\
\hline \multicolumn{6}{|c|}{ Fully unconditional model without predictor variables } \\
\hline \multicolumn{6}{|c|}{ Level one variance $\quad 1.182$} \\
\hline \multicolumn{2}{|c|}{ Level two variance } & \multicolumn{2}{|c|}{.001} & & \\
\hline \multicolumn{2}{|l|}{ Total Variance } & \multicolumn{2}{|c|}{1.183} & & \\
\hline \multicolumn{2}{|l|}{ Intraclass correlation } & \multicolumn{2}{|c|}{.0008} & & \\
\hline \multicolumn{2}{|l|}{ Number of parameters } & \multicolumn{2}{|c|}{3} & & \\
\hline \multicolumn{2}{|l|}{ Deviance } & \multicolumn{2}{|c|}{480.94} & & \\
\hline \multicolumn{2}{|c|}{$\mathrm{AIC}$} & \multicolumn{2}{|c|}{486.94} & & \\
\hline \multicolumn{6}{|c|}{ Final estimated model with predictor variables } \\
\hline \multicolumn{2}{|c|}{ Level one variance } & \multicolumn{2}{|c|}{0.770} & & \\
\hline \multicolumn{2}{|l|}{ Level two variance } & \multicolumn{2}{|c|}{0.110} & & \\
\hline \multicolumn{2}{|l|}{ Total variance } & \multicolumn{2}{|c|}{0.880} & & \\
\hline \multicolumn{2}{|l|}{ Number of parameters } & \multicolumn{2}{|c|}{9} & & \\
\hline \multicolumn{2}{|l|}{ Deviance } & \multicolumn{2}{|c|}{372.84} & & \\
\hline \multicolumn{2}{|l|}{$\mathrm{AIC}$} & \multicolumn{2}{|c|}{390.84} & & \\
\hline \multicolumn{2}{|c|}{ Proportional reduction in error } & \multicolumn{2}{|c|}{$25.6 \%$} & & \\
\hline
\end{tabular}

Table 4.12: final estimation for multilevel model of the effects of devaluation and discrimination, and stigma withdrawal, on quality of life, controlling for demographic information and case managers 


\title{
CHAPTER 5
}

\section{CONCLUSIONS}

\author{
Study Limitations
}

This study's research design, including measurement and sample recruitment, had a number of limitations. One limitation was the recruitment method used to select participants for this study. The researcher used a convenience sampling procedure to recruit subjects. Convenience sampling methods are associated with a strong possibility that those who volunteered to participate differed appreciably from those who did not (Kazdin, 2003). Comparisons between the sample used in this study and the population of persons receiving case management services at Southeast (table 3.2) suggest that the sample was different from the population on known information. A limitation of convenience sampling designs is an inability to draw statistically valid inferences from the data back to the population (Pedhazur and Pedhazur-Schmelkin, 1991). Finding from this study cannot be generalized beyond study participants. The potential utility of the findings from this study is hampered by the lack of generalizability of the findings to the broader population of persons receiving community mental health case management. However, this study sets the groundwork for future research on the relationships between self-stigma related variables, working alliance, and subjective quality of life, and provides a tentative model for understanding these relationships. 
A further limitation was the statistical power to detect true relationships between the independent and dependent variables. Initially, the researcher set the desired sample size to 175 participants based on the power to detect a two percent variance explained in the subjective quality of life by the combined effect of the independent variables. The researcher set the initial sample size based on ordinary least square regression. The researcher had an initial and valid sample of 175 participants. This sample was later reduced to 160 participants based on additional analytic concerns.

However, the researcher used a different statistical strategy than ordinary least squares regression. He used multilevel modeling because it became clear that case managers could be related to consumers' perceptions of subjective quality of life. The inclusion of case managers resulted in a nested data structure. Multilevel modeling provides an ecologically sound method for estimating parameters in situations where the data are nested (Luke, 2002).

Determining the statistical power for multilevel models required some additional considerations compared to determining statistical power for single-level ordinary least square models. In addition to specifying the probability of making a type one error, the effect size, and desired statistical power, the researcher needed to consider the sample size at level-2 and the intraclass-correlation, which is the amount of variance in the dependent variable accounted for by the level-2 sample (Hox, 2002). The researcher recalculated the needed sample size for a statistical power of .8 based on a level-2 sample size of 50, the probability of making a type one error of .05 , small standardized effect size of $\mathrm{d}=.2$ for each of the parameter estimates, and an inter-class correlation of .10 . According to Hox (2002), the required level-1 sample size was 312. The level-1 sample 
size, or consumers, used in this study $(\mathrm{n}=160)$ was far less than the 312 necessary to achieve the desired statistical power for multilevel modeling.

In the current study, the lack of statistical power suggests a greater probability of type II error, or the probability of not finding a statistical relationship between variables in a sample when a true relationship exists in the population from which the sample was drawn. Reduced statistical power might that mean some of the independent variables found to be unrelated to the dependent variables were truly related in the population. For example, the model of the effects of devaluation and discrimination, stigma withdrawal, and control variables on working alliance found that devaluation and discrimination was statistically unrelated to working alliance $(\beta=-.42, \mathrm{t}=-1.43, \mathrm{df}=124, \mathrm{p}=.153)$. This lack of a statistically significant association between devaluation and discrimination and working alliance could result from low statistical power to find a statistical relationship between working alliance and devaluation and discrimination.

Another design limitation was recruitment of the level-2 units, or case managers. Initially, the researcher planned to use case managers to recruit subjects, by having all case managers for each of the case management teams hand out the research questionnaire to clients and having clients return the instrument through United States Postal Service back to the researcher. However, the staff at the research site voiced concerns about using case managers to recruit subjects. As a result, the researcher could only recruit clients of Southeast and could not recruit case managers. Case managers represented in the study were included based on their clients' participation in the study. The researcher did not sample or recruit case managers for this study. As with consumer participants, the generalizability of findings about case manager effects was limited to the 
case managers who were included in the study because of their consumers participation in the study.

A related limitation was the lack of available demographic and other information about case managers. Information about case managers, including academic degree received and length of time as a case manager, might have illuminated some of the unexplained variance in subjective quality of life. Inspection of the QQ plots of the level2 variance component errors of the intercept suggest that the variance components were not randomly distributed. The lack of normally distributed variance component error terms suggested an under fit model at level-2 (Hox, 2002). Inclusion of information about case managers might have accounted for level-2 unexplained variance in subjective quality of life, which was .8 percent. Failure to include information about case managers was also a problem for the model that explored the effects of devaluation and discrimination and stigma withdrawal on working alliance. The unexplained variance in working alliance explained by case managers was about 10 percent $(\mathrm{ICC}=.098)$. The addition of information about each case manager could explain this unexplained variance associated with working alliance.

Another limitation of this study was the lack of inclusion of other extraneous variables that might have clarified some of the unexplained variance in subjective quality of life. The multilevel model of the effects of devaluation and discrimination, stigma withdrawal, working alliance, and control variables on subjective quality of life (see table 4.9) explained 27.5 percent of the variance in subjective quality of life associated with the null model. About 73 percent of the variance associated with the null model remained unexplained. Other, unmeasured variables, such as stereotypes associated with an 
alcohol or other drug diagnosis or homelessness, might have accounted for the unexplained variance in subjective quality of life.

The use of a cross sectional design, which is a non-experimental design, was a further limitation of this study. Cross-sectional designs do not allow causal inferences about the relationships between variables to be established. In order to establish causation, the research needs to: a) show that the independent variable precedes the dependent variables in time; b) show that the independent variables and the dependent variables are correlated; and c) show that no other rival hypotheses are tenable. Crosssection designs do not allow for time ordering of the independent and dependent variables. Pedhazur and Pedhazur-Schmelkin (1991) stated that the difference between experimental and non-experimental studies in terms of inferences made about the findings is demonstrated by the difference between explanation and prediction. For experimental designs, the researcher, by manipulating levels of the independent variable, is able to establish the time ordering of the independent and dependent variables. Experimental designs allow for explanatory interpretations of the findings. In contrast, the researcher did not control levels of the independent variables in cross-sectional designs. Thus, the researcher could make no claims about the time ordering of independent and dependent variables. Interpretation of findings from cross-sectional designs was limited to prediction. While the theory used in the current study suggested that perceptions of devaluation and discrimination, stigma withdrawal, and working alliance would affect perceptions of subjective quality of life, the opposite might also be plausible. Perceptions of subjective quality of life may affect perceptions of devaluation and discrimination, stigma withdrawal, and/or working alliance. Theory may suggest the 
time ordering of independent and dependent variables, but cross-sectional designs do not permit sorting out time ordering of effects.

A further set of research design limitations is associated with measurement error. One measurement error issue is linked to the potential for consumers to answer questions in a socially desirable way (Kazdin, 2003). While potentially problematic for all collected information, the social desirability limitation might have been particularly troublesome for working alliance scale. While the researcher explained to all participants that he was not an employee of Southeast, and stressed that each participant's answers to the research questions would be kept confidential, participants might have believed that their answers to the working alliance questions would be reported back to Southeast and to their case manager. Participants might have answered working alliance scale questions differently had they not feared that their results would revealed know to their case manager or to Southeast. This social desirability limitation, which could result in biased measurement, might have compromised the strength and direction of observed relationships.

Another measurement limitation was the use of secondary data for the control variables. The researcher collected data on the control variables from consumer recorders electronically warehoused at Southeast. Data on some of the control variables could have been collected a year before the face-to-face interview. Data collected on these control variables may have been no longer have been valid when data on the self-stigma related variables, working alliance variable, and subjective quality of life variable were collected. This was particularly a problem for the symptom distress scale. Unlike the demographic control variables, scores on the symptom distress scale were likely to change over time. 
Therefore, consumers may have been more or less symptomatic on the day of the interview than they were the day Southeast collected their information. As a result, any finding related to symptom distress could have been biased and could have consequently biased the estimation of the effects of other independent variables.

Finally, Pedhazur and Pedhazur and Schmelkin (1991) argue that the process of question ordering can present a limitation of research design. The researcher did not vary the ordering of the scales during the face-to-face interview. The working alliance scale was the only measured scale that assessed an aspect of services received from Southeast. The researcher worried that starting with working alliance questions might have scared respondents into believing that their responses would get back to Southeast. As a result, the researcher worried that respondents might have biased their answers to show a stronger working alliance, or might have terminated the interview early. Therefore, the interviewer first asked participants questions from the self-stigma related variables scales. Next, the interviewer asked questions from the working alliance scale. Finally, the interviewer asked questions from the subjective quality of life scale. Questions from the self-stigma scales may have influenced respondents' answers to the other scales. The self-stigma scales ask questions that have a negative connotation. Respondents' answers to the self-stigma questions, which were the first set of questions asked by the interviewer, may have resulted in respondents answering questions for the other scales more negatively.

\section{Conclusions: Research question one.}

The first research question required a test of the independent effects of the selfstigma related variables and the working alliance variable on subjective quality of life. 
The researcher developed one multilevel model to answer this research question. The first model assessed the independent effects of devaluation and discrimination $(\beta=-.94$, $\mathrm{t}=-4.48, \mathrm{df}=132, \mathrm{p}=.001)$, stigma withdrawal $(\beta=-.17, \mathrm{t}=-0.63, \mathrm{df}=132, \mathrm{p}>.05)$, and working alliance $(\beta=.12, \mathrm{t}=2.26, \mathrm{df}=132, \mathrm{p}=.025)$ on quality of life. Table 4.9 provides a summary of findings for this model. Results indicated perceptions of devaluation and discrimination and working alliance independently affected subjective quality of life. However, stigma withdrawal was unrelated to subjective quality of life. Perceptions of devaluation and discrimination seemed to be a barrier to positive appraisals of quality of life. Persons who hold greater beliefs that the society devalues and discriminates against persons with a SMD had negative appraisals of their subjective quality of life. In contrast, working alliance seemed to be catalysis for positive appraisals of quality of lie. Stronger working alliances were associated with positive perceptions of subjective quality of life. Both working alliance and devaluation and discrimination have statistically significant and opposite effects on subjective quality of life. Combined, working alliance, devaluation and discrimination, stigma withdrawal, and control variables accounted for 27.5 percent of the unexplained variance of the model with only case managers included as an independent variables.

The estimated model of the effects of self-stigma related variables and working alliance on subjective quality of life provides mixed support for the independent effects of self-stigma and working alliance on subjective quality of life. The known stereotypes of SMD, which the devaluation and discrimination scale measured, and working alliance were independent predictors of subjective quality of life. However, stigma withdrawal, which is a measure of the degree to which individuals do not interact with members of 
the public and interact with others with SMD, was not related to subjective quality of life. The findings support the conclusion that devaluation and discrimination and working alliance independently and oppositely affect subjective quality of life.

Conclusions: research question two

The second research question was a test of the mediating role of working alliance between the self-stigma related variables and subjective quality of life. This research question required the researcher to estimate two additional multilevel models. The first model assessed the effects of the self-stigma related variables on working alliance. One criterion for the establishment of mediation effects is that the independent variables, devaluation and discrimination and stigma withdrawal, must be related to the mediating variable, working alliance (Baron and Kenny, 1986). Table 4.10 provides statistical information for the effects of devaluation and discrimination and stigma withdrawal on working alliance. Neither devaluation and discrimination $(\beta=-.42, t=-1.43, \mathrm{df}=124, \mathrm{p}$ $=.153)$ nor stigma withdrawal $(\beta=-.40, \mathrm{t}=-1.21, \mathrm{df}=124, \mathrm{p}=.228)$ were related to working alliance.

A second model assessed the unique effects of devaluation and discrimination and stigma withdrawal on subjective quality of life. Table 4.11 provides statistical information for the effects of devaluation and discrimination on subjective quality of life. Devaluation and discrimination $(\beta=-1.00, \mathrm{t}=-4.32, \mathrm{df}=132, \mathrm{p}<.001)$ was related to subjective quality of life, and stigma withdrawal $(\beta=-.21, \mathrm{t}=-0.73, \mathrm{df}=132, \mathrm{p}>.05)$ was unrelated to subjective quality of life. The more the respondent endorsed knowledge of negative stereotypes of persons with SMD, the more negatively the respondent rated his or her subjective quality of life. 
The last set of analyses assessed the difference in slopes for the model with the independent variables only, and the model with the independent variable and the mediating variable. The difference in slopes is the effect of adding the mediation variables on the relationship between the independent variable and the dependent variable. Because stigma withdrawal was unrelated to subjective quality of life, the difference between the slopes was not assessed. The slope of devaluation and discrimination for the model with only devaluation and discrimination, stigma withdrawal, and controls was -1.00 . The slope for devaluation and discrimination for the model with devaluation and discrimination, stigma withdrawal, working alliance, and controls was -.94 . The difference between the slopes was .06. While the addition of the working alliance variable, which was the hypothesized mediating variable, explained some of the variance in subjective quality of life attributed to devaluation and discrimination, working alliance was unrelated to devaluation and discrimination. Based on Baron and Kenny's (1986) criteria for a mediating relationship, working alliance did not mediate the relationship between the self-stigma related variables and subjective quality of life.

Conclusion: comparing results for question one with question two

The two questions assessed the relationships between the self-stigma related variables and working alliance as they affect subjective quality of life. Specifically, the research questions asked whether the self-stigma related variables and working alliance variable independently affected subjective quality of life, or whether working alliance mediated the relationship between the self-stigma related variables and subjective quality of life. The evidence from this study suggested that working alliance does not mediate the 
relationship between the self-stigma related variables and subjective quality of life. Evidence also suggested that only one of the stigma related variables, devaluation and discrimination, was related to perceptions of subjective quality of life. Further, the evidence suggested that working alliance and devaluation and discrimination were independently related to subjective quality of life. Perceptions of devaluation and discrimination seemed to serve as a barrier and working alliance seemed to serve as a catalyst for positive perceptions of quality of life. The remaining discussion will mostly focus on the model predicting subjective quality of life by the independent effects of working alliance, devaluation and discrimination, and stigma withdrawal.

\section{Conclusions: other relevant findings}

The primary purpose of this study was to determine the relationships between the self-stigma related variables and working alliance, and these variables' effect on subjective quality of life. Three additional research findings are worth noting. The first two findings are the effects of gender and race on subjective quality of life within the multilevel model of the effects of devaluation and discrimination, stigma withdrawal, working alliance, and control variables on subjective quality of life. The researcher found participant race was associated with subjective quality of life. Specifically, persons who identified with a race other than African American or Caucasian $(\beta=.69, \mathrm{t}=$ $2.09, \mathrm{df}=132, \mathrm{p}=.038)$ had significantly more positive appraisals of their quality of life than did Caucasians. Past research on correlates of subjective quality of life among persons with SMD found persons who identified with a race other than Caucasian had significantly higher appraisals of their quality of life than did persons who identified with 
Caucasians (Lehman, et al., 1995). Another finding was the association between gender and subjective quality of life controlling for working alliance, devaluation and discrimination, and other control variables. Women $(\beta=-.43, \mathrm{t}=-3.20, \mathrm{df}=132, \mathrm{p}=$ .002) identified significantly less positive appraisals of their quality of life than did men. Past research on correlates of quality of life has likewise found that women have significantly more negative appraisals of their quality of life than men (Lehman, et al., 1995).

A final relevant finding was the amount of variance explained in working alliance by case managers. The researcher assessed the effects of case managers on both subjective quality of life and working alliance. The intraclass correlations (ICC) suggested that case managers explained about one percent of the variance in subjective quality of life (ICC $=.008, n=47)$. In contrast, case managers clearly explained almost ten percent of the variance in working alliance $(\mathrm{ICC}=.098, \mathrm{n}=47)$. Some case managers were more successful than others in establishing strong working alliances with their clients. The lack of demographic and other information about case managers, such as years of experience or embracement of a recovery orientation, did not allow for an understanding about which case manager-related variables affected working alliance.

Conclusions: Modified labeling theory of mental illness

The results from this research project provide partial support for modified labeling theory. Modified labeling theory predicts perceptions of devaluation and discrimination and endorsement of stigma withdrawal negatively relates to subjective quality of life (Link, 1989, Rosenfield, 1997). Participants endorsed knowing the 
negative stereotypes associated with SMD as evidenced by the mean item score of 2.71 $(\mathrm{SD}=.46)$ for the devaluation and discrimination scale, which was above the midpoint of 2.5 for that scale. Devaluation and discrimination was negatively related to subjective quality of life. The evidence suggested that persons do know the negative stereotypes about SMD and that this knowledge negatively affected appraisals of quality of life. Mead (1934) suggested that persons learn how society views social objects, such as persons with SMD, by taking the role of the generalized other. The generalized other is a person's conception of societies expectations about his or her behavior and actions. This research project did not ask participants how they learned about the stereotypes of SMD. However, consumer participants held negative stereotypes of SMD, which past research suggested are actually held by members of the public (Link, 1982). Further, the negative relationship between devaluation and discrimination and subjective quality of life provided support for the basic tenants of modified labeling theory.

Participants endorsed stigma withdrawal as a coping mechanism as evidenced by a mean item score of $2.79(\mathrm{SD}=.35)$, which was above the midpoint of the scale of 2.5. However, stigma withdrawal was not related to subjective quality of life. Goffman (1963) suggested that labeled individuals frequently limit their social interactions to the own and the wise, and suffer negative life consequences as a result. The research findings from this study provide partial support for Goffman's contention. Participants did endorse the use of stigma withdrawal as a coping mechanism. However, endorsement of stigma withdrawal was unrelated to subjective quality of life. Further, modified labeling theory posits that stigma withdrawal would be negatively related to labeled persons' psychological and social well being. 
Conclusions: Bordin's working alliance theory

The results from this research project support Bordin's (1979) pan-theoretical conceptualization of the working alliance as an important treatment-related component that, when present, leads to positive therapeutic outcomes. Participants in the current study generally endorsed having a strong working alliance with their case manager as evidenced by the mean item score of $5.12(\mathrm{SD}=1.49)$, which was above the midpoint of the scale of four. Stronger working alliance was associated with positive perceptions of subjective quality of life. The results from this study are consistent with results from other studies of the working alliance within case management which found that stronger working alliances were associated with positive perceptions of subjective quality of life (Solomon et al.,1995). The research finding that case managers accounted for about ten percent of the variance in working alliance scores contributes to theories of working alliance. This study adds case managers, themselves, to the list of factors associated with strong working alliance.

Conclusions: theories of the independent roles of stigma and treatment Link and colleagues (19970 and Rosenfield (1997) found self-stigma related variables and treatment related variables independently and oppositely affected persons with SMD. Self-stigma related variables negatively affected and treatment related variables positively affected the life chances and psychological states of persons with SMD. Findings from the current research project support these past research findings. Working alliance and devaluation and discrimination independently and oppositely 
affected perceptions of subjective quality of life of participants. The research findings support Rosenfield's contention that treatment operates within an oasis surrounded by a harsh stigmatizing environment.

Conclusions: Theories of mental health recovery.

Loveland and colleagues (2005) argued that social processes and treatment processes that facilitate or hinder recovery were not well understood. Findings from the current study suggest that one treatment related process, working alliance, and one cognitive component, perceptions of devaluation and discrimination, facilitate and hinder chances for recovery of persons with SMD, respectively. Thus, future models of recovery should include devaluation and discrimination and working alliance variables in their recovery model building processes

Implications: direct social work practice.

\section{Stigma findings and direct practice.}

The research findings about the negative effects of devaluation and discrimination on subjective quality of life are relevant for direct practice. At least three practice principles can be distilled from the findings. First, direct practice social workers should reconsider how they apply labels to individuals who suffer from psychiatric symptoms. Psychiatric label can be beneficial for persons who are labeled. Link and Cullen (1990) argued that psychiatric labels provide persons with an explanation of symptoms, and help those who are psychiatrically labeled get needed psychiatric services and governmental benefits. 
However, labels can hurt persons who receive them. The devaluation and discrimination scale used in this study measured participant understanding of the negative stereotypes associated with SMD. The researcher did not measure participants' acceptance of these stereotypes, which Corrigan and Kleinlein (2005) call prejudice. Past evidence from studies of modified labeling theory found that perceptions of devaluation and discrimination negatively affected the life chances and psychological states among persons in psychiatric treatment, while perceptions of devaluation and discrimination was unrelated to the life changes and psychological states of persons who were not receiving treatment (Link, 1987). While there is no evidence to suggest that participants in the current study accepted as valid the stereotypes of SMD they endorsed, the researcher found a statistical connection between these stereotypes and subjective quality of life. The link between the stereotypes and negative appraisals of subjective quality of life found in this study and the link between the label, stereotypes, and negative outcomes in past studies suggest that labels can also hurt. While it is commonplace that human service practitioners are cautioned in using labels unnecessarily, they should go one step farther to ensure that all other possible causes of psychiatric symptoms are ruled out before applying a psychiatric label to a person.

The second practice principle is that helping professionals should focus on strengths and capabilities of persons with SMD rather than on the negative and debilitating aspects of SMD, which contribute to self-stigma among consumers. Shibutani (1955), drawing on Cooley's (1967) conception of the looking-glass-self and Mead's (1934) conception of the generalized other, argued that individuals learn about themselves and the meaning of social objects from relevant societal subgroups, which he 
termed reference groups. Mental health case managers and other psychiatric professionals are one reference group, or subgroup, from whom persons with SMD learn about the meaning of having SMD and consequently their place in society. Practitioners need to recognize that persons with SMD look to them for the meaning of having a SMD. By focusing on the strengths and capacities of persons with SMD, treatment providers can maximize their role as a reference group and help persons with SMD see themselves as empowered and capable rather than as disabled and worthy of others' discrimination. Strengths based case management is an approach to practice that seeks to maximize consumers' strengths and capacities (Rapp, 1998). Adhering to the practice tenets of strengths based case management, as articulated by Rapp (1998), might be one way practitioners can help persons with SMD develop a meaning of SMD that is empowering and normalizing and not one that is stigmatizing.

Finally, stigma of SMD, and the associated stereotypes of persons with SMD, represented a barrier to recovery. A final recommendation for practice is to focus interventions that will challenge stigma and stereotypes of SMD at the societal or macro level. Interventional attempts to challenge held stereotypes of SMD among persons with SMD have not been fruitful. Link and his colleagues (2002) developed a psychoeducation intervention to challenge the stereotypes of SMD held by persons with a SMD. The authors' intervention focused on helping participants learn about the stigma of mental illness, share their experiences of stigma, and develop behavioral strategies for dealing with the effects of stigma, including self-stigma. The authors found that their intervention did not significantly change perceptions of devaluation and discrimination or endorsement of stigma withdrawal among participants. Corrigan (2004) argued that the 
target of anti-stigma interventions should be societal power groups who have the ability to discriminate against persons with SMD, such as employers and landlords. Challenging these groups' negative and uniformed beliefs about persons with SMD could challenge the already existing stigmatizing knowledge structure and lead to changed conceptualizations of persons with SMD.

\section{Working alliance and direct social work practice}

Controlling for perceptions of devaluation and discrimination and stigma withdrawal, working alliance was a positive predictor of subjective quality of life. At least two practice principles can be distilled from these findings about working alliance. First, case managers need to be aware of and develop strong working alliances with their clients. Bordin's (1979) conceptualization of the working alliance posited that strong working alliances were therapeutic relationships characterized by shared goals and tasks and a strong bond between the client and the helping professional. Social work, as a profession, has highlighted the important role of a collaborative relationship between social workers and clients (National Association of Social Workers, 1999). Social workers and other psychiatric professionals need to pay attention to how they establish goals and tasks with their clients. Practitioners need to work collaboratively with consumers on establishing goals and tasks of case management. In addition, helping professionals need to focus on developing a strong bond between themselves and their clients. Roger's (1957) criteria for working alliance, which require the helping professional to be congruent in the relationship, hold unconditional positive regard for the client, and express empathy towards the client, may be one way practitioners can strengthen the bond between themselves and their clients. 
Second, psychiatric helping professionals should use practice approaches that place a premium on the development of strong working alliances. One of the fundamental principles of strengths based case management is the development of a strong working alliance (Rapp, 1998). Further, strengths based case management holds that treatment decisions must be collaboratively developed, with weight given to the person with SMD in making final decisions about treatment (Rapp, 1998). Strengths based case management is one practice approach that could maximize the benefits of working alliance, because this approach focuses on the development of the relationship.

\section{Implications: Policy}

\section{Stigma and policy.}

One policy recommendation is changing the diagnostic system used to label persons with SMD. The American Psychiatric Association developed the Diagnostic and Statistical Manual of Mental Disorders (2000), which is the official mental illness classification system used by American psychiatric professionals. The American Psychiatric Association is one societal power group whose decisions about the classification of symptoms of mental illness affect persons who receive psychiatric labels. Corrigan (2007) argued for a dimensional classification system to replace the current diagnostic classification system. "Rather than assign someone to a class of people with similar symptoms, course, and disabilities, dimensional diagnosis seeks to describe a person's profile of symptoms on a continuum" (Corrigan, 2007, p 36). As a group of policy makers, the American Psychiatric Association has the power to change the meaning of SMD. Reclassifying mental illness through the use of a dimensional system 
would fundamentally change the meaning of having a SMD, and, consequently, could change the knowledge structure that supports current stereotypes of SMD. Challenging the current diagnostic system requires more than working with the American Psychiatric Association to change their system. State mental health funding systems, health insurance companies, and federal disability claims systems use the current diagnostic system to evaluate need and eligibility for services. For the dimensional approach to gain acceptance, these other systems will have to buy into the dimensional approach. Policy practitioners are encouraged to work with both the APA and other relevant mental health service funding sources to reconsider how psychiatric labels should be applied.

\section{Working alliance and policy}

The current research findings about working alliance support two recommendations for mental health policy. In an era of mental health recovery, policy makers need to support interventions, including interventions targeted at psychiatric helping professionals that increase consumers' chances for mental health recovery. Policy makers should build on the power of the working alliance as a potential catalyst of mental health recovery by supporting the development of working alliance training programs for direct service practitioners. These helping-professional-based interventions should build on teaching practitioners how to develop relationships characterized by shared goals and tasks of treatment and development of a bond between the helping professional and their consumers.

In addition, policy makers should support case management agencies in the hiring and retaining of professionally and academically trained helping professionals, including social workers. Persons who are academically trained helping professionals are trained in 
the development of strong working alliances with their clients. A potential drawback relating to case management is that case management is considered an entry-level position for many social workers. However, mental health case managers spend a significant amount of time with their clients. As within psychotherapy studies of the working alliance (Horvath, 2001), the current research project supports the positive role a strong working alliance has for consumers of case management services. Case managers, partially through the development of a strong working alliance, play a role in the recovery chances of persons with SMD. While it may be naive to think that case management would become more than an entry-level position with the mental health system of care, several factors might contribute to the hiring and retention of professionally trained case managers. Sheidow and colleagues (2007) found that low salaries were one reason for turnover in case management programs. Aarons and Sawitzky (2006) found that agency culture and climate were important contributors to staff turnover. Constructive cultures, which place a premium on staff interaction and supportiveness, were associated with less chances of employee turnover. Negative climates, which are characterized by a sense of depersonalization and emotional exhaustion by staff, were associated with increased chances of staff-turnover.

Policy makers can encourage academically trained helping professionals to remain employed in community mental health case management programs by increasing monies available to agencies for staff salary. Likewise, agency administrators can encourage constructive organization cultures and positive organizational climates to encourage staff retention. Glisson, Dukes, and Green (2006) developed an intervention, the Availability, Responsiveness and Continuity (ARC) organizational intervention, to help agencies 
create positive organizational climates. The ACR intervention was designed to help agencies streamline the bureaucratic process and remove barriers to helping consumers. The ARC intervention has been associated with positive changes to organizational climate (Glisson et al, 2006). Therefore, agency administrators are encouraged to assess their organizational culture and climate and intervene where appropriate

\section{Recommendations for future research}

Results from the current research project provide a tentative understanding of the effects of working alliance and self-stigma related variables on subjective quality of life of persons receiving ACT and ACT-like services. Methodological limitations, mentioned previously, preclude drawing strong causal and generalizabile inferences from the research findings. However, more research on the effects of working alliance and stigma related variables on subjective quality of life is required to strengthen the theoretical understanding of the relationships between these variables.

Future studies should use sampling plans that are more amenable to generalizability than the sampling plan used in the current study. Researchers should use a multistage sampling strategy. Researchers should randomly sample case managers and then either use all of the sampled case mangers' clients or sample clients of the sampled case managers. Random sampling provides greater assurance in the accuracy of standard errors associated with the data and allows for inferences to be made from the sample to the population from which the sample was drawn (Pedhazur \& Pedhazur-Schmelkin, 1991). The multistage sampling strategy would allow inferences to be drawn back to consumers and their case managers. 
Future studies should increase the sample sizes at both the case manager level, level-2, and the consumer level, level-1, to increase the statistical power and accurate estimation of the partial regression coefficients and the variance components. Statistical power was a major limitation of the current study, which will likely lead to issues with type II error. Power analysis suggested that a minimum sample of 312 consumers and 50 case managers was necessary to find a small effect for the partial regression coefficients at a power of .8. In addition to power estimates, rules of thumb about adequate sample sizes for multilevel models suggest 30 level-2 units each with 30 level-1 units are required for accurate estimation of the partial regression coefficients, and 100 level-2 units each with 10 level-1 units for accurate estimation of the variance components (Hox, 2002). Regardless of how an adequate sample size is selected, future studies need to increase statistical power and accurate estimation of the fixed effects and random components by increasing the size of each of the samples.

Future studies should measure and model case manager variations. In the current study, case managers accounted for variance in both subjective quality of life and working alliance. Including information about case managers would help in understanding which characteristics of case managers lead to positive outcomes for consumers. The current results only suggested that case managers, themselves, did affect consumers' perceptions of working alliance and subjective quality of life.

Future studies should also explore other potential variables that mediate the relationship between devaluation and discrimination and subjective quality of life. Findings from this study suggested that working alliance did not mediate the relationship between self-stigma related variables, including devaluation and discrimination, and 
subjective quality of life. Researchers need to determine whether other treatment related variables could lessen the effects of self-stigma related variables on subjective quality of life. Past research suggested that self-esteem was one mediating variable between stigma related variables and quality of life (Rosenfield, 1997). Treatment related variables might also serve as potential mediators between self-stigma related variables and subjective quality of life. For example, Rosenfield (1997) measured the effects of both the stigma related variables and consumers' perceptions that the treatment environment was empowering on subjective quality of life. Whether consumers' perceptions that the treatment environment was empowering was not tested as a mediating variable between self-stigma related variables and subjective quality of life. Future studies should explore if variables such as perceptions of an empowering treatment environment mediate the effects of self-stigma related variables on subjective quality of life.

Finally, researchers need to expand an understanding of the effects of self-stigma related variables and working alliance to other measures of mental health recovery. In addition to subjective quality of life, mental health recovery researchers suggested that hope, empowerment, supportive social networks, and the development of coping mechanisms are also recovery-oriented variables (Greene, Kondrat, Lee, et al. 2006). Self-stigma and working alliance did not co-vary, which suggested that working alliance does not mediate the effects of self-stigma on other variables (Baron and Kenny, 1986). However, expanding an understanding of the effects of self-stigma related variables and working alliance on these other mental health recovery oriented variables will further an understanding of mental health recovery, itself. 


\section{REFERENCES}

Aarons, G. A. \& Sawitzky, C. (2006). Organizational Climate Partially Mediates the Effect of Culture on Work Attitudes and Staff Turnover in Mental Health Services. Adminstration and Policy in Mental Health and Mental Health Services Research, 33(3), 289-301.

Adler, A.K. \& Wahl, O.F. (1998). Children's beliefs about people labeled mentally ill. American Journal of Orthopsychiatry, 68, 321-326.

Alcohol, Drug and Mental Health Board of Franklin County (2007). ADAMH Boucher, Retrieved February 14, 2008, from the Alcohol, Drug and Mental Health Board of Franklin County web site:

Httptp://www.adamhfranklin.org/about/docs/Fact\%20Sheet\%202006\%20update.p df

American Psychiatric Association. (1994). Diagnostic and statistical manual of mental disorders $\left(4^{\text {th }}\right.$ ed.) Washington, DC: Author.

American Psychiatric Association. (2000). Diagnostic and statistical manual of mental disorders $\left(4^{\text {th }}\right.$ ed. Text revision) Washington, DC: Author.

Angell, B. Cooke, A., \& Kovac (2004). First-person accounts of stigma. In P.W. Corrigan (Ed.). On the Stigma of Mental Illness. (pp. 69-98). Washington: American Psychological Association.

Anthony, W.A. (1993). Recovery from mental illness: The guiding vision of the mental health service system in the 1990s. Psychosocial Rehabilitation Journal, 16, 1123.

Anthony, W.A. (2000). A recovery-oriented service system: setting some system level standards. Psychiatric Rehabilitation Journal, 24 (2), 159-168.

Anthony, W.A. (2003a). Taking issue: Studying evidence based process, not practice. Psychiatric Services, 54, 7.

Anthony, W.A. (2003b). Letters: Process, not practice. Psychiatric Services, 54, 402. 
Anthony, W.A., Cohen, M., Farkas, M., \& Cohen, B. (1988) The chronically mentally ill Case Management: More a response to a dysfunctional system. Community Mental Health Journal, 24 (3), 219-228.

Anthony, W., Rogers, E.S., \& Farkas, M. (2003). Research on evidence-based practices: Future directions in an era of recovery. Community Mental Health Journal, 39 (2), 101-114.

Baron, R.M., \& Kenny, D.A. (1986). The moderator-mediator variable distinction in social psychological research: Conceptual, strategic and statistical considerations. Journal of Personality and Social Psychology, 51, 1173-1182.

Barry, K.L., Zeber, J.E., Blow, F.C., \& Valenstein, M. (2003). Effect of strengths model versus assertive community treatment model on participant outcomes and utilization: Two-year follow-up. Psychiatric Rehabilitation Journal, 26 (3), 268277.

Becker, H. (1964). The Other Side: Perspectives on Deviance. Free press: Glencoe.

Ben-Dror, R. (1994). Employee turnover in community mental health organization: A developmental stages study. Community Mental Health Journal, 30, 243-257.

Berry, W.D. (1993). Understanding Regression Assumptions. Newbury Park, CA: Sage.

Bond, G. R., et al. "Does competitive employment improve nonvocational outcomes for people with severe mental illness?" Journal of Consulting and Clinical Psychology, v. 69 issue 3, 2001, p. 489-501.

Bond, G.R., McDonel, E.G., Miller, L.D., \& Pensec, M. (1991). Assertive community treatment and reference groups: An evaluation of their effectiveness for young adults with serious mental illness and substance abuse problems. Psychosocial Rehabilitation Journal, 15 (2), 31-43.

Blumer, H. (1969). Symbolic Interactionism: Perspective and Method. Englewood Cliffs, NJ: Prentice-Hall.

Bond, G.R., Miller, L.D., Krumwied, \& Ward, R.S. (1988). Assertive case management in three CMHCs: A controlled study. Hospital and Community Psychiatry, 39 (4), 411-418

Bond, G., R, \& Salyers, P. (2004). Prediction of outcome from the Dartmouth assertive community treatment fidelity scale. CNS spectrums, 9(12), 937-942.

Bond, G.R., Witheridge, T.F., Dincin, J., Wasmer, D. Webb, J., \& De Graaf-Kaser, R. (1990). Assertive community treatment for frequent users of psychiatric hospitals 
in a large city: A controlled study. American Journal of Community Psychology, 18 (6), 865-891.

Bordin, E.S. (1979). The generalizability of the psychoanalytic concept of the working alliance. Psychotherapy: Theory, Research, and Practice, 16,252-260.

Burns, B.J. \& Santos, A.B. (1995). Assertive community treatment: an update of randomized trials. Psychiatric Services, 46 (7), 669-675.

Calsyn, R.J. Morse, G.A., Klinkenberg, W.D., Yonker, R.D.,\& Trusty, M.L. (2002). Moderators and mediators of client satisfaction in case management programs for clients with severe mental illness. Mental Health Service Research, 4, 267-275.

Charon, J.M. (2001). Symbolic Interactionism: An Introduction, an Interpretation, an Integration ( $7^{\text {th }}$ ed.). Upper Saddle River, NJ: Prentice-Hall.

Chinman, M., Allende, M., Bailey, P. Maust, J., Davidson, L. (1999). Therapeatic agents of assertive community treatment. Psychiatric Quarterly, 70, 137-162.

Chinman, M.J., Rosneheck, R., \& Lam, J.A. (2000). The case management relationship and outcomes of homeless persons with serious mental illness. Psychiatric Services, 51,1142-1147.

Clarke, G.N. Herinckx, H.A., Kinney, R.F., Paulson, R.L., Culter, D.L., Lewis, K., \& Oxman, E. (2000). Psychiatric hospitalizations, arrests, emergency room visits, and homelessness of clients with serious and persistent mental illness: Findings from a randomized trail of two act programs vs. care. Mental health Services Research, 2 (3), 155-164.

Cooley, C.H. (1967). Human Nature and the Social Order. New York: Schocken Books. (Original work published 1902.)

Corrigan, P.W. (2000). Mental health stigma as social attribution: Implications for research methods and attitude change. Clinical Psychology: Science and Practice, $7(1), 48-67$.

Corrigan, P. W. (2004). Target-Specific Stigma Change: A Strategy for Impacting Mental Illness Stigma. Psychiatric Rehabilitation Journal, 28(2), 113-121.

Corrigan, P.W. (2007). How clinical diagnosis might exacerbate the stigma of mental illness. Social Work, 52, 31-39.

Corrigan, P.W. \& Kleinlein, P. (2005).The impact of mental illness stigma. In P.W. Corrigan (Ed.). On the Stigma of Mental Illness. (pp. 11-44). Washington: American Psychological Association. 
Corrigan, P.W. \& Watson, A.C. (2002). The paradox of self-stigma and mental illness. Clinical Psychology: Science and Practice, 9 (1), 35-53.

Corrigan, W.P., Watson, A. C., \& Ottati, V. (2003). From whence comes mental illness stigma? International Journal of Social Psychiatry, 49 (2), 142-157.

Davidson, L. (2003). Living Outside Mental Illness: Qualitative Studies of Recovery from Schizophrenia. New York: New York University Press.

Deci, P.A., Santos, A.B, Hoitt, D.W., Schoenwald, S, \& Dias, J.K. (1995). Dissemination of assertive community treatment programs, Psychiatric Services, 46 (7), 676678.

Deegen, P. (1996). Recovery as a journey of the heart. Psychiatric Rehabilitation Journal, 19 (3), 91-97.

Derogatis, L.R. \& Cleary, P.A. (1977). Conformation of the dimensional structure of the SCL-90: A study of construct validation, Journal of Clincial Psychology, 33, 981989.

Drake, R.E., McHugo, G.J., Clark, R.E., Teague, G.B., Xie, H., Miles, K, Ackerson, T.H. (1998). Assertive community treatment for persons with co-occurring severe mental illness and substance use disorder: A clinical trial. American Journal of Orthopsychiatry, 68 (2), 201-215.

Draine, J., \& Solomon, P. (1996). Case management alliance with clients in an older cohort. Community Mental Health Journal, 32, 125-134.

Dixon, L. (2000). Assertive community treatment: Twenty-five years of gold. Psychiatric Services, 51, 759-765.

Eack, S. M.,\& Newhill, E. (2007). Psychiatric symptoms and quality of life in schizophrenia: A meta-analysis. Schizophrenia Bulletin, 33(5), 1225-1237.

Early, T.J. (1994). Factors affecting perception of positive contributions among parents of children with emotional disorders.(Doctoral dissertation, University of Kansas, 1994).

Eklund, M, Bäckströme,M., \& Hansson, L.(2003). Personality and self-variables Important determinants of subjective quality of life in schizophrenia out-patients Acta Psychiatrica Scandinavica, 108, 134-143.

Fakhoury. (2002). Subjective quality of life: its association with other constructs. International Review of Psychiatry, 14(3), 219. 
Fekete, D. M. (1998). Rural assertive community treatment: A field experiment. Psychiatric Rehabilitation Journal, 21(4), 371-379.

Fanks, D.D. \& Gecas, V. (1992). Autonomy and conformity in Cooley's self-theory: The looking-glass self and beyond. Symbolic Interaction, 15 (1), 49-68.

Gallo, K. M. (1994). First person account: Self-stigmatization. Schizophrenia Bulletin, 20(2), 407-410.

Glisson, C., Dukes, D., \& Green, P. (2006). The effects of the ARC organizational intervention on caseworker turnover, climate, and culture in children's service systems. Child Abuse \& Neglect, 30(8), 855-880.

Gladis, M.M., Gosh, E.A., Dishuk, N.M., \& Crits-Christopher, P. (1999). Quality of Life: Expanding the scope of clinical significance. Journal of Consulting and Clinical Psychology, 67 (3), 320-331.

Goffman, E. (1959). Presentation of self in everyday life. Doubleday

Goffman, E. (1961). Asylums: Essays on the Social Situation of Mental Patents and Other Inmates. Garden City, NY: Anchor.

Goffman, E. (1963). Stigma: Notes on the Management of Spoiled Identity. Englewood Cliffs, NJ: Prentice-Hall.

Goldberg,R. W. (2004). The working alliance inventory: Modification and use with people with serious mental illnesses in a vocational rehabilitation program. Psychiatric Rehabilitation Journal, 27(3), 267-270.

Gove, W. (1970). Societal reaction as an explanation of mental illness: An evaluation. American Sociological Review, 35, 873-884.

Gove, W. (1982). The current state of the labeling theory of mental illness. In W. Gove (Ed.) Deviance and Mental Illness. (273-300). Beverly Hills, CA: Sage.

Gove W. \& Fain, T. (1973). The stigma of mental hospitalization: An attempt to evaluate its consequences. Archives of General Psychiatry, 29, 494-500.

Gravetter, F.J., \& Wallnau, L.B. (2000).Statistics for the Behavioral Sciences (5 ${ }^{\text {th }}$ ed.). Belmont, CA: Wadsworth.

Greene, G. J., Kondrat, D. C., Lee, M. Y., Clement, J., Siebert, H., Mentzer, R. A., et al. (2006). A solution-focused approach to case management and recovery with consumers who have a severe mental disability. Families in Society, 87(3), 339350 . 
Hair, J.F., Anderson, R.E., Tatham, R.L., \& Black, W.C. (1998). Mulitvariate Data Analysis $\left(5^{\text {th }}\right.$ ed.). Upper Saddle River, NJ: Prentice Hall.

Herman-Kinney, N.J. (2003). Deviance. In L.T. Reynolds \& N.J. Herman-Kinney (Eds.). Handbook of Symbolic Interaction (pp.695-720). Walnut Creek, CA: AltaMira Press.

Hill, M.A. (1997). SPSS Missing Value Analysis: Chicago, Il: SPSS.

Hohmann, A. (1999). A contextual model for clinical mental health effectiveness research. Mental Health Services Research, 1, 83-91.

Holloway, F. \& Carson J. (2002). Quality of life in severe mental illness. International Review of Psychiatry, 14,175-184.

Horvath, A.O. (1994). Empirical validation of Bordin's pantheoretical model of the alliance: The working alliance inventory perspective. In A.O. Horvath \& L.S. Greenberg (Eds.) The Working Alliance: Theory, Research, and Practice.(109128). New York: John Wiley \& Sons.

Horvath, A.O. (2001). The Alliance. Psychotherapy, 38, 365-372.

Horvath, A.O. \& Greenberg, L.S. (1989). Development and validation of the working alliance inventory. Journal of Counseling Psychology, 36, 223-233.

Horvath A. O \& Symonds, B.D. Relation between working alliance and outcome in psychotherapy: A meta-analysis. Journal of Counseling Psychology, 38, 139-149

Howgego, I.M., Yellowlees, P., Owen, C., Meldrum, L., \& Dark F. (2003). The therapeutic alliance: The key to effective patient outcome? A descriptive review of the evidence in community mental health case management. Australian and New Zealand Journal of Psychiatry, 37, 169-183.

Hox, J.J. (2002). Multilevel analysis: Techniques and applications. Mahwah, NJ: Lawrence Erlbaum Associates.

Kamis-Gould, E. \& Staines, G.L. (1986). Manpower information and the community mental health system. Hospital and Community Psychiatry, 37, 1030-1034.

Kanhng, S.K., Mowbray (2005a). What affects self-esteem of persons with psychiatric disabilities: the causal attribution of mental illness. Psychiatric Rehabilitation Journal, 28 (4). 354-351. 
Kanhng, S.K., Mowbray (2005b). Psychological traits and behavioral coping of psychiatric consumers: The mediating role of self-esteem. Health and Social Work, 30 (2), 87-97

Kazdin, A.E. (2003). Research Design in Clinical Psychology. (4 ${ }^{\text {th }}$ ed.). Boston: Allen \& Bacon.

Kessler, R. C., Chiu, W. T., Demler, O., \& Walters, E. E. (2005). Prevalence, Severity, and Comorbidity of 12-Month DSM-IV Disorders in the National Comorbidity Survey Replication. Archives of General Psychiatry, 62(6), 617627.

Kienast, T., \& Heinz, A. (2006). Dopamine and the diseased brain. CNS \& neurological disorders drug targets, 5(1), 109-131.

Klinkenberg, W.D., Calsyn, R.J. \& Morse, G.A. (1998). The helping alliance in case management for homeless persons with severe mental illness. Community Mental Health Journal, 34, 569-578.

Korr, W.S.., \& Ford, B.C. (2003). Measuring quality of life in the mentally ill. Quality of Life Research, 12(suppl. 1), 17-23.

Kruger, A. (2000). Schizophrenia: Recovery and hope. Psychiatric Rehabilitation Journal, 24 (1), 29-37.

Lafave, H. G., de Souza, H. R., \& Gerber, G. J. (1996). Assertive community treatment of severe mental illness: A Canadian experience. Psychiatric Services, 47(7), 757759.

Lam, J. A., \& Rosencheck, R. (1998). The effect of victimization on clinical outcomes of homeless persons with serious mental illness. Psychiatric Services, 49(5), 678683.

Lemert, E.M. (1967). Human Deviance Social Problems, and Social Control. Englewood Cliffs, NJ: Prentice Hall.

Lehman, A.F. (1983). The effects of psychiatric symptoms on quality of life assessments among the chronic mentally ill. Evaluation and Program Planning, 6, 143-151.

Lehman, A.F. (1988). A quality of life interview for the chronically mentally ill. Evaluation and Program Planning, 11, 51-62. 
Lehman, A.F., Dixon, L.B., Kerman, E., Deforge, B.R., Postrado, L.T. (1997). A randomized trial of Assertive Community Treatment for homeless persons with severe mental illness. Archives of General Psychiatry, 54, 1038-1043.

Lehman, A.F., Kreyenbuhl, J., Buchanan, R.W., Dickerson, F.B., Dixon, L.B., Goldberg, R., Green-Paden, L.D., Tenhula, W.N., Boerescu, D., Tek, C., Sandson, N., \& Steinwachs, D.M. (2004), The schizophrenia patient outcomes research team (PORT): updated treatment recommendations 2003. Schizophrenia Bulletin, 30 (2), 193-217.

Lehman, A.F. (1996). Measures of quality of life among persons with severe and persistent mental disorders. In G. Thornicroft \& M. Tansella (Eds.) Mental Health Outcome Measures. (pp. 75 - 92) New York: Springer.

Lehman, A.F., Postrado, L.T., \& Rachuba, L.T. (1993). Convergent validity of quality of life assessments for persons with severe mental illnesses. Quality of Life Research, 2, 327-333.

Lehman, A.F., Possidente, S., \& Hawker, F. (1986). The quality of life of chronic patients in a state hospital and in community residences. Hospital and Community Psychiatry, 37, 901-907.

Lehman, A. F., Rachuba, L. T., \& Postrado, L. T. (1995). Demographic influences on quality of life among persons with chronic mental illnesses. Evaluation and Program Planning, 18(2), 155-164.

Lehman, A.F., Slaughter, J.C., Myers, C.P. (1992). Quality of life experiences of the chronically mentally ill: Gender and stage of life effects. Evaluation and Program Planning, 15, 7-12.

Liberman, R.P. \& Kopelowicz (2004). Recovery from schizophrenia: A criterion-based approach. In R.O. Ralph \& P.W. Corrigan (Eds.). Recovery in Mental Illness: Broadening Our Understanding of Wellness (101-129). Washington: American Psychological Association.

Link, B. (1982). Mental patient status, work, and income: An examination of the effects of a psychiatric label. American Sociological Review, 47, 202-215.

Link, B.G. (1987) Understanding labeling effects in the area of mental disorders: An assessment of the effects of expectation of rejection. American Sociological Review, 52, 96-112.

Link, B. \& Cullen, F.T. (1990). The labeling theory of mental disorders: A review of the evidence. In J.R. Greenley. Research in community mental health. Greenwich, Conn.: JAI press 
Link, B.G., Cullen, F.T., Struening, E., Shrout, P.E., \& Dohrenwend, B.P. (1989). A modified labeling theory approach to mental disorders: An empirical assessment. American Sociological Review, 54, 400-432.

Link, B.G., Mirotznik, J. Cullen, F.T. (1991). The effectiveness of stigma coping orientations: Can negative consequences of mental illness labeling be avoided? Journal of health and social behavior, 32, 302-320.

Link, B.G. \& Phelan, J.C. (2001). Conceptualizing Stigma. Annual Review of Sociology, 27, 363-385.

Link, B.G., Phelan, J., Bresnahan, M., Stueve, A., \& Pescosolido, B.A. (1999). Public conceptions of mental illness: Labels, causes, dangerousness, and social distance. American journal of Public Health, 89, 1328-1333.

Link, B.G., Struening, E.L., Neese-Todd, S., Asmussen, S., \& Phelan, J.C. (2002). On describing and seeking to change the experiences of stigma. Psychiatric Rehabilitation Skills, 6, 201-231.

Link, B.G., Struening, E.L., Rahav, M., Phelan, J.C., \& Nuttbrock, L.(1997). On stigma and its consequences: Evidence from a longitudinal study of men with dual diagnoses of mental illness and substance abuse. Journal of Health and Social Behavior, 38 (2), 177-190.

Link, B.G., Yang, L.H., Phelan, J.C., \& Collins, P.Y. (2004). Measuring mental illness stigma. Schizophrenia Bulletin, 30, 511-541.

Loveland, D, Randall, K. W., \& Corrigan, P.W. (2005). Research methods for exploring and assessing recovery. In R.O Ralph \& P.W. Corrigan (Eds.). Recovery in Mental Illness: Broadening Our Understanding of Wellness. (19-59): American Psychological Association.

Luborsky (1984). Principals of psychodynamic psychotherapy. New York: Basic Books.

Luke, D.A. (2004). Multilevel Modeling. Thousand Oaks, CA: Sage.

Lysaker, P.A., Davis, L.D, Warman, D.M., Strasburger, A., \& Beattie, N. (2007). Stigma, social functioning and symptoms in schizophrenia and schizoaffective disorder: Associations across 6 months. Psychiatry Research, 149, 89-95.

Markowitz, F.E. (1998). The effects of stigma on psychological well-being and life satisfaction of persons with mental illness. Journal of Health and Social Behavior, 39, 335-347. 
Markowitz, F.E. (2005a). Sociological models of mental illness stigma: Progress and prospects. In P.W. Corrigan (Ed.). On the Stigma of Mental Illness. (pp. 129-143). Washington: American Psychological Association.

Markowitz, F.E. (2005b). Sociological models of recovery. In P.W.Corrigan \& R.Ralph (Eds.) Recovery in Mental Illness: Broadening Our Understanding of Wellness. (pp.85-99). Washington: American Psychological Association.

Maas, C.J., \& Hox, J.L., (2005). Sufficient sample sizes for multilevel modeling. Methodology, 1, 85-91.

Martin, D.J., Garske, J.P., \& Davis, M.K., (2000). Relation of the therapeutic alliance with outcome and other variables: A meta-analytic review. Journal of Counseling and Clinical Psychology, 68, 432-450.

Martin, J.K., Pescosolido, B.A., \& Tush, S.A. (2000). Of fear and loathing: The role of "disturbing behavior" labels and causal attributions in shaping public attitudes towards persons with mental illness. Journal of Health and Social Behavior, 42, 208-223.

Marx, A.J., Test, M.A., \& Stein, L.I. (1973). Extrohospital management of severe mental illness: feasibility and effects of social functioning. Archives of General Psychiatry, 29, 505-511.

Mead, G.H. (1934). Mind, Self \& Society From the Standpoint of a Social Behaviorist. Chicago: The University of Chicago Press.

McCabe, R. \& Priebe, S. (2004). The therapeutic relationship in the treatment of severe mental illness: A review of methods and findings. International Journal of Social Psychiatry, 50 (2), 115-128.

McGrew, J.H. \& Bond, G.R. (1995). Critical ingredients of assertive community treatment: Judgments of the experts. Journal of Mental Health Administration, 22 (2), 113-125.

Miller, L. Smith, K. (1983). Handling nonresponse issues. Journal of Extension, 21, 45.

Mueser, K.T., Torrey, W.C., Lynde D., Singer, P., \& Drake, R.E. (2003). Implementing evidence-based practices for people with severe mental illness. Behavior Modification, 27 (3), 381-411.

National Association of Social Workers, (1999). Code of Ethics. Washington, DC: author. 
Neale, M.S. \& Rosenheck, R.A. (1995). Therapeutic alliance and outcome in a VA intensive case management program. Psychiatric Services, 46, 719-721.

Nguyen, T.D., Attkisson, C.C., \& Stengner, B.L. (1983). Assessment of patient satisfaction: Development and refinement of a service evaluation questionnaire. Evaluation and Program Planning, 6, 299-314.

Noordsy, D. Torry, W., Mueser, K., Mead, S., O’Keefe, C. \& Fox, L. (2002). Recovery from severe mental illness: an intrapersonal and functional outcome definition. International Review of Psychiatry, 14, 318-326.

Ohio Department of Mental Health (2005). The Ohio mental Health Consumer Outcomes System: Procedural Manual. ( $7^{\text {th }}$ ed revised). Columbus, $\mathrm{OH}$ : Author.

Ohio's Mental Health Commission (2001). Changing Lives: Ohio's Action Agenda for Mental Health. Columbus, OH: Ohio Department of Mental Health.

Olfson, M. (1990). Assertive community treatment: An evaluation of the experimental evidence. Hospital and Community Psychiatry, 41 (6), 634-641.

Pedhazuer E.J. \& Pedhazur-Schmelkin L. (1991). Measurement, Design and analysis: An Integrated Approach.: Hilldale, NJ: Lawrence Erlbaum.

Perlick, D.A. (2001). Special section on stigma as a barrier to recovery: Introduction. Psychiatric Services, 52, 1613-1614.

Philo, G. (1997). Changing media representations of mental health. Psychiatric Bulletin, 21, 171-172.

Pescosolido, B. A., Monahan, J., Link, B. G., Stueve, A., \& Kikuzawa, S. (1999). The public's view of the competence, dangerousness, and need for legal coercion of persons with mental health problems. American Journal of Public Health, 89(9), 1339-1345.

Priebe, S., \& Gruyters, (1993). The role of the helping alliance in psychiatric community care: A prospective study. The Journal of Nervous and Mental Disease, 181, 552557.

Prince, P.N. \& Prince, C.R. (2002)/ Perceived stigma and community integration among clients of assertive community treatment. Psychiatric Rehabilitation Journal, 25 (4), 323-331.

Resnick, S.G., Fontana, A., Lehman, A.F., Rosenheck, R.A., (2005). An empirical conceptualization of the recovery orientation. Schizophrenia Research, 75, 119128. 
Rapp, C.A. (1998). The Strengths Model: Case Management with People Suffering from Severe and Persistent Mental Illness. New York: Oxford University Press.

Raudebush, S.W. \& Bryk, A.S. (2002). Hierarchical Linear Models: Application and Data Analysis Methods. Newbury Park, CA: Sage.

Rogers, C.R. (1957) The necessary and sufficient conditions of therapeutic personality change. Journal of Counseling Psychology, 21 (2), 95-103.

Rogers, C.R. (1959). A theory or therapy, personality, and interpersonal relationships as developed in the client-centered framework. In Koch (Ed). Psychology: A Study of Science: Formulations of the Person and the Social Context (pp 184-256). New York: McGraw-Hill.

Rosenfield, S. (1997). Labeling mental illness: The effects of received services and perceived stigma on life satisfaction. American Sociological Review, 62, 660-672.

Rubin, D.B. (1996). Multiple imputation after 18+ years. Journal of the American Statistical Association, 91, 473-489.

Ryan, C.S., Sherman, P.S., \& Judd, C.M. (1994). Accounting for case manager effects in the evaluation of mental health services. Journal of Consulting and Clinical Psychology, 62, 965 -974.

Saunders J A, Morrow-Howell N, Spitznagel E, Dore P., Proctor E K, \& Pescarino R, (2006). Imputing missing data: a comparison of methods for social work researchers. Social Work Research, 30(1), 19-31.

Schafer, J.L. \& Graham, J. W. (2002). Missing data: Our view of the state of the art. Psychological Methods, 7, 147-177.

Scheff, T.J. (1966). Being Mentally Ill: A Sociological Theory. New York: Aldine.

Scheff, T. J. (1970). Schizophrenia as ideology. Schizophrenia Bulletin, 2, 15-20.

Scheff, T.J. (1974) The Labeling theory of mental illness. American Sociological Review, $39,444-452$.

Scheff, T. J. (1999). Being Mentally Ill: A Sociological Theory. ( ${ }^{\text {rd }}$ Ed.). New York: Aldine.

Sheidow, A. J., Schoenwald, S. K., Wagner, H. R., Allred, C. A., \& Burns, B. J. (2007). Predictors of Workforce Turnover in a Transported Treatment Program. 
Administration and Policy in Mental Health and Mental Health Services Research, 34(1), 45 - 56.

Shibutani, T. (1955). Reference group as perspectives. American Journal of Sociology, $60,562-569$.

Sirey, J.A., Bruce, M.L., Alexopoulos, G.S., Perlick, D.A., Friedman, S.J., \& Meyers, B.S. (2001). Perceived stigma and patient rated severity of illness as predictors of antidepressant drug adherence. Psychiatric Services, 52, 1615 - 1620.

Smith, M.K. (2000). Recovery from a severe psychiatric disability: Findings of a qualitative study. Psychiatric Rehabilitation Journal, 24, 149-158.

Solomon, P., Draine, J., Delaney, M.A. (1995). The working alliance and consumer case management. Journal of Mental Health Administration, 22, 126-134

Solomon, P. \& Stanhope, V. (2004). Recovery: Expanding the vision of evidence-based practice. Brief treatment and crisis intervention, 4, 311-321.

Stein, L. I., Barry, K. L., Van Dien, G., Hollingsworth, E. J., \& Sweeney, J. K. (1999). Work and social support: A comparison of consumers who have achieved stability in ACT and clubhouse programs. Community Mental Health Journal, 35(2), 193204.

Stein, L.I., \& Santos, A.B. (1998). Assertive Community Treatment of Persons with Severe Mental Illness. New York: Norton.

Stein, L.I., \& Test, M.A. (1980). Alternative to mental hospital treatment: I. conceptual model, treatment program, and clinical evaluation. Archives of General Psychiatry, 37, 392-397.

Strong, S.R. (1968). Counseling: An interpersonal influence process. Journal of Counseling Psychology, 115, 117-126.

Test. M. A. (1981). Effective community treatment of the chronically mentally ill: What is necessary? Journal of Social Issues, 37 (3), 71-86.

Test, M.A. (1992). Training in Community Living. In R.P Liberman (Ed). Handbook of Psychiatric Rehabilitation. (pp. 153 - 170). New York: Macmillan.

Tracey, T.J. \& Kokotovic, A.M. (1989). Factor structure if the working alliance. Psychological Assessment: A Journal of Counseling and Clinical Psychology, 1, 207-210. 
Tyrrell, C.L., Dozier, M., Teague, G.B., \& Fallot, R.D. (1999). Effective treatment relationships for persons with serious psychiatric disorders: The importance of attachment states of mind. Journal of Counseling and Clinical Psychology, 67, $725-733$.

University of Bristol (2007, September 10-11). Course handout: Day 1. NCRM/Lemma Multilevel modeling workshop using MLwiN. Retrieved February 4, 2008, from http://www.cmm.bristol.ac.uk/MLwiN/techsupport/workshops/materials/workshopday1 sep07.ppt\#566,11,Slide 11

Watson, A.C. \& River, L.P. (2005). A social-cognitive model of personal responses to stigma. In P.W. Corrigan (Ed.). On the Stigma of Mental Illness. (pp. 69-98). Washington: American Psychological Association.

Weisbrod, B.A., Test, M.A., \& Stein, L.I. (1980). Alternative to mental hospital treatment II: Economic benefit-cost analysis. Archives of General Psychiatry, 37, 400-405.

Witheridge, T.F. (1991). The "active ingredients" of assertive outreach. In N.L. Cohen (Ed.) Psychiatric Outreach to the Mentally Ill, 47-64. San Francisco: Jossey-Bass. 
APPENDIX

INTER VIEW SCHEDULE 
(INFORMATION IN CAPITAL LETTERS AND IN BRACKETS ARE INSTRUCTIONS TO THE INTERVIEWER AND ARE NOT TO BE READ TO THE RESPONDENT)

PARTICIPANT'S NAME

INTERVIEWER'S NAME

DATE 1

\section{(STIGMA SCALES)}

Please look at this card (HAND SUBJECT AGREEMENT - DISAGREEMENT CARD). This is called the agreement-disagreement scale.

(POINT TO THE CORRESPONDING PLACES ON THE AGREEMENTDISAGREEMENT CARD AS YOU DESCRIBE THE RATINGS) The scale goes from strongly disagree, which is the lowest ranking of 1 , to strongly agree which is the highest ranking of 4 . In between strongly disagree and strongly agree there are two more points on this scale: There is also point 2, which is disagree, and 3 which is to agree.

The next 25 statements are ways in which members of society might view a person living with a mental illness and ways that a person with a mental illness may feel and act as a result of how members of society view persons with a mental illness.

For each of these statements, use this agreement- disagreement scale to let me know what you think about the statement. If you do not know, just say that you do not know. Use this agreement-disagreement scale card to help you as you think about how you want to answer. Do you have any questions? Let's begin.

(READ EACH STATEMENT TO THE RESPONDENT AND CIRCLE THEIR RESPONSES IN THE RESPONSE SECTION, WHICH IS LOCATED BELOW EACH STATEMENT. PROMPT THE RESPONDENT TO THE AGREEMENTDISAGREEMENT SCALE AS NECESSARY)

1. Most people would accept a former mental patient as a close friend.

\begin{tabular}{c|c|c|c|c}
\hline Strongly Disagree & Disagree & Agree & Strongly Agree & Don’t Know \\
1 & 2 & 3 & 4 & DK \\
\hline
\end{tabular}

2. Most people believe that a person who has been in a mental hospital is just as intelligent as the average person.

\begin{tabular}{|c|c|c|c|c|}
\hline Strongly Disagree & Disagree & Agree & Strongly Agree & Don't Know \\
1 & 2 & 3 & 4 & DK \\
\hline
\end{tabular}

(CONTINUE ON NEXT PAGE) 


\section{(CONTINUE WITH AGREEMENT-DISAGREEMENT SCALE)}

3. Most people believe that a former mental patient is just as trustworthy as the average citizen.

\begin{tabular}{c|c|c|c|c} 
Strongly Disagree & Disagree & Agree & Strongly Agree & Don't Know \\
1 & 2 & 3 & 4 & DK \\
\hline
\end{tabular}

4. Most people would accept a fully recovered former mental patient as a teacher of young children in a public school.
Strongly Disagree
Disagree
Agree
Strongly Agree
Don't Know
DK

5. Most people believe that entering a mental hospital is a sign of personal failure.

\begin{tabular}{|c|c|c|c|c|}
\hline Strongly Disagree & Disagree & Agree & Strongly Agree & Don’t Know \\
1 & 2 & 3 & 4 & DK \\
\hline
\end{tabular}

6. Most people would not hire a former mental patient to take care of their children, even if he or she had been well for some time.

\begin{tabular}{c|c|c|c|c} 
Strongly Disagree & Disagree & Agree & Strongly Agree & Don't Know \\
1 & 2 & 3 & 4 & DK \\
\hline
\end{tabular}

7. Most people think less of a person who has been in a mental hospital.

\begin{tabular}{c|c|c|c|c} 
Strongly Disagree & Disagree & Agree & Strongly Agree & Don’t Know \\
1 & 2 & 3 & 4 & DK \\
\hline
\end{tabular}

8. Most employers will hire a former mental patient if he or she is qualified for the job.
Strongly Disagree
Disagree
Agree
Strongly Agree
Don't Know
1
2
3
4
DK

9. Most employers will pass over the application of a former mental patient in favor of another applicant.

\begin{tabular}{|c|c|c|c|c|}
\hline Strongly Disagree & Disagree & Agree & Strongly Agree & Don't Know \\
1 & 2 & 3 & 4 & DK \\
\hline
\end{tabular}

10. Most people in your community would treat a former mental patient just as they would treat anyone.

\begin{tabular}{|c|c|c|c|c|}
\hline Strongly Disagree & Disagree & Agree & Strongly Agree & Don’t Know \\
1 & 2 & 3 & 4 & DK \\
\hline
\end{tabular}

11. Most young women would be reluctant to date a man who has been hospitalized for serious mental disorder.

\begin{tabular}{|c|c|c|c|c|}
\hline Strongly Disagree & Disagree & Agree & Strongly Agree & Don't Know \\
1 & 2 & 3 & 4 & DK \\
\hline
\end{tabular}

(CONTINUE ON NEXT PAGE) 
12. Once they know a person was in a mental hospital, most people will take his or her opinion less seriously.

\begin{tabular}{|c|c|c|c|c|}
\hline Strongly Disagree & Disagree & Agree & Strongly Agree & Don't Know \\
1 & 2 & 3 & 4 & DK \\
\hline
\end{tabular}

13. If you thought someone you knew held negative opinions about psychiatric patients, you would avoid him or her.

\begin{tabular}{|c|c|c|c|c|}
\hline Strongly Disagree & Disagree & Agree & Strongly Agree & Don't Know \\
1 & 2 & 3 & 4 & DK \\
\hline
\end{tabular}

14. Places of work should be organized so that people who have experienced a severe mental illness can work together.

\begin{tabular}{c|c|c|c|c}
\hline Strongly Disagree & Disagree & Agree & Strongly Agree & Don't Know \\
1 & 2 & 3 & 4 & DK \\
\hline
\end{tabular}

15. It is easier for you to be friendly with people who have been psychiatric patients.

\begin{tabular}{|c|c|c|c|c|}
\hline Strongly Disagree & Disagree & Agree & Strongly Agree & Don't Know \\
1 & 2 & 3 & 4 & DK \\
\hline
\end{tabular}

16. If a person thought less of you because you had been in psychiatric treatment, you would avoid him or her.

\begin{tabular}{|c|c|c|c|c|}
\hline Strongly Disagree & Disagree & Agree & Strongly Agree & Don't Know \\
1 & 2 & 3 & 4 & DK \\
\hline
\end{tabular}

17. People who have had a serious mental illness will find it less stressful to socialize with people who have also had a serious mental illness.

\begin{tabular}{c|c|c|c|c} 
Strongly Disagree & Disagree & Agree & Strongly Agree & Don't Know \\
1 & 2 & 3 & 4 & DK \\
\hline
\end{tabular}

18. If a friend of yours developed a serious mental illness you would advise him or her to spend most of his or her free time with people who have also experienced a serious mental illness.
Strongly Disagree
Disagree
Agree
Strongly Agree
Don't Know
1
2
3
4
DK

19. You believe that people who have a serious mental illness feel most comfortable when they are with people who also have a serious mental illness.

\begin{tabular}{|c|c|c|c|c|}
\hline Strongly Disagree & Disagree & Agree & Strongly Agree & Don't Know \\
1 & 2 & 3 & 4 & DK \\
\hline
\end{tabular}

20. You have a lot in common with people who have experienced a serious mental illness

\begin{tabular}{c|c|c|c|c}
\hline Strongly Disagree & Disagree & Agree & Strongly Agree & Don't Know \\
1 & 2 & 3 & 4 & DK \\
\hline
\end{tabular}

(CONTINUE WITH STIGMA SCALES ON NEXT PAGE) 


\section{(CONTINUE WITH AGREEMENT-DISAGREEMENT SCALE)}

21. When you meet people for the first time, you make a special effort to keep the fact that you have been in psychiatric treatment to yourself.

\begin{tabular}{|c|c|c|c|c|}
\hline Strongly Disagree & Disagree & Agree & Strongly Agree & Don't Know \\
1 & 2 & 3 & 4 & DK \\
\hline
\end{tabular}

22. There is something about the experience of being in a mental hospital that sets you apart from others.

\begin{tabular}{|c|c|c|c|c|}
\hline Strongly Disagree & Disagree & Agree & Strongly Agree & Don't Know \\
1 & 2 & 3 & 4 & DK \\
\hline
\end{tabular}

23. There is an important part of you that only people with a serious mental illness can understand.

\begin{tabular}{|c|c|c|c|c|}
\hline $\begin{array}{c}\text { Strongly Disagree } \\
1\end{array}$ & $\begin{array}{c}\text { Disagree } \\
2\end{array}$ & $\begin{array}{l}\text { Agree } \\
3\end{array}$ & $\begin{array}{c}\text { Strongly Agree } \\
4\end{array}$ & $\begin{array}{c}\text { Don't Know } \\
\text { DK }\end{array}$ \\
\hline \multicolumn{5}{|c|}{ 24. Having experienced mental illness has made you feel very different from other people. } \\
\hline $\begin{array}{c}\text { Strongly Disagree } \\
1\end{array}$ & $\begin{array}{c}\text { Disagree } \\
2\end{array}$ & $\begin{array}{c}\text { Agree } \\
3\end{array}$ & $\begin{array}{c}\text { Strongly Agree } \\
4\end{array}$ & $\begin{array}{c}\text { Don't Know } \\
\text { DK }\end{array}$ \\
\hline \multicolumn{5}{|c|}{ 25. The experience of entering a mental hospital made you feel ashamed. } \\
\hline $\begin{array}{c}\text { Strongly Disagree } \\
1\end{array}$ & $\begin{array}{c}\text { Disagree } \\
2\end{array}$ & $\begin{array}{c}\text { Agree } \\
3\end{array}$ & $\begin{array}{c}\text { Strongly Agree } \\
4\end{array}$ & $\begin{array}{c}\text { Don't Know } \\
\text { DK }\end{array}$ \\
\hline
\end{tabular}


(INFORMATION IN CAPITAL LETTERS AND IN BRACKETS ARE INSTRUCTIONS TO THE INTERVIEWER AND ARE NOT TO BE READ TO THE RESPONDENT)

PARTICIPANT'S NAME

INTERVIEWER'S NAME

DATE 1

\section{(WORKING ALLIANCE SCALE)*}

I would now like to know about the relationship you have established with your primary case manager here at Southeast, Inc. Remember that information you provide will remain confidential, neither your case manager nor other Southeast staff will know how you respond to the following set of statements.

B. What case management team do you receive services from at Southeast?

A. What is the first name of your case manager? (SUBSTITUTE THE NAME THE RESPONDENT PROVIDED IN PLACE OF THE REMAINING UNDERLINED PARTS OF THIS SECTION)

For the next 12 questions, please refer to this card. (HAND SUBJECT NEVER TO ALWAYS CARD). This is called a never to always scale.

(AS YOU EXPLAIN THE RANKINGS, POINT TO THE CORRESPONDING POINTS ON THE NEVER TO ALWAYS SCALE) This scale goes from never, which is the lowest ranking of 1 , to always which is the highest ranking of 7 . There are also points rarely, which is numbered 2, occasionally, which is numbered 3, sometimes, which is numbered 4, often, which is numbered 5, and very often, which is numbered 6.

Each question describes some different ways that a person might think or feel about her or his relationship with her or his case manager. For each question, use the never to always scale to let me know how you feel or think about your relationship with . If you don't know, just tell me that you do not know. Do you have any questions? Let's begin.

(READ EACH STATEMENT TO THE RESPONDENT AND RECORD THEIR RESPONSES IN THE RESPONSE SECTION, WHICH IS BELOW EACH STATEMENT. PROMPT THE RESPONDENT AS TO THE NEVER-ALWAYS SCALE AS NECESSARY) 
*The working alliance inventory is copyright protected.

\begin{tabular}{|c|c|c|c|c|c|c|c|}
\hline \multicolumn{8}{|c|}{$\begin{array}{l}\text { 1.How often do } \\
\text { improve your situation? }\end{array}$} \\
\hline $\begin{array}{c}\text { Never } \\
1 \\
\end{array}$ & $\begin{array}{c}\text { Rarely } \\
2\end{array}$ & $\begin{array}{c}\text { Occasionally } \\
3 \\
\end{array}$ & $\begin{array}{c}\text { Sometimes } \\
4\end{array}$ & $\begin{array}{c}\text { Often } \\
5\end{array}$ & $\begin{array}{l}\text { Very Often } \\
6\end{array}$ & $\begin{array}{c}\text { Always } \\
7\end{array}$ & $\begin{array}{c}\text { Don't Know } \\
\text { DK }\end{array}$ \\
\hline \multicolumn{8}{|c|}{ 2.How often does what you are doing in case management give you new ways of looking at your problem? } \\
\hline $\begin{array}{c}\text { Never } \\
1\end{array}$ & $\begin{array}{c}\text { Rarely } \\
2\end{array}$ & $\begin{array}{c}\text { Occasionally } \\
3\end{array}$ & $\begin{array}{c}\text { Sometimes } \\
4\end{array}$ & $\begin{array}{l}\text { Often } \\
5\end{array}$ & $\begin{array}{c}\text { Very Often } \\
6\end{array}$ & $\begin{array}{c}\text { Always } \\
7\end{array}$ & $\begin{array}{c}\text { Don't Know } \\
\text { DK }\end{array}$ \\
\hline \multicolumn{8}{|c|}{ 3. How often do you believe _______ likes you? } \\
\hline $\begin{array}{c}\text { Never } \\
1 \\
\end{array}$ & $\begin{array}{c}\text { Rarely } \\
2 \\
\end{array}$ & $\begin{array}{c}\text { Occasionally } \\
3 \\
\end{array}$ & $\begin{array}{c}\text { Sometimes } \\
4 \\
\end{array}$ & $\begin{array}{c}\text { Often } \\
5 \\
\end{array}$ & $\begin{array}{c}\text { Very Often } \\
6 \\
\end{array}$ & $\begin{array}{c}\text { Always } \\
7 \\
\end{array}$ & $\begin{array}{c}\text { Don't Know } \\
\text { DK } \\
\end{array}$ \\
\hline \multicolumn{8}{|c|}{ 4. How often does } \\
\hline $\begin{array}{c}\text { Never } \\
1 \\
\end{array}$ & $\begin{array}{c}\text { Rarely } \\
2 \\
\end{array}$ & $\begin{array}{c}\text { Occasionally } \\
3 \\
\end{array}$ & $\begin{array}{c}\text { Sometimes } \\
4 \\
\end{array}$ & $\begin{array}{l}\text { Often } \\
5\end{array}$ & $\begin{array}{c}\text { Very Often } \\
6 \\
\end{array}$ & $\begin{array}{c}\text { Always } \\
7\end{array}$ & $\begin{array}{c}\text { Don't Know } \\
\text { DK } \\
\end{array}$ \\
\hline \multicolumn{8}{|c|}{ 5. How often are you confident in _____ 's ability to help you? } \\
\hline $\begin{array}{c}\text { Never } \\
1\end{array}$ & $\begin{array}{c}\text { Rarely } \\
2\end{array}$ & $\begin{array}{c}\text { Occasionally } \\
3\end{array}$ & $\begin{array}{c}\text { Sometimes } \\
4\end{array}$ & $\begin{array}{c}\text { Often } \\
5\end{array}$ & $\begin{array}{c}\text { Very Often } \\
6\end{array}$ & $\begin{array}{c}\text { Always } \\
7\end{array}$ & $\begin{array}{c}\text { Don't Know } \\
\text { DK }\end{array}$ \\
\hline \multicolumn{8}{|c|}{ 6. How often are } \\
\hline $\begin{array}{c}\text { Never } \\
1\end{array}$ & $\begin{array}{c}\text { Rarely } \\
2\end{array}$ & $\begin{array}{c}\text { Occasionally } \\
3\end{array}$ & $\begin{array}{c}\text { Sometimes } \\
4\end{array}$ & $\begin{array}{l}\text { Often } \\
5\end{array}$ & $\begin{array}{c}\text { Very Often } \\
6\end{array}$ & $\begin{array}{c}\text { Always } \\
7\end{array}$ & $\begin{array}{c}\text { Don't Know } \\
\text { DK }\end{array}$ \\
\hline \multicolumn{8}{|c|}{ 7. How often do you feel that __________ appreciates you? } \\
\hline $\begin{array}{c}\text { Never } \\
1 \\
\end{array}$ & $\begin{array}{c}\text { Rarely } \\
2\end{array}$ & $\begin{array}{c}\text { Occasionally } \\
3 \\
\end{array}$ & $\begin{array}{c}\text { Sometimes } \\
4 \\
\end{array}$ & $\begin{array}{c}\text { Often } \\
5 \\
\end{array}$ & $\begin{array}{c}\text { Very Often } \\
6 \\
\end{array}$ & $\begin{array}{c}\text { Always } \\
7 \\
\end{array}$ & $\begin{array}{c}\text { Don't Know } \\
\text { DK } \\
\end{array}$ \\
\hline \multicolumn{8}{|c|}{ 8.How often do ___ and you agree on what is important for you to work on? } \\
\hline $\begin{array}{c}\text { Never } \\
1 \\
\end{array}$ & $\begin{array}{c}\text { Rarely } \\
2 \\
\end{array}$ & $\begin{array}{c}\text { Occasionally } \\
3 \\
\end{array}$ & $\begin{array}{c}\text { Sometimes } \\
4\end{array}$ & $\begin{array}{c}\text { Often } \\
5 \\
\end{array}$ & $\begin{array}{c}\text { Very Often } \\
6 \\
\end{array}$ & $\begin{array}{c}\text { Always } \\
7\end{array}$ & $\begin{array}{c}\text { Don't Know } \\
\text { DK }\end{array}$ \\
\hline \multicolumn{8}{|c|}{ 9. How often do } \\
\hline $\begin{array}{c}\text { Never } \\
1\end{array}$ & $\begin{array}{c}\text { Rarely } \\
2\end{array}$ & $\begin{array}{c}\text { Occasionally } \\
3\end{array}$ & $\begin{array}{c}\text { Sometimes } \\
4\end{array}$ & $\begin{array}{c}\text { Often } \\
5\end{array}$ & $\begin{array}{c}\text { Very Often } \\
6\end{array}$ & $\begin{array}{c}\text { Always } \\
7\end{array}$ & $\begin{array}{c}\text { Don't Know } \\
\text { DK }\end{array}$ \\
\hline \multicolumn{8}{|c|}{ 10.How often do ___ } \\
\hline $\begin{array}{c}\text { Never } \\
1\end{array}$ & $\begin{array}{c}\text { Rarely } \\
2\end{array}$ & $\begin{array}{c}\text { Occasionally } \\
3\end{array}$ & $\begin{array}{c}\text { Sometimes } \\
4\end{array}$ & $\begin{array}{c}\text { Often } \\
5\end{array}$ & $\begin{array}{c}\text { Very Often } \\
6\end{array}$ & $\begin{array}{c}\text { Always } \\
7\end{array}$ & $\begin{array}{c}\text { Don't Know } \\
\text { DK }\end{array}$ \\
\hline
\end{tabular}

(CONTINUE ON NEXT PAGE) 


\section{(CONTINUE WITH READING EACH STATEMENT AND USING THE AGREEMENT-DISAGREEMENT SCALE)}

11. How much have ___ and you established a good understanding of the kind of changes that would be good for you?

\begin{tabular}{|c|c|c|c|c|c|c|c|}
\hline $\begin{array}{c}\text { Never } \\
1\end{array}$ & $\begin{array}{c}\text { Rarely } \\
2\end{array}$ & $\begin{array}{c}\text { Occasionally } \\
3\end{array}$ & $\begin{array}{c}\text { Sometimes } \\
4\end{array}$ & $\begin{array}{c}\text { Often } \\
5\end{array}$ & $\begin{array}{c}\text { Very Often } \\
6\end{array}$ & $\begin{array}{c}\text { Always } \\
7\end{array}$ & $\begin{array}{c}\text { Don't } \\
\text { Know } \\
\text { DK }\end{array}$ \\
12. How often do you believe the way you two are working with your problem is correct? \\
\hline \begin{tabular}{c|c|c|c|c|c|c|} 
Never \\
1
\end{tabular} & $\begin{array}{c}\text { Rarely } \\
2\end{array}$ & $\begin{array}{c}\text { Occasionally } \\
3\end{array}$ & $\begin{array}{c}\text { Sometimes } \\
4\end{array}$ & $\begin{array}{c}\text { Often } \\
\text { Very Often }\end{array}$ & $\begin{array}{c}\text { Don't } \\
\text { Know } \\
\text { DK }\end{array}$ \\
\hline
\end{tabular}


(INFORMATION IN CAPITAL LETTERS AND IN BRACKETS ARE

INSTRUCTIONS TO THE INTERVIEWER AND ARE NOT TO BE READ TO THE RESPONDENT)

PARTICIPANT'S NAME

INTERVIEWER'S NAME

DATE I______

\section{(SUBJECTIVE QUALITY OF LIFE)}

Please look at this card. (HAND SUBJECT THE DELIGHTED-TERRIBLE SCALE). This is called the Delighted-Terrible Scale.

(POINT TO THE CORRESPONDING PLACES ON THE DELIGHTED- TERRIBLE SCALE CARD AS YOU DESCRIBE THE RATINGS) The scale goes from Terrible, which is the lowest ranking of 1 , to delighted, which is the highest ranking of 7 . As you can see there are also points 2 , which is unhappy, 3 , which is mostly dissatisfied, 4 which is mixed, 5 which is mostly satisfied, and 6 , which is pleased.

The next 44 statements relate to aspects of your quality of life, including statements about your life in general, your living situation, your daily activities, your family, your friends, your finances, your work, your safety, and your health. For each of these statements, use this agreement- disagreement scale to let me know what you think about that aspect of your quality of life. If you do not know, just state that you do not know. Use this agreement-disagreement card to help you as you think about how each statement relates to your life. Do you have any questions? Let's begin

(READ EACH STATEMENT TO THE RESPONDENT AND CIRCLE THEIR RESPONSES IN THE RESPONSE SECTION, WHICH IS BELOW EACH STATEMENT. PROMPT THE RESPONDENT AS TO THE DELIGHTED-TERRIBLE SCALE AS NECESSARY)

\section{(SECTION 1)}

The first question is a very general one

\begin{tabular}{|c|c|c|c|c|c|c|c|}
\hline Terrible & unhappy & $\begin{array}{c}\text { Mostly } \\
\text { dissatisfied }\end{array}$ & Mixed & $\begin{array}{l}\text { Mostly } \\
\text { satisfied }\end{array}$ & & & $\begin{array}{l}\text { Don't } \\
\text { Know }\end{array}$ \\
\hline 1 & 2 & 3 & 4 & 5 & 6 & 7 & DK \\
\hline
\end{tabular}

(CONTINUE ON NEXT PAGE) (SECTION 2) 
The next few questions relate to your current living arrangements. Take a few moments to think about the place you live. (GIVE RESPONDENT A FEW SECONDS TO THINK ABOUT WHERE THEY LIVE). Are you ready? For each statement, please use the delighted to terrible scale to state what you think about yourself related to that statement.

2. how do you feel about the living arrangements where you live?

\begin{tabular}{c|c|c|c|c|c|c|c|} 
Terrible & unhappy & $\begin{array}{c}\text { Mostly } \\
\text { dissatisfied }\end{array}$ & Mixed & $\begin{array}{c}\text { Mostly } \\
\text { satisfied }\end{array}$ & Pleased & Delighted & Don't Know \\
DK
\end{tabular}

3. About the food there?

\begin{tabular}{|c|c|c|c|c|c|c|c|}
\hline Terrible & $\begin{array}{c}\text { unhappy } \\
2 \\
\end{array}$ & $\begin{array}{c}\text { Mostly } \\
\text { dissatisfied } \\
3\end{array}$ & Mixed & $\begin{array}{c}\text { Mostly } \\
\text { satisfied } \\
5\end{array}$ & $\begin{array}{c}\text { Pleased } \\
6 \\
6\end{array}$ & $\begin{array}{c}\text { Delighted } \\
7 \\
\end{array}$ & $\begin{array}{c}\text { Don't Know } \\
\text { DK }\end{array}$ \\
\hline \multicolumn{8}{|c|}{ 4. About the rules there? } \\
\hline Terrible & unhappy & $\begin{array}{c}\text { Mostly } \\
\text { dissatisfied }\end{array}$ & Mixed & $\begin{array}{l}\text { Mostly } \\
\text { satisfied }\end{array}$ & Pleased & Delighted & $\begin{array}{c}\text { Don't Know } \\
\text { DK }\end{array}$ \\
\hline 1 & 2 & 3 & 4 & 5 & 6 & 7 & \\
\hline
\end{tabular}

5. how do you feel about the privacy you have there?

\begin{tabular}{c|c|c|c|c|c|c|c|}
\hline Terrible & unhappy & $\begin{array}{c}\text { Mostly } \\
\text { dissatisfied }\end{array}$ & Mixed & $\begin{array}{c}\text { Mostly } \\
\text { satisfied }\end{array}$ & Pleased & Delighted & $\begin{array}{c}\text { Don't Know } \\
\text { DK }\end{array}$ \\
\hline 1 & 2 & 3 & 4 & 5 & 6 & 7 & \\
\hline
\end{tabular}

6. about the amount of freedom you have there?

\begin{tabular}{c|c|c|c|c|c|c|c|} 
Terrible & unhappy & $\begin{array}{c}\text { Mostly } \\
\text { dissatisfied }\end{array}$ & Mixed & $\begin{array}{c}\text { Mostly } \\
\text { satisfied }\end{array}$ & Pleased & Delighted & $\begin{array}{c}\text { Don't Know } \\
\text { DK }\end{array}$ \\
1 & 2 & 3 & 4 & 5 & 6 & 7 & \\
\hline
\end{tabular}

7. about the prospect of staying on where you currently live for a long period of time?

\begin{tabular}{|c|c|c|c|c|c|c|c|}
\hline Terrible & unhappy & $\begin{array}{c}\text { Mostly } \\
\text { dissatisfied }\end{array}$ & Mixed & $\begin{array}{c}\text { Mostly } \\
\text { satisfied }\end{array}$ & Pleased & $\begin{array}{c}\text { Delighted } \\
\text { Don't Know } \\
\text { DK }\end{array}$ \\
\hline
\end{tabular}

\section{(CONTINUE ON NEXT PAGE)}




\section{(SECTION 3)}

Now I am going to ask you some questions about your leisure time. Take a few moments to think about your leisure time. (GIVE RESPONDENT A FEW SECONDS TO THINK ABOUT THEIR LEISURE TIME). Are you ready? Again please use the terribledelighted scale to respond to each question.

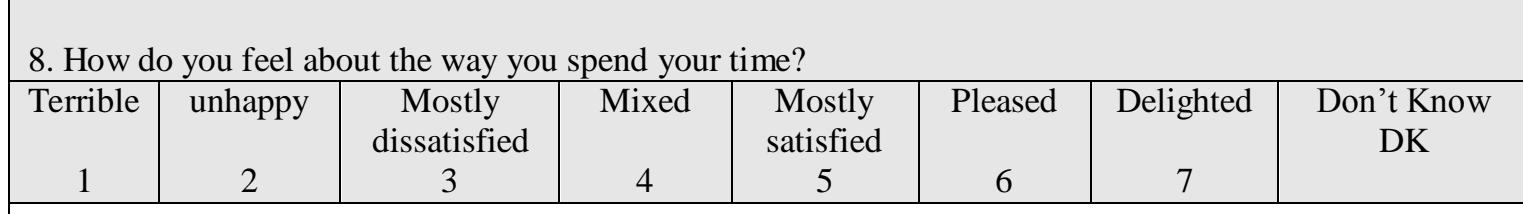

9. About the amount of time you have to do the things you want to do?

\begin{tabular}{|c|c|c|c|c|c|c|c|}
\hline Terrible & unhappy & $\begin{array}{c}\text { Mostly } \\
\text { dissatisfied }\end{array}$ & Mixed & $\begin{array}{c}\text { Mostly } \\
\text { satisfied }\end{array}$ & Pleased & Delighted & $\begin{array}{c}\text { Don't Know } \\
\text { DK }\end{array}$ \\
1 & 2 & 3 & 4 & 5 & 6 & 7 & \\
\hline
\end{tabular}

10. About the chance you have to enjoy pleasant or beautiful things?

\begin{tabular}{|c|c|c|c|c|c|c|c|}
\hline Terrible & unhappy & $\begin{array}{c}\text { Mostly } \\
\text { dissatisfied }\end{array}$ & Mixed & $\begin{array}{c}\text { Mostly } \\
\text { satisfied }\end{array}$ & Pleased & Delighted & $\begin{array}{c}\text { Don’t Know } \\
\text { DK }\end{array}$ \\
\hline 1 & 2 & 3 & 4 & 5 & 6 & 7 & \\
\hline
\end{tabular}

11. How do you feel about the amount of fun you have?

\begin{tabular}{|c|c|c|c|c|c|c|c|}
\hline Terrible & unhappy & $\begin{array}{c}\text { Mostly } \\
\text { dissatisfied }\end{array}$ & Mixed & $\begin{array}{c}\text { Mostly } \\
\text { satisfied }\end{array}$ & Pleased & Delighted & $\begin{array}{c}\text { Don't Know } \\
\text { DK }\end{array}$ \\
\hline 1 & 2 & 3 & 4 & 5 & 6 & 7 & \\
\hline
\end{tabular}

12. About the amount of relaxation in your life?

\begin{tabular}{|c|c|c|c|c|c|c|c|}
\hline Terrible & unhappy & $\begin{array}{c}\text { Mostly } \\
\text { dissatisfied }\end{array}$ & Mixed & $\begin{array}{c}\text { Mostly } \\
\text { satisfied }\end{array}$ & Pleased & Delighted & $\begin{array}{c}\text { Don't Know } \\
\text { DK }\end{array}$ \\
\hline 1 & 2 & 3 & 4 & 5 & 6 & 7 & \\
\hline
\end{tabular}

13. About the pleasure you get from the television or radio?

\begin{tabular}{|c|c|c|c|c|c|c|c|}
\hline Terrible & unhappy & $\begin{array}{c}\text { Mostly } \\
\text { dissatisfied }\end{array}$ & Mixed & $\begin{array}{c}\text { Mostly } \\
\text { satisfied }\end{array}$ & Pleased & Delighted & $\begin{array}{c}\text { Don’t Know } \\
\text { DK }\end{array}$ \\
1 & 2 & 3 & 4 & 5 & 6 & 7 & \\
\hline
\end{tabular}

\section{(CONTINUE ON NEXT PAGE)}




\section{(SECTION 4)}

The next few questions are about your relationships with your family including any relatives with whom you live. Take a few moments to think about members of your family. (GIVE RESPONDENT A FEW MOMENTS TO THINK ABOUT THEIR FAMILY) Are you ready? For each question, answer using the Delighted-Terrible scale

\begin{tabular}{|c|c|c|c|c|c|c|c|}
\hline \multicolumn{1}{|c|}{ 14. How do you feel about your family in general? } \\
\hline Terrible & unhappy & $\begin{array}{c}\text { Mostly } \\
\text { dissatisfied }\end{array}$ & Mixed & $\begin{array}{c}\text { Mostly } \\
\text { satisfied }\end{array}$ & Pleased & Delighted & $\begin{array}{c}\text { Don't } \\
\text { Know } \\
\text { DK }\end{array}$ \\
\hline 1 & 2 & 3 & 4 & 5 & 6 & 7 & \\
\hline
\end{tabular}

15. About how often you have contact with your family?

\begin{tabular}{|c|c|c|c|c|c|c|c|}
\hline Terrible & unhappy & $\begin{array}{c}\text { Mostly } \\
\text { dissatisfied }\end{array}$ & Mixed & $\begin{array}{c}\text { Mostly } \\
\text { satisfied }\end{array}$ & Pleased & Delighted & $\begin{array}{c}\text { Don't } \\
\text { Know } \\
\text { DK }\end{array}$ \\
\hline 1 & 2 & 3 & 4 & 5 & 6 & 7 & ( \\
\hline
\end{tabular}

16. How do you feel about the way you and your family act towards each other?

\begin{tabular}{c|c|c|c|c|c|c|c|} 
Terrible & unhappy & $\begin{array}{c}\text { Mostly } \\
\text { dissatisfied }\end{array}$ & Mixed & $\begin{array}{c}\text { Mostly } \\
\text { satisfied }\end{array}$ & Pleased & Delighted & $\begin{array}{c}\text { Don’t } \\
\text { Know } \\
1\end{array}$ \\
\hline & 2 & 3 & 4 & 5 & 6 & 7 & DK \\
\hline
\end{tabular}

17. About the way things are in general between you and your family?

\begin{tabular}{|c|c|c|c|c|c|c|c|}
\hline Terrible & unhappy & $\begin{array}{c}\text { Mostly } \\
\text { dissatisfied }\end{array}$ & Mixed & $\begin{array}{c}\text { Mostly } \\
\text { satisfied }\end{array}$ & Pleased & Delighted & $\begin{array}{c}\text { Don't } \\
\text { Know } \\
1\end{array}$ \\
2 & 3 & 4 & 5 & 6 & 7 & DK \\
\hline
\end{tabular}

\section{(SECTION 5)}

I am now going to ask you how you feel about other people in your life, that is, people who are not in your family. Pease take a few moments to think about these persons. (GIVE RESPONDENT A FEW SECONDS TO THINK ABOUT THESE PEOPLE) Are you ready? Again, please use the delighted-terrible scale to answer each question.

\begin{tabular}{|c|c|c|c|c|c|c|c|}
\hline 18. How do you feel about the things you do with other people? \\
\hline Terrible & unhappy & $\begin{array}{c}\text { Mostly } \\
\text { dissatisfied }\end{array}$ & Mixed & $\begin{array}{c}\text { Mostly } \\
\text { satisfied }\end{array}$ & Pleased & Delighted & $\begin{array}{c}\text { Don't } \\
\text { Know } \\
\text { DK }\end{array}$ \\
\hline
\end{tabular}

(CONTINUE SECTION 5 ON NEXT PAGE) 


\section{(CONTINUE SECTION 5)}

19. About the amount of time you spend with other people?

\begin{tabular}{|c|c|c|c|c|c|c|c|}
\hline Terrible & $\begin{array}{c}\text { unhappy } \\
2 \\
\end{array}$ & $\begin{array}{c}\text { Mostly } \\
\text { dissatisfied } \\
3 \\
\end{array}$ & $\begin{array}{c}\text { Mixed } \\
4 \\
\end{array}$ & $\begin{array}{c}\text { Mostly } \\
\text { satisfied } \\
5 \\
\end{array}$ & $\begin{array}{c}\text { Pleased } \\
6 \\
\end{array}$ & $\begin{array}{c}\text { Delighted } \\
7 \\
\end{array}$ & $\begin{array}{c}\text { Don’t } \\
\text { Know } \\
\text { DK }\end{array}$ \\
\hline \multicolumn{8}{|c|}{ 20. About the people you see socially? } \\
\hline Terrible & unhappy & $\begin{array}{c}\text { Mostly } \\
\text { dissatisfied } \\
3\end{array}$ & $\begin{array}{c}\text { Mixed } \\
4\end{array}$ & $\begin{array}{c}\text { Mostly } \\
\text { satisfied } \\
5\end{array}$ & Pleased & $\begin{array}{c}\text { Delighted } \\
7\end{array}$ & $\begin{array}{c}\text { Don’t } \\
\text { Know } \\
\text { DK }\end{array}$ \\
\hline
\end{tabular}

21. How do you feel about how you get along with other people in general?

\begin{tabular}{c|c|c|c|c|c|c|c|}
\hline Terrible & unhappy & $\begin{array}{c}\text { Mostly } \\
\text { dissatisfied }\end{array}$ & Mixed & $\begin{array}{c}\text { Mostly } \\
\text { satisfied }\end{array}$ & Pleased & Delighted & $\begin{array}{c}\text { Don’t } \\
\text { Know } \\
\text { DK }\end{array}$ \\
\hline 1 & 2 & 3 & 4 & 5 & 6 & 7 & \\
\hline
\end{tabular}

22. About the chance you have to know people with whom you really feel comfortable?

\begin{tabular}{|c|c|c|c|c|c|c|c|}
\hline Terrible & $\begin{array}{c}\text { unhappy } \\
2 \\
\end{array}$ & $\begin{array}{c}\text { Mostly } \\
\text { dissatisfied } \\
3 \\
\end{array}$ & $\begin{array}{c}\text { Mixed } \\
4 \\
\end{array}$ & $\begin{array}{c}\text { Mostly } \\
\text { satisfied } \\
5 \\
\end{array}$ & $\begin{array}{c}\text { Pleased } \\
6 \\
\end{array}$ & $\begin{array}{c}\text { Delighted } \\
7 \\
\end{array}$ & $\begin{array}{c}\text { Don't } \\
\text { Know } \\
\text { DK }\end{array}$ \\
\hline \multicolumn{8}{|c|}{ 23. About the amount of friendship in your life? } \\
\hline Terrible & unhappy & $\begin{array}{c}\text { Mostly } \\
\text { dissatisfied } \\
3\end{array}$ & Mixed & $\begin{array}{c}\text { Mostly } \\
\text { satisfied } \\
5\end{array}$ & Pleased & Delighted & $\begin{array}{c}\text { Don't } \\
\text { Know } \\
\text { DK }\end{array}$ \\
\hline
\end{tabular}

\section{(SECTION 6)}

I am now going to ask you a few questions about your money situation. Take a few moments to think about your money situation (GIVE THE RESPONDENT A FEW SECONDS TO THINK ABOUT THEIR MONEY SITUATION). Are you ready? Please use the delighted-terrible scale to respond to each question.

24. How do you feel about the amount of money you get?

\begin{tabular}{c|c|c|c|c|c|c|c|} 
Terrible & unhappy & $\begin{array}{c}\text { Mostly } \\
\text { dissatisfied }\end{array}$ & Mixed & $\begin{array}{c}\text { Mostly } \\
\text { satisfied }\end{array}$ & Pleased & Delighted & $\begin{array}{c}\text { Don't } \\
\text { Know } \\
1\end{array}$ \\
\hline & 3 & 4 & 5 & 6 & 7 & DK \\
\hline
\end{tabular}

25. About the money you have to cover basic necessities such as food, housing, and clothes?

\begin{tabular}{|c|c|c|c|c|c|c|c|} 
Terrible & unhappy & $\begin{array}{c}\text { Mostly } \\
\text { dissatisfied }\end{array}$ & Mixed & $\begin{array}{c}\text { Mostly } \\
\text { satisfied }\end{array}$ & Pleased & Delighted & $\begin{array}{c}\text { Don't } \\
\text { Know } \\
1\end{array}$ \\
2 & 3 & 4 & 5 & 6 & 7 & DK \\
\hline
\end{tabular}

(CONTINUE SECTION 6 ON NEXT PAGE) 


\section{(CONTINUE SECTION 6)}

26. How you feel about how comfortable and well-off you are financially?

\begin{tabular}{c|c|c|c|c|c|c|c|} 
Terrible & unhappy & $\begin{array}{c}\text { Mostly } \\
\text { dissatisfied }\end{array}$ & Mixed & $\begin{array}{c}\text { Mostly } \\
\text { satisfied }\end{array}$ & Pleased & Delighted & Don't \\
Know \\
1
\end{tabular}

27. About the amount of money you have available to spend for fun?

\begin{tabular}{|c|c|c|c|c|c|c|c|}
\hline Terrible & unhappy & $\begin{array}{c}\text { Mostly } \\
\text { dissatisfied }\end{array}$ & Mixed & $\begin{array}{c}\text { Mostly } \\
\text { satisfied }\end{array}$ & Pleased & Delighted & $\begin{array}{c}\text { Don't } \\
\text { Know } \\
1\end{array}$ \\
2 & 3 & 4 & 5 & 6 & 7 & DK \\
\hline
\end{tabular}

\section{(SECTION 7)}

I now have a question that is a little different from the rest.

28. Are you currently employed? Yes

No

\section{(IF NO, SKIP TO SECTION 8, IF YES CONTINUE WITH SECTION 7)}

For the next set of questions, I want you to think about the place that you work. Please take a few moments to think about your job (GIVE RESPONDET A FEW SECONDS TO THINK). Are you ready? Please use the delighted-terrible scale to answer each question.

29. How do you feel about your job?

\begin{tabular}{|c|c|c|c|c|c|c|c|}
\hline Terrible & unhappy & $\begin{array}{c}\text { Mostly } \\
\text { dissatisfied }\end{array}$ & Mixed & $\begin{array}{c}\text { Mostly } \\
\text { satisfied }\end{array}$ & Pleased & Delighted & Don't \\
Know \\
1
\end{tabular}

30. About the people you work with?

\begin{tabular}{|c|c|c|c|c|c|c|c|}
\hline Terrible & $\begin{array}{c}\text { unhappy } \\
2\end{array}$ & $\begin{array}{c}\text { Mostly } \\
\text { dissatisfied } \\
3\end{array}$ & $\begin{array}{c}\text { Mixed } \\
4\end{array}$ & $\begin{array}{c}\text { Mostly } \\
\text { satisfied } \\
5 \\
\end{array}$ & $\begin{array}{c}\text { Pleased } \\
6\end{array}$ & $\begin{array}{c}\text { Delighted } \\
7 \\
\end{array}$ & $\begin{array}{c}\text { Don't } \\
\text { Know } \\
\text { DK }\end{array}$ \\
\hline 31. How & $f_{f o l}$ & what it is lik & lere you & $\mathrm{x}$, that is $\mathrm{t}$ & nysical su & undings? & \\
\hline Terrible & unhappy & $\begin{array}{c}\text { Mostly } \\
\text { dissatisfied } \\
3\end{array}$ & Mixed & $\begin{array}{c}\text { Mostly } \\
\text { satisfied } \\
5\end{array}$ & $\begin{array}{c}\text { Pleased } \\
6\end{array}$ & Delighted & $\begin{array}{c}\text { Don't } \\
\text { Know } \\
\text { DK }\end{array}$ \\
\hline
\end{tabular}

\section{(CONTINUE SECTION 7 ON NEXT PAGE)}


32. about the number of hours you work?

\begin{tabular}{|c|c|c|c|c|c|c|c|}
\hline Terrible & $\begin{array}{c}\text { unhappy } \\
2\end{array}$ & $\begin{array}{c}\text { Mostly } \\
\text { dissatisfied } \\
3\end{array}$ & $\begin{array}{c}\text { Mixed } \\
4\end{array}$ & $\begin{array}{c}\text { Mostly } \\
\text { satisfied } \\
5\end{array}$ & $\begin{array}{c}\text { Pleased } \\
6\end{array}$ & $\begin{array}{c}\text { Delighted } \\
7\end{array}$ & $\begin{array}{c}\text { Don't } \\
\text { Know } \\
\text { DK }\end{array}$ \\
\hline \multicolumn{8}{|c|}{ 33. about the amount you get paid? } \\
\hline Terrible & unhappy & $\begin{array}{c}\text { Mostly } \\
\text { dissatisfied } \\
3\end{array}$ & $\begin{array}{c}\text { Mixed } \\
4\end{array}$ & $\begin{array}{c}\text { Mostly } \\
\text { satisfied } \\
5\end{array}$ & $\begin{array}{c}\text { Pleased } \\
6\end{array}$ & $\begin{array}{c}\text { Delighted } \\
7\end{array}$ & $\begin{array}{c}\text { Don't } \\
\text { Know } \\
\text { DK }\end{array}$ \\
\hline
\end{tabular}

\section{(SECTION 8).}

I am now going to ask you a few questions about your personal safety. Take a few moments to think about your sense of personal safety. (GIVE RESPONDENT A FEW SECONDS TO THINK ABOUT THEIR SAFETY). Are you ready? Please use the delighted-terrible scale to respond to each question.

34. How do you feel about your personal safety?

\begin{tabular}{|c|c|c|c|c|c|c|c|} 
Terrible & unhappy & $\begin{array}{c}\text { Mostly } \\
\text { dissatisfied }\end{array}$ & Mixed & $\begin{array}{c}\text { Mostly } \\
\text { satisfied }\end{array}$ & Pleased & Delighted & $\begin{array}{c}\text { Don't } \\
\text { Know } \\
1\end{array}$ \\
\hline
\end{tabular}

35. About how safe you are on the streets in your neighborhood?

\begin{tabular}{c|c|c|c|c|c|c|c|}
\hline Terrible & unhappy & $\begin{array}{c}\text { Mostly } \\
\text { dissatisfied }\end{array}$ & Mixed & $\begin{array}{c}\text { Mostly } \\
\text { satisfied }\end{array}$ & Pleased & Delighted & $\begin{array}{c}\text { Don't } \\
\text { Know } \\
1\end{array}$ \\
2 & 3 & 4 & 5 & 6 & 7 & DK \\
\hline
\end{tabular}

36. About how safe you are where you live?

\begin{tabular}{|c|c|c|c|c|c|c|c|}
\hline Terrible & unhappy & $\begin{array}{c}\text { Mostly } \\
\text { dissatisfied }\end{array}$ & Mixed & $\begin{array}{c}\text { Mostly } \\
\text { satisfied }\end{array}$ & Pleased & Delighted & $\begin{array}{c}\text { Don`t } \\
\text { Know } \\
1\end{array}$ \\
2 & 3 & 4 & 5 & 6 & 7 & DK \\
\hline
\end{tabular}

37. How do you feel about the protection you have against being robbed or attacked?

\begin{tabular}{c|c|c|c|c|c|c|c|} 
Terrible & unhappy & $\begin{array}{c}\text { Mostly } \\
\text { dissatisfied }\end{array}$ & Mixed & $\begin{array}{c}\text { Mostly } \\
\text { satisfied }\end{array}$ & Pleased & Delighted & $\begin{array}{c}\text { Don't } \\
\text { Know } \\
1\end{array}$ \\
2 & 3 & 4 & 5 & 6 & 7 & DK \\
\hline
\end{tabular}

38. About your chance of finding a police officer if you need one?

\begin{tabular}{|c|c|c|c|c|c|c|c|}
\hline Terrible & unhappy & $\begin{array}{c}\text { Mostly } \\
\text { dissatisfied }\end{array}$ & Mixed & $\begin{array}{c}\text { Mostly } \\
\text { satisfied }\end{array}$ & Pleased & Delighted & $\begin{array}{c}\text { Don't } \\
\text { Know } \\
\text { DK }\end{array}$ \\
\hline
\end{tabular}

(CONTINUE ON NEXT PAGE) 


\section{(SECTION 9)}

I am now going to ask you a few questions about your health. Please take a few moments to think about your health. (GIVE RESPONDENT A FEW SECONDS TO THINK ABOUT THEIR HEALTH). Are you ready? Please use the delighted-terrible scale to respond to each question.

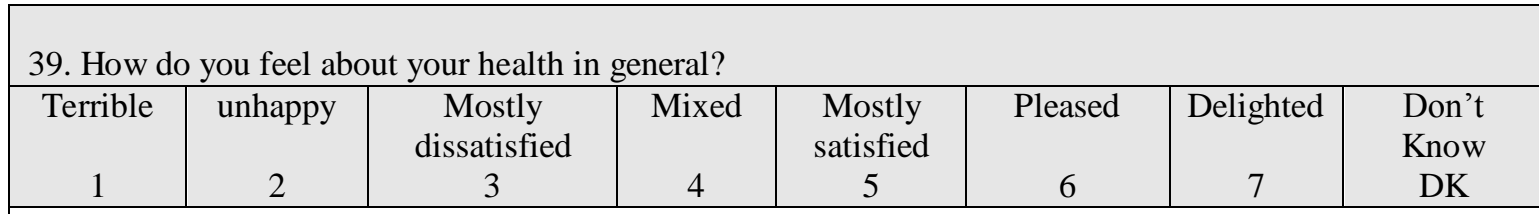

40. About the medical care available to you if you need it?

\begin{tabular}{|c|c|c|c|c|c|c|c|}
\hline Terrible & $\begin{array}{c}\text { unhappy } \\
2 \\
\end{array}$ & $\begin{array}{c}\text { Mostly } \\
\text { dissatisfied } \\
3 \\
\end{array}$ & $\begin{array}{c}\text { Mixed } \\
4\end{array}$ & $\begin{array}{c}\text { Mostly } \\
\text { satisfied } \\
5 \\
\end{array}$ & $\begin{array}{c}\text { Pleased } \\
6 \\
6\end{array}$ & $\begin{array}{c}\text { Delighted } \\
7 \\
\end{array}$ & $\begin{array}{l}\text { Don't } \\
\text { Know } \\
\text { DK } \\
\end{array}$ \\
\hline \multicolumn{8}{|c|}{ 41. How do you feel about how often you see a doctor? } \\
\hline Terrible & $\begin{array}{c}\text { unhappy } \\
2\end{array}$ & $\begin{array}{c}\text { Mostly } \\
\text { dissatisfied } \\
3\end{array}$ & $\begin{array}{c}\text { Mixed } \\
4\end{array}$ & $\begin{array}{c}\text { Mostly } \\
\text { satisfied } \\
5\end{array}$ & $\begin{array}{c}\text { Pleased } \\
6\end{array}$ & $\begin{array}{c}\text { Delighted } \\
7\end{array}$ & $\begin{array}{l}\text { Don't } \\
\text { Know } \\
\text { DK }\end{array}$ \\
\hline
\end{tabular}

42. About the chance you have to talk with a therapist?

\begin{tabular}{c|c|c|c|c|c|c|c|}
\hline Terrible & unhappy & $\begin{array}{c}\text { Mostly } \\
\text { dissatisfied }\end{array}$ & Mixed & $\begin{array}{c}\text { Mostly } \\
\text { satisfied }\end{array}$ & Pleased & Delighted & $\begin{array}{c}\text { Don't } \\
\text { Know }\end{array}$ \\
1 & 2 & 3 & 4 & 5 & 6 & 7 & DK \\
\hline
\end{tabular}

43. How do you feel about your physical condition?

\begin{tabular}{|c|c|c|c|c|c|c|c|}
\hline $\begin{array}{c}\text { Terrible } \\
1 \\
\end{array}$ & $\begin{array}{c}\text { unhappy } \\
2 \\
\end{array}$ & $\begin{array}{c}\text { Mostly } \\
\text { dissatisfied } \\
3\end{array}$ & $\begin{array}{c}\text { Mixed } \\
4 \\
\end{array}$ & $\begin{array}{c}\text { Mostly } \\
\text { satisfied } \\
5\end{array}$ & $\begin{array}{c}\text { Pleased } \\
6 \\
6\end{array}$ & $\begin{array}{c}\text { Delighted } \\
7 \\
\end{array}$ & $\begin{array}{l}\text { Don't } \\
\text { Know } \\
\text { DK }\end{array}$ \\
\hline \multicolumn{8}{|c|}{ 44. about your emotional well-being? } \\
\hline Terrible & $\begin{array}{c}\text { unhappy } \\
2 \\
\end{array}$ & $\begin{array}{c}\text { Mostly } \\
\text { dissatisfied } \\
3 \\
\end{array}$ & $\begin{array}{c}\text { Mixed } \\
4 \\
\end{array}$ & $\begin{array}{c}\text { Mostly } \\
\text { satisfied } \\
5\end{array}$ & $\begin{array}{c}\text { Pleased } \\
6 \\
6\end{array}$ & $\begin{array}{c}\text { Delighted } \\
7 \\
\end{array}$ & $\begin{array}{c}\text { Don't } \\
\text { Know } \\
\text { DK }\end{array}$ \\
\hline
\end{tabular}

(

(SECTION 10)

I have one more very general question again.

45 Using the Delighted-Terrible scale again, how do you feel about your life in general?

\begin{tabular}{|c|c|c|c|c|c|c|c|}
\hline Terrible & unhappy & $\begin{array}{c}\text { Mostly } \\
\text { dissatisfied }\end{array}$ & Mixed & $\begin{array}{c}\text { Mostly } \\
\text { satisfied }\end{array}$ & Pleased & Delighted & Don't \\
Know \\
1
\end{tabular}

